\title{
Elektronenmikroskopische 3D Strukturbestimmung des Spleißosoms
}

\author{
Dissertation \\ zur Erlangung des Doktorgrads \\ der Mathematisch-Naturwissenschaftlichen Fakultäten \\ der Georg-August-Universität zu Göttingen \\ vorgelegt von \\ Daniel Böhringer \\ aus Siegen
}

Göttingen 2005 
D7

Referent:

Herr Prof. Dr. R. Ficner

Abteilung für Molekulare Strukturbiologie

Institut für Mikrobiologie \& Genetik

Georg-August-Universität Göttingen

Korreferent: $\quad$ Herr Prof. Dr. R. Jahn

Abteilung Neurobiologie

Max-Planck-Institut für biophysikalische Chemie

Göttingen

Tag der mündlichen Prüfung: 30.06.2005 
Die vorliegende Arbeit wurde in der Arbeitsgruppe Elektronenkryomikroskopie bei Dr. Holger Stark in der Abteilung Zelluläre Biochemie von Prof. Reinhard Lührmann am MaxPlanck-Institut für biophysikalische Chemie in Göttingen angefertigt. An der Georg-AugustUniversität Göttingen wurde die Dissertation von Prof. Ralf Ficner betreut.

Teile dieser Arbeit wurden veröffentlicht in:

Boehringer, D., Makarov, E.M., Sander, B., Makarova, O.V., Kastner, B., Lührmann, R. and Stark, H. (2004) Three-dimensional structure of a pre-catalytic human spliceosomal complex B. Nat. Struct. Mol. Biol., 11, 463-468. 



\section{Inhaltsverzeichnis}

1. Zusammenfassung ......................................................................................................1

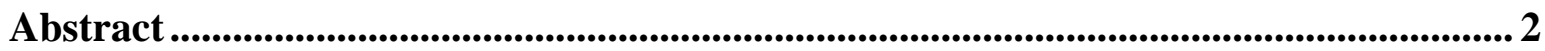

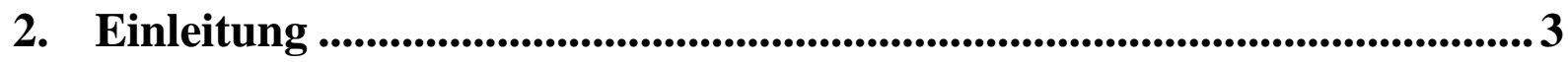

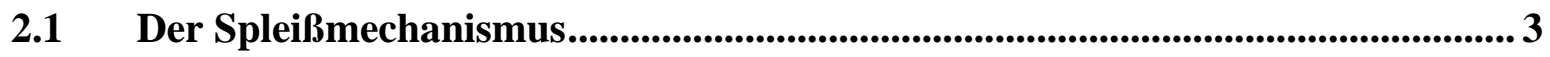

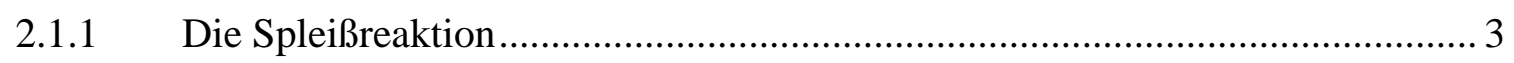

2.1.2 Erkennung der Spleißstellen............................................................... 4

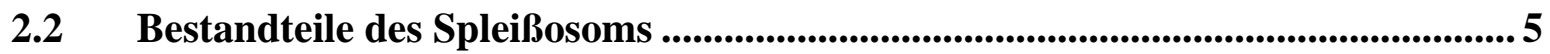

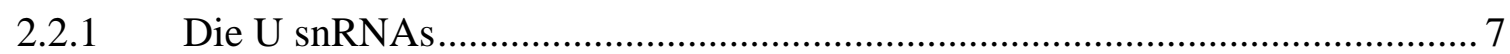

2.2.2 Gemeinsame Proteine der U snRNPs.......................................................... 7

2.2.3 Partikelspezifische Proteine und Struktur der U snRNPs ................................. 8

2.2.4 Nicht snRNP assoziierte Spleißfaktoren ..................................................... 13

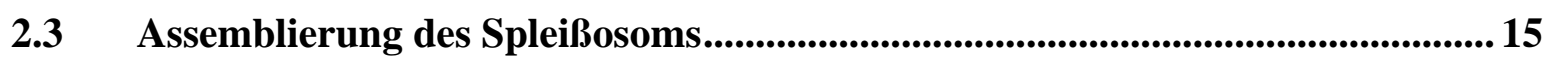

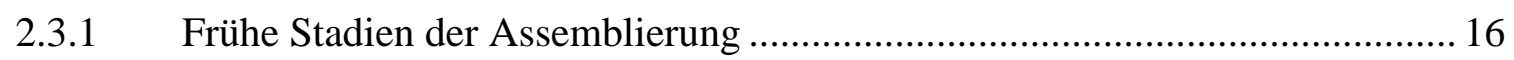

2.3.2 Integration des tri-snRNPs - Assemblierung des Komplexes B ...................... 18

2.3.3 Katalytische Aktivierung - Bildung des Komplexes B* ................................. 18

2.3.4 Zweiter Schritt der Spleißreaktion - Bildung des Komplexes C ....................... 21

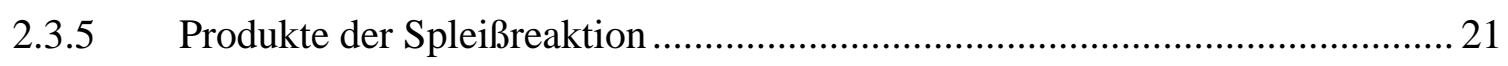

2.4 Strukturuntersuchungen an vollständig assemblierten Spleißosomen ............. 22

2.5 Einzelmolekül-Elektronenmikroskopie...................................................... 22

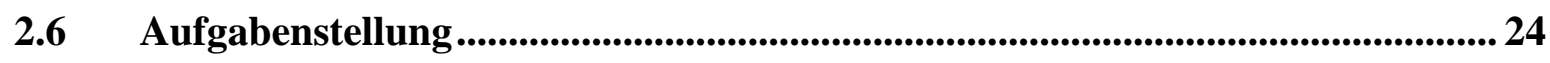

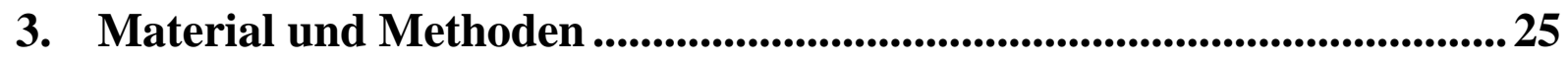

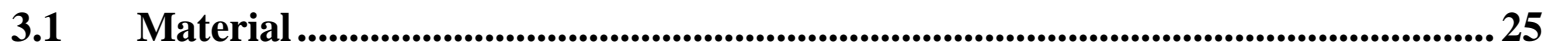

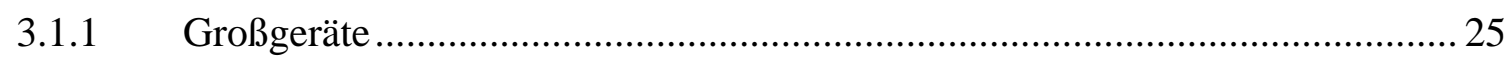

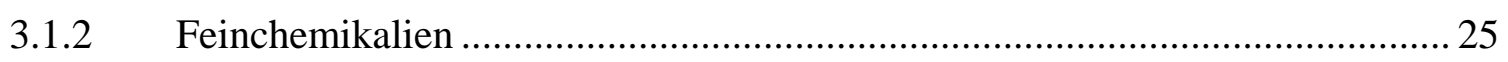

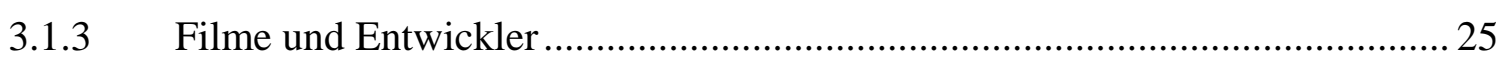

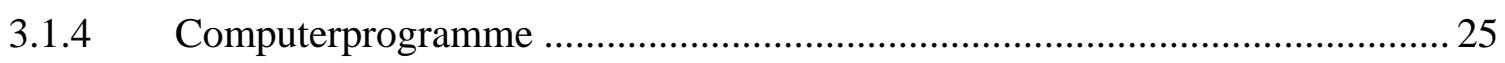

3.2 Molekularbiologische Methoden............................................................................ 25

3.2.1 Aufreinigung des spleißosomalen Komplexes B $\Delta \mathrm{U} 1$.................................... 27

3.2.2 Aufreinigung des 25S U4/U6.U5 tri-snRNP ................................................ 27 
Elektronenmikroskopische Methoden............................................................... 27

3.3.1 Herstellung negativ kontrastierter Proben ..................................................... 27

3.3.2 Elektronenmikroskopische Aufnahmen des Komplexes B $\Delta \mathrm{U} 1$..................... 28

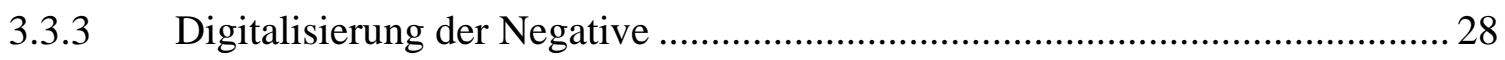

3.3.4 Auswahl und Bildverarbeitung der Einzelbilder............................................. 28

3.3.5 Multivariate Statistische Analyse der Einzelbilder ........................................ 29

3.3.6 Verbesserung der Klassensummen............................................................... 32

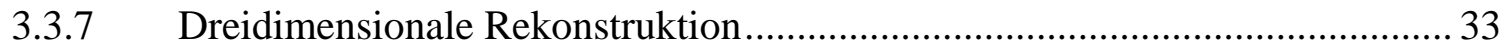

3.3.8 Verbesserung der Projektionswinkelbestimmung .......................................... 41

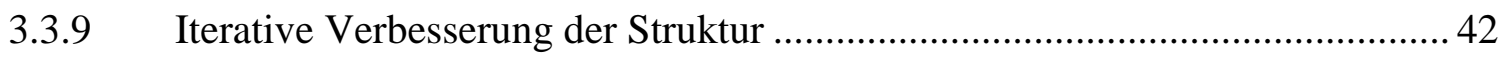

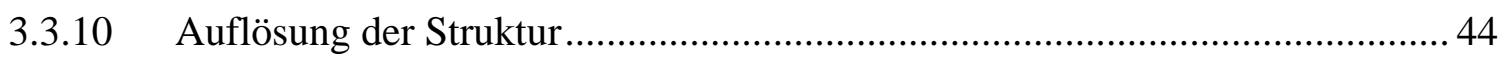

3.3.11 Visualisierung der dreidimensionalen Struktur............................................. 45

3.3.12 Analyse struktureller Heterogenität ............................................................. 45

3.3.13 Berechnung einer höher aufgelösten Sub-Struktur ........................................ 46

4. Ergebnisse ............................................................................................................4

4.1 Elektronenmikroskopische Aufnahmen des Komplexes B $\Delta \mathrm{U} 1$.......................... 47

4.1.1 Ansichten einzelner Komplexe ........................................................... 47

4.2 Statistische Analyse der Einzelpartikelbilder................................................. 49

4.2.1 Berechnung von gemittelten Ansichten ....................................................... 49

4.2.2 Analyse von Aufnahmen mit gekipptem Probenhalter ................................... 51

4.3 Startmodelle für die dreidimensionale Rekonstruktion ................................... 54

4.3.1 ,Random Conical Tilt' - Rekonstruktion .......................................................... 54

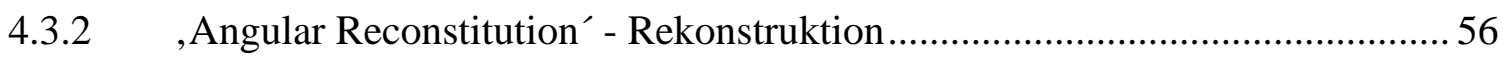

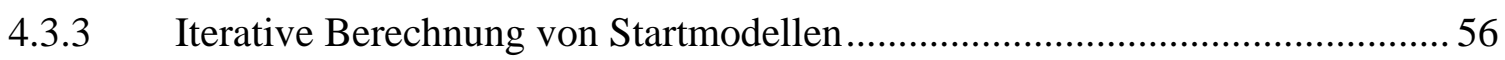

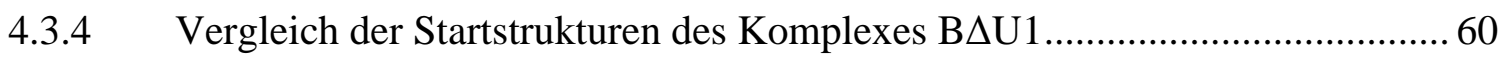

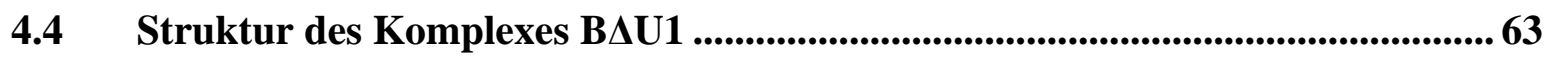

4.4.1 Verbesserung der Auflösung der dreidimensionalen Struktur ......................... 63

4.4.2 Strukturelle Organisation des Komplexes B $\Delta$ UU1 .........................................66

4.4.3 Flexible Domänen des Komplexes BAU1 ................................................... 69

4.4.4 Berechnung einer höher aufgelösten Struktur der dreieckigen Domäne........... 71

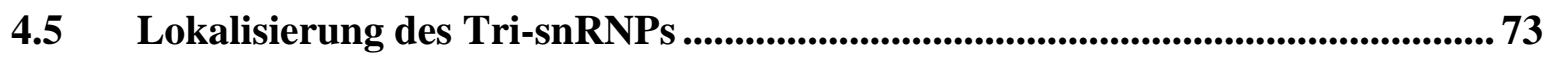

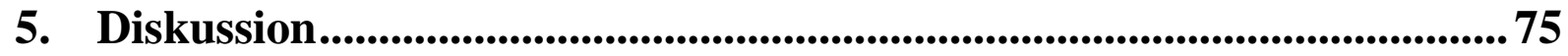


5.1 Die Struktur des Komplexes B BU1 ........................................................... 75

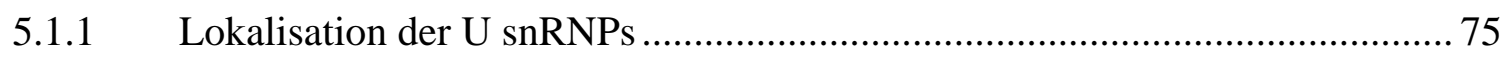

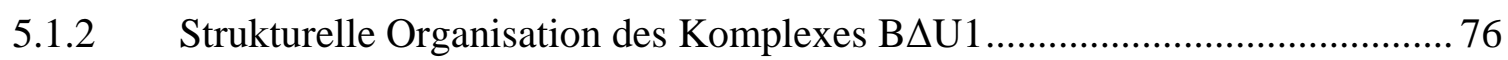

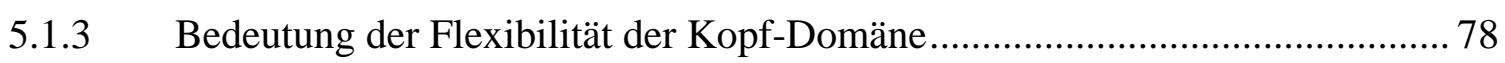

5.1.4 Strukturelle Dynamik des Komplexes B $\Delta \mathrm{U} 1$.............................................. 78

5.1.5 Stöchiometrie der Bestandteile des B $\Delta \mathrm{U} 1$ Komplexes .................................... 79

5.1.6 Vergleich mit strukturellen Daten anderer spleißosomaler Komplexe ............. 80

5.2 Rekonstruktion von flexiblen makromolekularen Komplexen.......................... 84

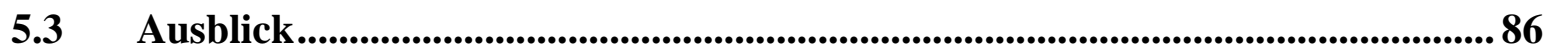

6. Literaturverzeichnis ...............................................................................8 87

7. Anhang...................................................................................................... 102 



\section{Zusammenfassung}

Um die Konformationsänderungen des Spleißosoms bei der Ausbildung des katalytischen Zentrums aufzuklären, sind detaillierte dreidimensionale Strukturen notwendig. Die 3D Struktur des Spleißosoms hilft zu verstehen, wie die eukaryotische Genexpression auf der Ebene der RNA reguliert wird. Das Spleißosom wird an den Spleißstellen der prä-mRNA jeweils neu aus den fünf snRNPs (,small nuuclear ribonulceoprotein particles') und weiteren Faktoren aufgebaut. Der spleißosomale Komplex A, bestehend aus U1 und U2 snRNP, verbindet sich mit dem U4/U6.U5 tri-snRNP, einem Komplex der U4, U5, U6 snRNPs, um den prä-katalytischen Komplex B zu bilden. Nach der Dissoziation von U1 snRNP und U4 snRNP entsteht ein Netzwerk von Basenpaar-Interaktionen zwischen der U2 snRNA und den U5 und U6 snRNAs, welches das katalytische Zentrum des Spleißosoms bildet. Der katalytisch aktivierte Komplex B* katalysiert dann den ersten Schritt der Spleißreaktion. Durch eine Immunaffinitätsaufreinigung kann aus menschlichen Zellen der prä-katalytische Komplex $\mathrm{B} \Delta \mathrm{U} 1$ isoliert werden, in dem $\mathrm{U} 1$ schon dissoziiert ist, das katalytische Zentrum aber noch nicht ausgebildet wurde.

In dieser Arbeit wurde die Struktur des Komplexes B $\Delta \mathrm{U} 1$ mittels EinzelmolekülElektronenmikroskopie bestimmt. Die dreidimensionale Struktur des Komplexes B $\Delta \mathrm{U} 1$ misst $370 \times 270 \times 170 \AA$ und kann in zwei Domänen unterteilt werden. Eine größere dreieckige Domäne ist flexibel mit einer kleineren Kopfdomäne verbunden. Die Flexibilität beschränkt die Auflösung der Gesamtstruktur auf 40 Å. Die dreieckige Domäne mit einer maximalen Ausdehnung von $300 \AA$ kann dem tri-snRNP zugeordnet werden, da sie in Form und Größe dem isolierten tri-snRNP ähnlich ist. Sie besteht aus einer zentralen Dichte, welche von drei Dichtearmen umgeben ist. Die Ansichten verschiedener Konformere des Komplexes B $\Delta \mathrm{U} 1$ zeigen eine Bewegung der Kopfdomäne von mindestens $60 \AA$ um einen Dichtearm. Einerseits deuten die unterschiedlichen Konformere auf mehrere Reaktionswege bei der Ausbildung des RNA-Netzwerkes in menschlichen Spleißosomen hin. Andererseits könnte die Flexibilität der Kopfdomäne die Bindung des Prp19 Proteinkomplexes ermöglichen, der für die katalytische Aktivierung notwendig ist. Die Struktur des Komplexes $\mathrm{B} \Delta \mathrm{U} 1$ wird als Basis für weitere Strukturuntersuchungen an Komplex A und C dienen und so helfen, die Strukturänderungen bei der Spleißreaktion zu verstehen. 


\section{Abstract}

In order to elucidate the conformational changes of the spliceosome that occur during its catalytic activation it is necessary to obtain high resolution 3D structures. The 3D structure of the spliceosome helps to understand how eukaryotic gene expression is regulated at the RNA level. The spliceosome builds up de novo on each pre-mRNA by a stepwise assembly of the five snRNPs (ㅍmall nuclear ribonucleoprotein particles) and additional proteins. First, Complex A, which is composed of U1 and U2 snRNP, is joined by the tri-snRNP, consisting of U4, U5 and U6 snRNP, and additional proteins to form the pre-catalytic complex B. After U1 snRNP and U4 snRNP leave the complex, a complex network of basepair interactions between the U2 snRNA and the U5 and U6 snRNA is assembled, which forms the catalytic center of the spliceosome. This catalytically activated complex B* performs the first step of splicing. By using an immunoaffinity purification strategy the human pre-catalytic complex $\mathrm{B} \Delta \mathrm{U} 1$ could be isolated at a stage after $\mathrm{U} 1$ dissociation but before catalytic activation.

Here, the three-dimensional structure of the complex $B \Delta U 1$ was determined by single particle electron microscopy. Average images of the complex $\mathrm{B} \Delta \mathrm{U} 1$ show rhombic structures with a maximum dimension of 300-370 A. The three dimensional structure has an overall size of $370 \times 270 \times 170 \AA$. A larger triangular domain is linked flexibly to a smaller head domain. The flexibility of this domain limited the resolution of the structure to $40 \AA$. The triangular domain, with a maximum dimension of $300 \AA$, can be assigned to the tri-snRNP by its similarity in size and shape to the isolated tri-snRNP. This domain features a central density surrounded by three peripheral density elements. Views of complex $\mathrm{B} \Delta \mathrm{U} 1$ in different conformations show a movement of the head domain of $60 \AA$, with one of the peripheral density elements being the pivot point. On the one hand, the different conformations suggest different pathways for assembly of the RNA-network of the human spliceosome. On the other hand, the flexibility of the head domain could be of functional importance for the integration of the Prp19 protein complex, that is essential for catalytic activation. The structure of the complex $\mathrm{B} \Delta \mathrm{U} 1$ will be the starting point for further studies of the structures of complex $\mathrm{A}$ and complex $\mathrm{C}$ and will thus help to understand the rearrangements during the reaction sequence of splicing. 


\section{Einleitung}

Die Gene höherer Eukaryoten enthalten neben kodierenden Sequenzbereichen (Exons) Abschnitte, die keine Aminosäuresequenz kodieren (Introns). Beide Bereiche werden zunächst von der DNA in ein Primärtranskript (prä-RNA) transkribiert. Die prä-mRNA wird im Zellkern modifiziert. An das 5' Ende wird ein methyliertes Guanosintriphosphat angefügt ( $\mathrm{m}^{7} \mathrm{G}$-Kappe) und das 3' Ende wird um 100-200 Adenosin-Nucleotide verlängert (Poly(A)Schwanz). Die nicht kodierenden Introns werden entfernt und die kodierenden Exons zusammen gefügt. Dieser Prozess wird als nukleäres prä-mRNA-Spleißen bezeichnet. Die prä-mRNA wird dann in das Zytoplasma transportiert, wo die Translation der mRNA Sequenz in Proteine erfolgt. Werden unterschiedliche Kombinationen von Exons zusammengefügt (alternatives Spleißen), können so von einem Gen ausgehend unterschiedliche Proteine entstehen. Das Spleißen erfordert die genaue Einhaltung des Leserasters auf der mRNA und damit eine hohe Genauigkeit bei der Erkennung der Grenzen von Intron und Exon, den Spleißstellen (engl. ,splice sites’). Diese Aufgabe wird von einem mehrere Megadalton großen Ribonukleoprotein-Komplex, dem Spleißosom, geleistet. Das Spleißosom wird auf jeder prä-mRNA neu aus kleinen kernlokalisierten Ribonucleopartikeln (,uridin rich small nuclear ribonucleoprotein particels', U snRNPs) und zusätzlichen Proteinen assembliert. Die U snRNPs bestehen jeweils aus einer RNA Komponente (snRNA), die reich an Uridinnucleotiden ist, und zusätzlichen Proteinen. Die Sequenzen der snRNAs sowie eine Vielzahl von Proteinen sind in Organismen hoch konserviert, die evolutionsgeschichtlich weit auseinander liegen, so auch zwischen Spleißosomen aus Mensch und Hefe.'

\subsection{Der Spleißmechanismus}

\subsubsection{Die Spleißreaktion}

Das Spleißosom ist ein dynamischer makromolekularer Komplex, der die Bindung und Freisetzung einer Vielzahl von U snRNPs und Proteinen koordiniert und dazu die Hydrolyse von ATP benötigt (Burge et al., 1999; Moore et al., 1993). Das Spleißosom katalysiert zwei nacheinander ablaufende Transesterifizierungsreaktionen (Abbildung 2.1). Im ersten Schritt wird die 5' Exon-Intron Verbindung durch den nukleophilen Angriff der 2'OH Gruppe eines konservierten Adenosins des Introns, der sogenanten Verzweigungsstelle (engl. „branch site“) auf die Phosphodiesterbindung getrennt. Dabei entsteht am 5’ Exon Ende eine freie 3’OH Gruppe, während das Intron eine zusätzliche intramolekulare Bindung eingeht und somit das 3' Intron-Exon Molekül in Form eines Lassos vorliegt. Im zweiten Schritt wird die 3’ Intron-Exon Verbindung von der freien 3’OH Gruppe des 5' Exons angegriffen. Die beiden 
Exons werden miteinander in dieser zweiten Transesterifizierungsreaktion verknüpft und das Intron freigesetzt. Der Reaktionsmechanismus ist ähnlich der Reaktion von ,group 2 selfsplicing' Introns (Wise, 1993). Die Gesamtzahl der Phosphodiesterbindungen bleibt in der Spleißreaktion erhalten. Die Spleißreaktionen benötigen deshalb nicht zwingend Energie in Form von Nukleosidtriphosphathydrolyse (Padgett et al., 1986). Jedoch ist die ATP Hydrolyse für die Konformationsänderungen des Spleißosoms notwendig (Burge et al., 1999).

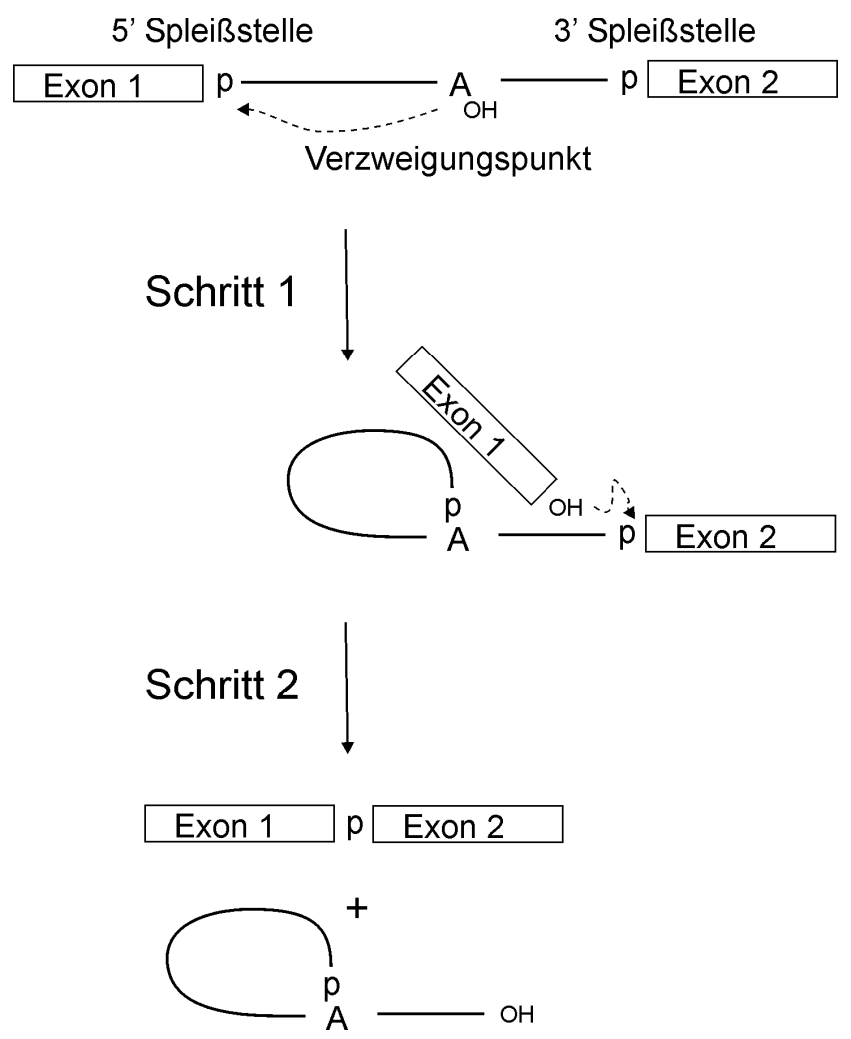

\section{Abbildung 2.1 Die Spleißreaktion}

Die Spleißreaktion läuft in zwei Schritten ab. Im ersten Schritt greift die 2' Hydroxylgruppe des Verzweigungsadenosins die Phosphodiesterbindung der 5' Spleißstelle an. Im zweiten Schritt erfolgt der nukleophile Angriff der im ersten Schritt erzeugten 3'-OH Gruppe des Exons 1 auf die Phosphodiesterbindung der 3' Spleißstelle.

\subsubsection{Erkennung der Spleißstellen}

Die Spleißstellen müssen mit hoher Präzision erkannt werden, damit das Leseraster der mRNA erhalten bleibt. Die Spleißstellen zeichnen sich durch eine konservierte Basensequenz aus (Abbildung 2.2). Sie werden in den meisten Fällen von den snRNPs U1, U2, U4/U6 und U5 sowie einer Vielzahl weiterer Proteine erkannt, die sich zum sogenannten majoren Spleißosom zusammensetzen. Eine geringe Zahl von Introns höherer Eukaryoten wird allerdings von einem anderen Komplex erkannt, dem minoren Spleißosom, der die snRNPs U11, U12 U4atac und U6atac beinhaltet (Hall and Padgett, 1994; Patel and Steitz, 
2003). Die Komponenten des minoren Spleißosoms sind denen des majoren Spleißosoms funktional analog, besitzen aber nur geringe Sequenzhomologie zu U1, U2, U4 und U6. Es wird deshalb zwischen U2- und U12-abhängigen Introns unterschieden. Die U2-abhängigen Introns beginnen in der Regel mit dem Dinukleotid GT und enden mit dem Dinukleotid AG, während am Anfang von U12-Typ Introns meistens das Dinukleotid AT und am Ende das Dinukleotid AC gefunden wird (Burge et al., 1998). Im Folgenden wird, falls nicht ausdrücklich erwähnt, die Spleißreaktion für das wesentlich häufigere (ca. 99,8\%) (Burge et al., 1998) U2-abhängige Intron beschrieben.

Während die Dinukleotide an den Spleißstellen hoch konserviert sind, zeigen die Sequenzen, welche die Spleißstellen flankieren, nur eine geringe Präferenz für bestimmte Nukleotide. Zusätzliche Elemente auf der RNA sind deshalb notwendig, um die Spleißstellen zu markieren (Burge et al., 1998). Dazu gehört die Sequenzumgebung des Verzweigungspunktes, der sich meistens 20-40 Nukleotide vor der 3'-Spleißstelle befindet. Innerhalb dieses Abschnitts befindet sich eine Polypyrimidin-reiche Sequenz variabler Länge, der Polypyrimidintrakt, der auch der Erkennung der Spleißstellen dient. Der Polypyrimidintrakt ist in Hefen schwächer ausgeprägt als in höheren Eukaryonten, während die Sequenzumgebung des Verzweigungspunktes in Hefen stärker konserviert ist.

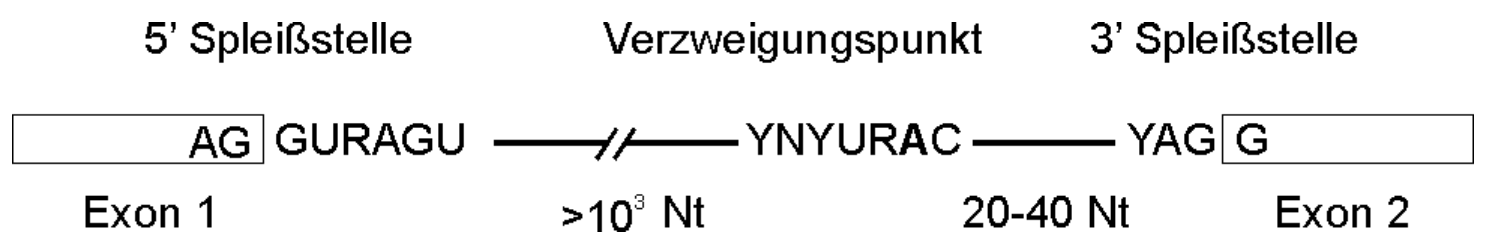

\section{Abbildung 2.2 Konsensussequenz des Introns}

Dargestellt ist die Konsensussequenz des U2-abhängigen Introns von Metazoen. Exons sind als Boxen, das Intron als Linie dargestellt. Die Sequenz der konservierten Nukleotide ist angegeben: Das Verzweigungsadenosin ist hervorgehoben, Y und R kennzeichnen Pyrimidine und Purine, N steht für ein beliebiges Nukleotid. Die durchschnittliche Länge des Introns ist in Nukleotiden (Nt) angegeben (nach Burge et al., 1999)

\subsection{Bestandteile des Spleißosoms}

Das Spleißosom setzt sich aus den U snRNPs und zusätzlichen Proteinen zusammen. Die U snRNPs bestehen aus einer U1, U2 und U5 bzw. zwei assoziierten U4/U6 snRNAs, die an gemeinsame und $U$ snRNP spezifische Proteine gebunden sind. Die RNA Komponente macht nur einen geringen Teil der Masse eines U snRNPs aus (Will and Lührmann, 1997b). 

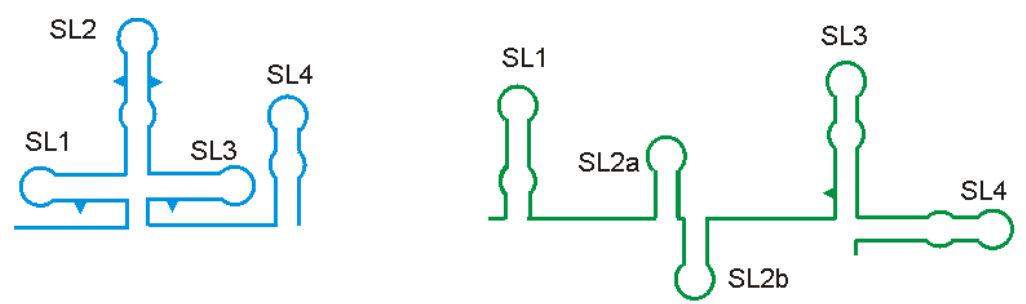

\section{Sm Proteine}

\section{Sm Proteine}

U1 $\begin{aligned} & \text { U1-70K } \\ & \text { U1-A } \\ & \text { U1-C }\end{aligned}$

$\begin{array}{lll}\text { U2A' } & \text { 17S U2 } \\ \text { U2B" } & \text { assozierte } \\ \text { SF3a120 } & \text { SF3a66 } & \\ \text { SFRP43 } & \text { SPF45 } \\ \text { SF3a60 } & \text { SPF30 } \\ \text { SF3b155 } & \text { U2AF65 } \\ \text { SF3b145 } & \text { U2AF35 } \\ \text { SF3b130 } & \text { SF3b49 } & \text { SPF31 } \\ \text { SF3b14a } & \text { SPRP5 } \\ \text { SF3b14b } & \text { SR140 } \\ \text { SF3b10 } & \text { CHERP }\end{array}$
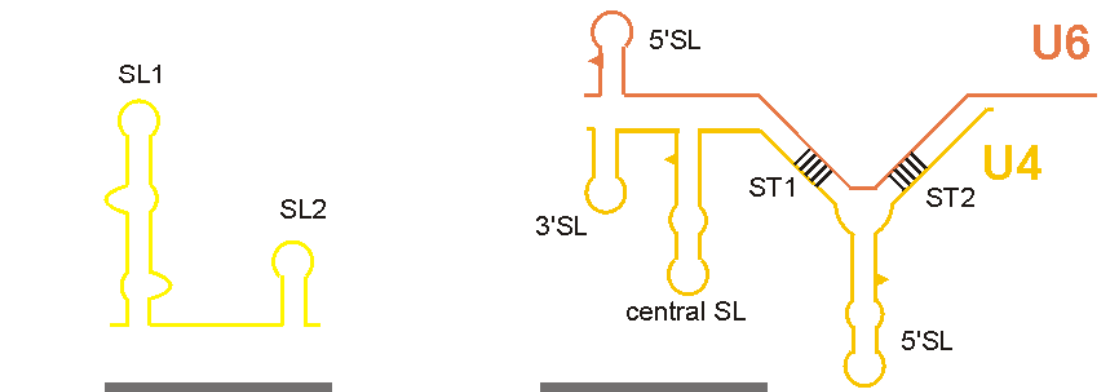

\section{Sm Proteine}

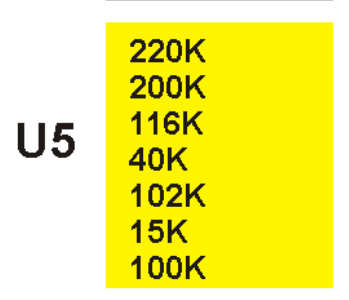

\section{Sm Proteine}

\section{LSm2-8}

U4/U6

$90 \mathrm{~K}$
$60 \mathrm{~K}$
$20 \mathrm{~K}$
$61 \mathrm{~K}$
$15.5 \mathrm{~K}$

U4/U6.U5

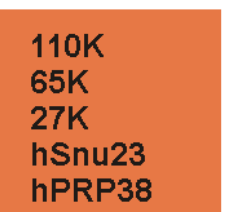

\section{Abbildung 2.3 Zusammensetzung der U snRNPs}

Die Sekundärstruktur der U snRNPs ist schematisch dargestellt: blau U1 snRNA, grün U2 snRNA, gelb U5 snRNA, orange U4 snRNA, rot U6 snRNA. Haarnadelschleifen der snRNAs sind mit SL bezeichnet. Die intermolekularen Helices des U4/U6 di-snRNPs sind durch schwarze Balken hervorgehoben und mit ST1 und ST2 bezeichnet. Die Proteinzusammensetzung der U snRNPs ist in farblich markierten Boxen angeben. U5 und U4/U6 bilden zusammen mit den rot markierten tri-snRNP Proteinen den U4/U6.U5 tri-snRNP (nach Will and Lührmann, 1997b). 


\subsubsection{Die U snRNAs}

Die RNA Komponente der humanen U snRNPs ist mit einer Länge von 106-187 Nukleotiden vergleichsweise klein. Die snRNAs werden mit Ausnahme der U6 snRNA von der RNA Polymerase II transkribiert und posttranskriptional modifiziert. Nach dem Export in das Zytoplasma werden die 5' Enden $\mathrm{zu}$ einem 2,2,7-Trimethylguanosin umgewandelt (5’ m ${ }_{3} \mathrm{G}$-Kappe) und die 3' Enden verkürzt (Reddy and Busch, 1988). Die Primärsequenzen weisen eine Uridin-reiche Sequenz, eine sogenannte Sm-Stelle auf, an die spezifisch SmProteine binden (Branlant et al., 1982). Die U6 snRNA wird von RNA Polymerase III transkribiert und wird nicht in das Zytoplasma exportiert, sondern verbleibt im Kern (Baserga and Steitz, 1993). Dort erhält die U6 snRNA eine ungewöhnliche $\gamma$-Monomethylphosphatkappe. Eine Sm-Stelle fehlt, U6 snRNA interagiert aber mit homologen LSm Proteinen (Singh and Reddy, 1989). Die snRNAs weisen posttranskriptionell modifizierte Nukleotide auf, wie Pseudouridine und 6-Methyladenosine, die für die Funktion der snRNAs essentiell sind (Dönmez et al., 2004; Yu et al., 1998). Phylogenetische Analysen sowie chemische und enzymatische ,footprinting'-Analysen haben zur Vorhersage der Sekundärstruktur der snRNAs gedient (Baserga and Steitz, 1993; Burge et al., 1999)(Abbildung 2.3). Die in Abbildung 1.3 gezeigten Konformationen sind aber abhängig vom funktionellen Zustand des Spleißosoms. Insbesondere U2, U4, U6 liegen in unterschiedlichen intermolekularen Basenpaarungen und intramolekularen Sekundärstrukturen vor (Nilsen, 1994). Die Primär- und Sekundärstruktur der snRNAs ist hoch konserviert (Guthrie and Patterson, 1988). Zwar kann die Länge der U snRNA deutlich variieren, so ist S. cerevisiae U2 snRNA um 1000 Nucelotide länger als die humane U2 snRNA. Die Unterschiede sind aber meistens auf wenige Insertionssequenzen beschränkt (Guthrie and Patterson, 1988).

\subsubsection{Gemeinsame Proteine der U snRNPs}

Die Hauptmasse der U snRNPs wird von Proteinen gebildet. Die Proteine sind phylogenetisch hoch konserviert und homologe Proteine lassen sich vom Menschen bis zur Hefe finden (Burge et al., 1999) Neben den Sm bzw. LSm Proteinen, die allen U snRNPs gemein sind, besitzen alle $U$ snRNPs neben den unterschiedlichen snRNAs auch jeweils U snRNP spezifische Proteine.

Die Sm Proteine B/B', D1, D2 ,D3, E, F und G sind mit den U snRNPs U1, U2, U5 und U4 snRNA des U4/U6 snRNPs assoziiert. Sequenzanalysen identifizierten zusätzlich homologe LSm Proteine, die unter anderem U6 snRNA binden. B und B' sind jedoch alternativ gespleißte Formen desselben Gens und unterscheiden sich nur in 11 C-terminalen 
Aminosäuren (Raker et al., 1999). Oligomere Komplexe aller sieben Sm Proteine binden an die Sm-Stellen der U snRNAs von U1, U2, U4 und U5, wo sie einen heptameren Ring bilden (Achsel et al., 2001; Collins et al., 2001; Kambach et al., 1999b; Raker et al., 1999). Die Bindung erfolgt wahrscheinlich durch basische Aminosäuren an der Innenkante des Rings (Kambach et al., 1999b; Urlaub et al., 2001). Die Sm Proteine bleiben auch bei höherer Ionenstärke mit den U snRNAs assoziiert und werden deshalb auch als Kern (engl. ,core') snRNP Struktur bezeichnet. In manchen Fällen binden die Sm Proteine partikelspezifische Proteine (Nelissen et al., 1994). Die molekulare Funktion der Sm Proteine in der Spleißreaktion ist aber wenig verstanden. Die Bedeutung der Sm Proteine für die Biogenese der U snRNPs ist hingegen gut belegt. Die Hypermethylierung der 5’ Kappe der U snRNAs ist von der Anlagerung der Sm Proteine abhängig (Mattaj, 1986), ebenso wie die Prozessierung der 3’ Enden (Seipelt et al., 1999). Auch stellt der Sm-Kern einen Teil der Erkennungssequenz für den Rücktransport der reifen U snRNPs in den Kern dar (Fischer et al., 1993).

\subsubsection{Partikelspezifische Proteine und Struktur der U snRNPs}

Die $U$ snRNPs enthalten neben der für jeden $U$ snRNP spezifischen $U$ snRNA partikelspezifische Proteine, die essentiell für die Assemblierung und Katalyse des Spleißosoms sind (Will and Lührmann, 1997b). Bei in vitro Spleißreaktion, unter physiologischen Bedingungen (150 mM Salz), liegen drei funktionelle U snRNPs vor: U1 snRNP, U2 snRNP, und U4/U6.U5 tri-snRNP (Kastner and Lührmann, 1999). Im Lauf der Spleißreaktion und dem Recycling der beteiligten Faktoren liegen alle U snRNAs aber auch isoliert in U snRNPs vor. Die Zusammensetzung von aufgereinigten U snRNPs hängt stark von der Ionenstärke der Isolierungspuffer ab. Mit zunehmender Salzkonzentration, gebräuchlich sind $150 \mathrm{mM}$ bis $500 \mathrm{mM} \mathrm{KCl}$, können U snRNPs mit abnehmendem Sedimentationskoeffizienten erhalten werden (Kastner, 1998). Der definierte Verlust von Proteinen und die Analyse mit Hilfe der Elektronenmikroskopie gibt dabei einen ersten Einblick in die grobe strukturelle Organisation der U snRNPs.

\section{Der U1 snRNP}

Der U1 snRNP enthält neben dem Sm-Kern drei U1 spezifische Proteine 70K, A und C (Will and Lührmann, 1997b) (Abbildung 2.3). Es handelt sich um den U snRNP mit dem kleinsten Sedimentationskoeffizienten (12S) und dem geringsten Molekulargewicht (240 kDa). Das 70K Protein bindet an die Haarnadelschleife 1 der U1 snRNA (Query et al., 1989). Das Protein A interagiert über das N-terminale Ribonucleoproteinmotiv (RNP) mit der 
snRNA (Scherly et al., 1989). Das Protein C interagiert nicht direkt mit der U1 snRNA, sondern ist über das 70K Protein an den Partikel gebunden (Nelissen et al., 1994). Erste Einblicke in die Gesamtstruktur des U1 snRNP wurden durch die Elektronenmikroskopie von antikörpermakierten U1 snRNPs möglich (Hoet et al., 1993; Kastner et al., 1992; Kastner and Lührmann, 1989). Die dreidimensionale Struktur des U1 snRNPs wurde durch Elektronenkryomikroskopie bestimmt (Stark et al., 2001) (Abbildung 2.4). Zentrales Element der Struktur ist eine ringförmige Dichte, die dem heptameren Sm-Kern zugeordnet wurde. Zwei größere Dichten zweigen von diesem Ring ab, die vom 70K und A Protein, sowie den von ihnen gebunden U snRNA Haarnadelstrukturen, ausgefüllt werden. Die snRNA wurde als eine ,four-way helical junction' (Vier RNA Helices; in Kreuzform verbunden) modelliert, welche die beiden Haarnadelstrukturen verbindet. Von den beiden verbleibenden Helices der ,four-way junction' weist eine in die Lösung, während die andere zur Innenkante des Sm-Kerns zeigt. Auf diese Helix folgt die Sm-Stelle, die an der Innenkannte des ringförmigen Sm-Kerns gebunden ist.
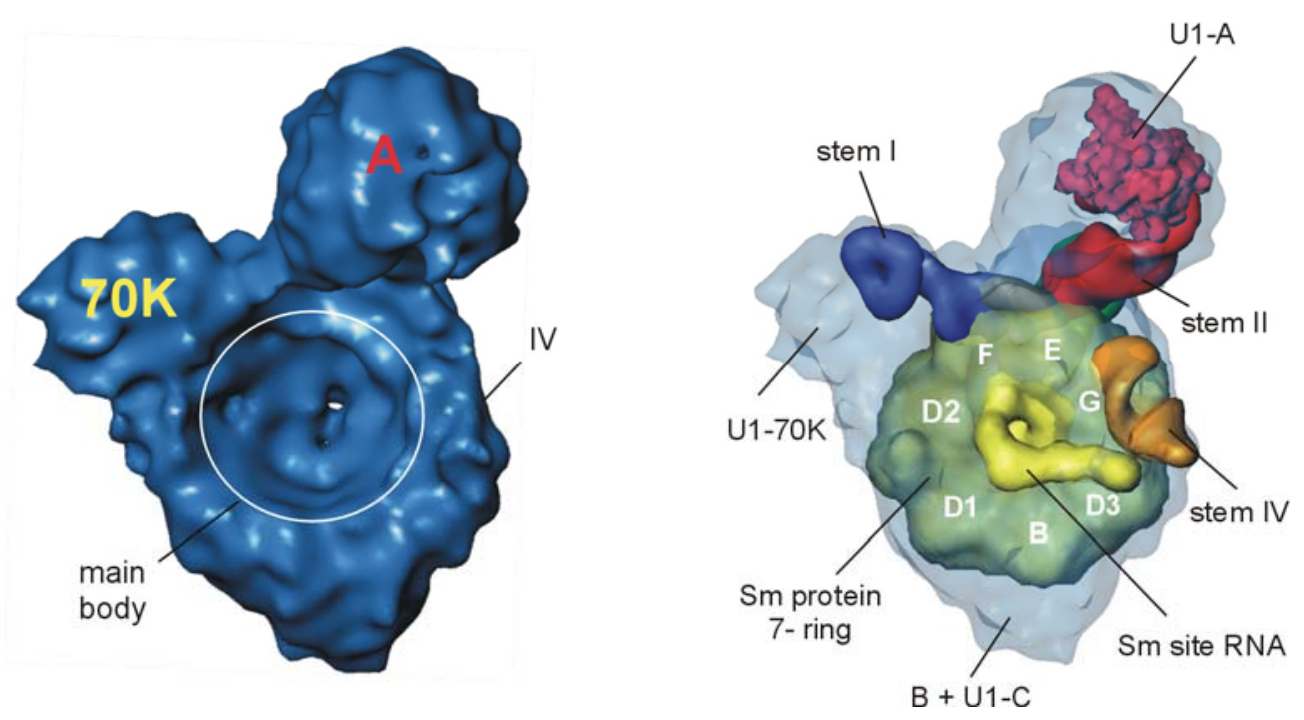

\section{Abbildung 2.4 Dreidimensionale Struktur des U1 snRNP}

Die Struktur des U1 snRNP wurde elektronenmikroskopisch bestimmt. Links ist eine Oberflächendarstellung abgebildet, rechts ist ein Modell der Anordnung von bekannten Kristallstrukturen der snRNA dargestellt. Die Position der Proteine U1-A, U1-B, U1-C sowie eines Modells des Sm-Kerns ist angegeben. Die Haarnadelschleifen der U1 snRNA sind bezeichnet mit stem I-IV. ( entnommen Stark et al., 2001) 


\section{Der U2 snRNP}

Die Zusammensetzung des U2 snRNPs ist wesentlich komplexer als die des U1 nRNPs. Bei physiologischen Salzkonzentrationen (150 mM KCl) liegt die U2 snRNA in einem Komplex mit 12 U2 snRNP spezifischen Proteinen und einem Sedimentationskoeffizienten von 17S vor, der für die Assemblierung des Spleißosoms und die Erkennung des Verzweigungspunktes auf der prä-mRNA notwendig ist (Will and Lührmann, 1997a; Will et al., 2002) (Abbildung 2.3). Der 17S U2 snRNP dissoziiert bei erhöhten Salzkonzentrationen (>250 mM KCL) in einen 12S U2 snRNP und zwei heteromere Komplexe, den Spleißfaktoren (SF) SF3a und SF3b (Behrens et al., 1993; Brosi et al., 1993b).

Der 12S U2 snRNP enthält neben der U2 snRNA die Sm Poteine sowie die U2 spezfischen Proteine U2A' und U2B“. Die elektronenmikroskopische Analyse der 12S U2 nRNP Komplexe zeigt eine Ringstruktur mit einer Protuberanz (Behrens et al., 1993; Kastner et al., 1990). Die Dimensionen der Ringstruktur, welche den Sm Proteinen zugeordnet wurde, ähneln der Struktur im U1 snRNP. Die Protuberanz kann den U2A'/U2B“ Proteinen zugeordnet werden.

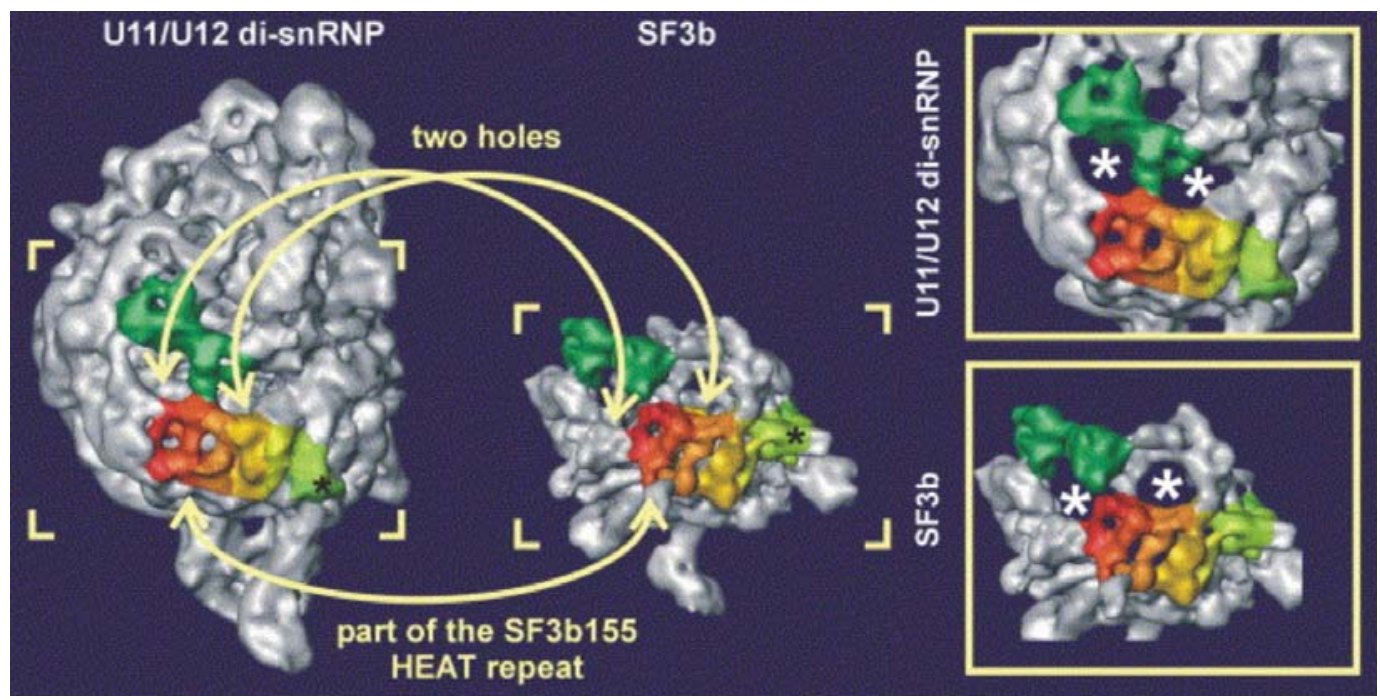

Abbildung 2.5 Dreidimensionale Struktur des U11/U12 di-snRNP und des Speißfaktors SF3b

Die Struktur des U11/U12 di-snRNP ist im Vergleich zum Spleißfaktor SF3b dargestellt. Ein Teil der HEATRepeats des Sf3b 155 Proteins ist farblich gelb und rot hervorgehoben. Das SF3b49 Protein ist grün dargestellt (entnommen Golas et al., 2005)

Die SF3b Komponente des 17S U2 snRNPs besteht aus sieben Proteinen (Abbildung 1.3) (Das et al., 1999; Will et al., 2002). Der SF3b Komplex ist auch bei hohen Salzkonzentrationen (600 mM KCL) stabil. Die Struktur des isolierten SF3b Komplex wurde mittels Elektronenkryomikroskopie bestimmt und zeigte zwei schalenförmige Dichten, die ein 
zentrales Dichteelement umschließen (Abbildung 2.5) (Golas et al., 2003). Ein wesentliches Element der Dichtehülle ist das SF3b 155 Protein, das mit seinen 22 ,HEAT-Repeats', einer leiterförmigen Struktur von $\alpha$ Helix Bündeln, den Innenraum des SF3b S-förmig umschließt. Die Dichte im Innern der Hülle wurde als Protein p14 identifiziert, das mit dem Adenosin des Verzweigunspunkts quervernetzt werden kann (Query et al., 1996). Elektronenmikroskopische Aufnahmen eines Komplexes des 12S U2snRNP und SF3b zeigen zwei verbundene globuläre Strukturen (Krämer et al., 1999). Die Bindung von SF3b an die 5' terminale Sequenz der U2 snRNA ist Voraussetzung für die Bindung von SF3a, das aus drei Proteinen besteht, und weiteren sieben Faktoren (Tabelle 1)(Brosi et al., 1993a).

SF3b ist ebenfalls Bestandteil des U11/U12 di-snRNPs, der die Spleißreaktion der U12 abhängigen Introns katalysiert. Die dreidimensionale Struktur des U11/U12 di-snRNP wurde vor kurzem bestimmt (Golas et al., 2005) (Abbildung 2.5). In dieser Struktur ist die schalenförmige Struktur von SF3b geöffnet und p14 befindet sich an Oberfläche des Komplexes.

\section{Der U4/U6.U5 tri-snRNP}

Der U4/U6.U5 tri-snRNP ist der U snRNP mit der komplexesten Zusammensetzung. Neben den drei snRNAs und den gemeinsamen Sm/Lsm Proteinen enthält der U4/U6.U5 tri-snRNP 16 spezifische Proteine, die phylogenetisch hoch konserviert sind (Will and Lührmann, 1997b). Der U4/U6.U5 tri-snRNP dissoziiert bei hoher Salzkonzentration (350$400 \mathrm{mM} \mathrm{KCl}$ ) in einen 20S U5 snRNP sowie den U4/U6 di-snRNP (Black and Pinto, 1989).

Der 20S U5 snRNP besteht neben dem Sm-Kern (Kastner et al., 1990) aus 7 U5 spezifischen Proteinen 220K, 200K, 116K, 102K, 100K, 40K und 15K (Abbildung 2.3)(Bach et al., 1989). Im Kernextrakt assoziiert mit diesem Komplex noch das 52K Protein, das aber nicht im U4/U6.U5 tri-snRNP enthalten ist (Bach et al., 1989; Laggerbauer et al., 2005). Das U5 220K Protein, homolog zum Protein Prp8 (engl. ,Precursor of $\underline{R} N A$ Processing') in S. cerevisiae, kann mit dem Verzweigungspunkt und den endständigen Nukleotiden des 3' und 5' Exons quervernetzt werden (Teigelkamp et al., 1995) und ist als Kernstruktur des U5 beschrieben worden (Collins and Guthrie, 2000). Es bildet eine Bindungsplattform für das U5 116K Protein, das homolog zu EF2 ist (Fabrizio et al., 1997) und U5 200K, einer DExH/D-Box Protein (Achsel et al., 1998; Laggerbauer et al., 1998; Lauber et al., 1996). Zusammen mit den U5 100K Protein, einem weiteren DExH/D-Box Protein, sind diese Proteine mit der Umordnung der Basenpaarung der U snRNPs in der Spleißreaktion in Verbindung gebracht worden (Laggerbauer et al., 1998; Liu et al., 1997). Einige U5 Proteine besitzen RS Domänen (Birney et al., 1993), die sich durch einen hohen Anteil an SR 
Dipeptiden definieren und häufig Protein-Protein Interaktionen vermitteln (Graveley, 2000). Die U5 snRNA ist fast vollständig gegen Nukleasespaltung geschützt und verschiedene Proteine konnten mit beiden U5 Haarnadelschleifen quervernetzt werden (Bach and Lührmann, 1991; Black and Pinto, 1989). Elektronenmikroskopische Aufnahmen von 20S U5 snRNPs zeigen kompakte längliche Partikel mit einer maximalen Dimension von 250-300 A (Kastner et al., 1990) (Abbildung 2.6). Mit Antikörpermarkierungen wurde die 5' m ${ }_{3} \mathrm{G}$-Kappe der U5 snRNA und der Schleife der Haarnadel 1 an einem Ende an der Längsseite des Partikels lokalisiert (Kastner, 1998; Kastner et al., 1990).

tri-snRNP

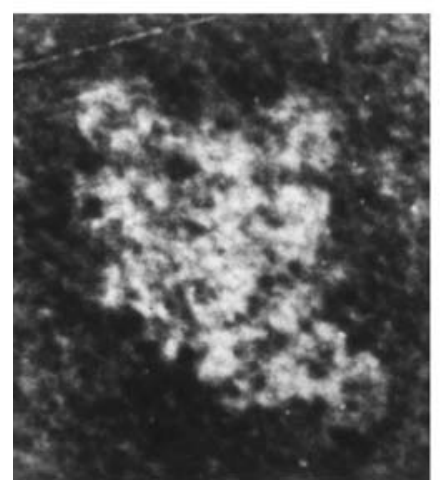

U5

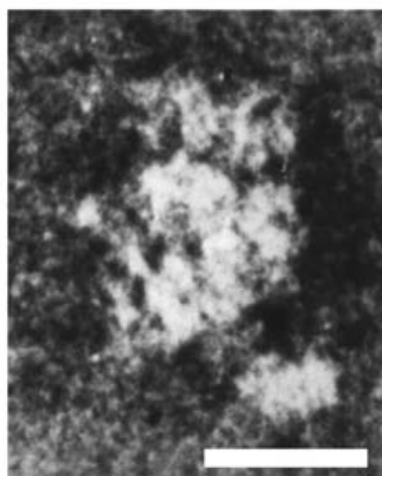

Abbildung 2.6 Elektronenmikroskopische Aufnahmen von U5 snRNP und tri-snRNP

Abbildungen von repräsentativen, negativ kontrastierten, U5 snRNP und tri-snRNP Einzelpartikeln. Die Markierung hat eine Länge von 100 Å. (entnommen Fabrizio et al., 1994; Kastner et al., 1990)

Der U4/U6 di-snRNP besteht aus den gemeinsamen Sm bzw. LSm Proteinen sowie fünf U4/U6 spezifischen Proteinen mit den Molekulargewichten 90, 61, 60, 20, 15,5 kDa. Bei hohen Salzkonzentrationen dissoziieren die spezifischen Proteinfaktoren und die LSm Proteine. Elektronenmikroskopische Aufnahmen dieses Komplexes zeigen die typische Struktur des Sm-Kerns gebunden an ein Y-förmiges Filament (Kastner et al., 1991). Der isolierte Lsm-Kern weist eine dem Sm-Kern ähnliche elektronenmikroskopische Struktur auf (Achsel et al., 1999). Das 15,5K Protein bindet direkt an die 5' Haarnadelschleife der U4 snRNA (Nottrott et al., 1999). Die Bindung des 15,5K Proteins ist die Voraussetzung für die Bindung eines trimeren Komplexes bestehend aus dem 20K, dem 60K und dem 90K Protein (Nottrott et al., 2002; Teigelkamp et al., 1998). Das 61K Protein bindet wie das 15,5K Protein die 5' Haarnadelschleife der U4 snRNA. Außerdem interagiert das 61K Protein mit dem U5 102K Protein (Makarova et al., 2002). Dies ist die einzige bisher bekannte Interaktion des U4/U6 di-snRNP mit dem 20S U5 snRNP. In Übereinstimmung mit dieser Funktion kann gezeigt werden, dass das 61K Protein für die Stabilität des tri-snRNP essentiell ist (Makarova et al., 2002). 
Der tri-snRNP enthält neben den bereits beschriebenen Proteinen noch drei weitere Proteine mit den Molekulargewichten 27kDa, 110kDa und 65kDa (Fetzer et al., 1997; Makarova et al., 2001). Der Vergleich von massenspektrometrischen Untersuchungen an Spleißosomen aus HeLa Zellkernextrakten (Makarova et al., 2004) mit der tri-snRNP Zusammensetzung in S. cerevisiae (Gottschalk et al., 1999; Stevens et al., 2001) lässt vermuten, dass die Proteine hSnu23 (engl. ,human snurp associated' Protein) und hPrp38 mit dem HeLa tri-nRNP assoziiert sind. Die Proteine 27K, 110K und 65K besitzen alle eine RS Domäne, die wahrscheinlich für die Ausbildung von Protein-Protein Interaktionen von Bedeutung ist (Makarova et al., 2001; Roscigno and Garcia-Blanco, 1995). Die Proteine 110K und 65K sind für die Assemblierung des spleißosomalen B-Komplexes essentiell, aber nicht für die Stabilität des tri-snRNP notwendig (Makarova et al., 2001). Elektronenmikroskopische Aufnahmen des tri-snRNPs zeigen dreieckige Partikelansichten mit einer maximalen Dimension von 300 $\AA$ (Abbildung 2.6) (Fabrizio et al., 1994; Kastner, 1998). Wahrscheinlich macht der U5 snRNP in diesen dreieckigen Ansichten eine Längsseite aus, während der U4/U6 snRNP eine Spitze des Dreiecks bildet (Kambach et al., 1999a; Kastner, 1998).

Nach der Spleißreaktion liegen die U snRNPs zunächst in Komplexen mit veränderter Proteinzusammensetzung vor. So wurde ein 35S U5 Komplex isoliert, der nur vier der beschriebenen U5 spezifischen Proteine, dazu aber 25 weitere Faktoren enthielt (Makarova et al., 2002). Die U snRNPs werden für weitere Spleißreaktionen wieder aus den snRNAs und snRNP Proteinen assembliert.

\subsubsection{Nicht snRNP assoziierte Spleißfaktoren}

Die prä-mRNA liegt nie frei vor, sondern wird bei oder unmittelbar nach der Transkription von Proteinen gebunden, die zum Teil in Spleißosomen identifiziert wurden. Im Verlauf der Spleißreaktion assoziieren weitere Proteine, die vorher nicht mit einer U snRNA assoziiert waren, mit dem Spleißosom. Die Massenspektrometrie von spleißosomalen Komplexen in definierten Funktionszuständen hat einen Überblick über die beteiligten Proteine gegeben (Hartmuth et al., 2002; Jurica et al., 2002; Makarova et al., 2002; Makarova et al., 2001).

Der CBC Komplex (engl. ,cap binding complex'), bestehend aus dem CBP80 (engl. ,cap binding protein') und dem CBP20 Protein, bindet die $\mathrm{m}^{7} \mathrm{G}-$ Kappe der prä-mRNA (Izaurralde et al., 1994). Die Bindung erfolgt schon während der Transkription der RNA und ist für eine effiziente Spleißreaktion notwendig. Eine weitere Gruppe von Proteinen, die prä-mRNA unmittelbar und relativ sequenzabhängig binden, bilden die A, B und C Gruppe 
der hnRNP Proteine (Krecic and Swanson, 1999). Stabile Komplexe mit einem Sedimentationskoeffizienten von 40S und einer durch elektronenmikroskopische Analysen bestätigten globulären Gestalt, können in vitro und in vivo nachgewiesen werden (Huang et al., 1994). Die hnRNP Proteine können im Prozess des alternativen Spleißens die Rolle von Aktivatoren oder Repressoren bestimmter Spleiß-Stellen übernehmen (Krecic and Swanson, 1999).

Für die Assoziation der U snRNPs mit der prä-mRNA sind SR Proteine notwendig. Diese Proteine setzen sich aus ein oder zwei RNA bindenden RRM Domänen am N-Terminus und einer RS Domäne am C-Terminus zusammen (Graveley, 2000). Über Protein-Protein Wechselwirkungen der RS Domäne bringen sie die 5' und 3' Spleißstellen auf der prä-mRNA in räumliche Nähe (Kohtz et al., 1994).

Für die Spleißreaktion essentiell ist ein Proteinkomplex, der das Protein Prp19 beinhaltet und deshalb als Prp19 Komplex oder NTC (engl. ,ineteen complex') bezeichnet wird (Cheng et al., 1993; Tarn et al., 1994). Der Komplex wurde zunächst in Hefe identifiziert, wo er sich aus mindestens acht Proteinen zusammensetzt (Chen et al., 2002). In humanen Zellkernextrakten wurden homologe NTC Komplexe von unterschiedlicher Zusammensetzung isoliert, den Kernbestandteil scheinen jedoch die Proteine CDC5L, PRL1 und SPF27 zu bilden (Ajuh et al., 2000; Makarova et al., 2004). Mit diesen Proteinen sind wahrscheinlich bis zu 15 weitere Faktoren assoziiert. Komplexe, die das Prp19 Protein beinhalten, werden unmittelbar vor dem ersten Katalyseschritt in das Spleißosom integriert und bleiben mit diesem während der Spleißreaktion assoziiert (Chan et al., 2003; Makarov et al., 2002; Makarova et al., 2004).

$\mathrm{Zu}$ den beschriebenen Proteingruppen kommen noch weitere Proteine, die zum Teil nur mit spleißosomalen Komplexen eines Funktionszustands assoziiert sind. Diese Proteine bilden wahrscheinlich keine festen Komplexe und sind in Struktur und Funktion sehr heterogen. Von besonderer Bedeutung sind insbesondere einige DExD/H-box Proteine, hPrp2, hPrp16 und hPrp22, wie Mutationsstudien in S. cerevisiae gezeigt haben (Staley and Guthrie, 1998). Sie sind wahrscheinlich für die Umlagerung der RNA-RNA und RNA-Protein Interaktionen notwendig. 


\subsection{Assemblierung des Spleißosoms}

Auf der prä-mRNA setzt sich das Spleißosom jeweils neu aus den U snRNPs und weiteren Proteinfaktoren zusammen. Schrittweise wird dabei ein komplexes RNA Netzwerk aufgebaut, das für die Spleißreaktion essentiell ist. Die Assemblierung des Spleißosoms erfordert die Energie in Form von ATP Hydrolyse, während die eigentliche Spleißreaktion keine Energiezufuhr erfordert. Die verschiedenen Stadien der Assemblierung des Spleißosoms wurden zunächst durch das sequentielle Auftreten von Komplexen in der nativen Gelelektrophorese von Spleißreaktionen bestimmt (Michaud and Reed, 1991). Auf die Bildung des E Komplexes folgen A, B und C Komplex (Reed and Palandjian, 1997) (Abbildung 2.7). Wie auch bei der Zusammensetzung der $U$ snRNPs ist die Zusammensetzung der spleißosomalen Komplexe abhängig von der Isolierungsmethode. So haben neue auf Affinitätschromatographie basierende Aufreinigungen und Kompetitionsexperimente zusätzliche Faktoren der spleißosomalen Komplexe identifiziert (Das et al., 2000; Maroney et al., 2000). Die Proteinzusammensetzung dieser spleißosomalen Komplexe wurde massenspektrometrisch untersucht (Hartmuth et al., 2002; Jurica et al., 2002; Makarova et al., 2002; Makarova et al., 2001) (Abbildung 2.8).

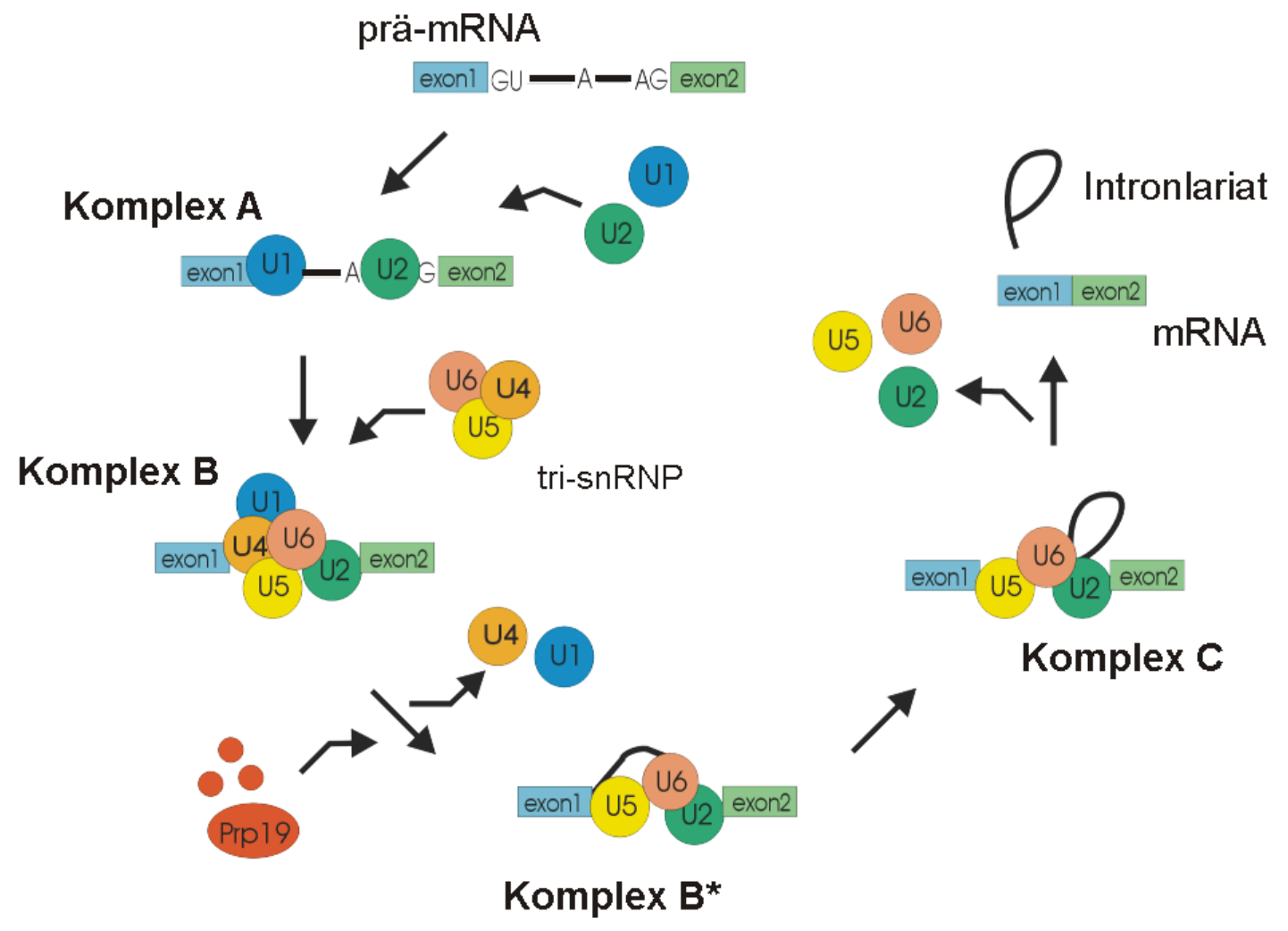

Abbildung 2.7 Schematische Darstellung des Spleißosomalen Zyklus

Die snRNPs sind als Kreise, die beiden Exons als Boxen und das Intron als Linie dargestellt (siehe Text). 


\subsubsection{Frühe Stadien der Assemblierung}

Ausgangspunkt der Assemblierung des Spleißosoms ist die von hnRNP Proteinen gebunden prä-mRNA. Dieser Komplex wird auch als H-Komplex bezeichnet. In einem ersten ATP unabhängigen Schritt werden die prä-mRNAs, die eine 3' und 5' Spleißstelle tragen, im Komplex E gebunden. Der Komplex E wird auch als ,commitment' Komplex bezeichnet, da prä-mRNAs in diesem Komplex gegenüber Kompetitor-RNA präferentiell gespleißt werden. In diesem Stadium der Assemblierung des Spleißosoms wird durch synergistische Wechselwirkung vieler Faktoren die Wahl der Spleißstellen festgelegt und reguliert. Die 5' Spleißstelle wird sowohl vom U1 snRNP durch Basenpaarung mit dem 5' Endes der U1 snRNA, als auch durch Wechselwirkung der U1 Proteine 70K und C gebunden (Du and Rosbash, 2002; Heinrichs et al., 1990). Zusätzlich wird die Interaktion von U1 snRNP mit der prä-mRNA durch das SR-Protein SF2/ASF verstärkt (Kohtz et al., 1994).

Der Polypyrimidintrakt wird durch das SR Protein U2AF65 (engl. ,U2 auxiliary factor') gebunden (Ruskin et al., 1988). Die Verzweigungsstelle interagiert mit SF1/mBBP (engl. branchpoint binding protein) (Abovich and Rosbash, 1997). Zusammen mit weiteren SR-Proteine werden durch Protein-Protein Interaktionen die 5' und 3' Spleißstellen miteinander verbunden. Der U2 snRNP ist unter in vitro Spleißreaktions-Bedingungen wahrscheinlich im Komplex E enthalten, interagiert aber nicht direkt mit der prä-mRNA.

Aus dem Komplex E wird in einem schnellen ATP-abhängigen Prozeß Komplex A gebildet. Die U2 snRNA wird durch Basenpaarung an den Verzweigungspunkt gebunden. Das Adenosin des Verzweigungspunkts bleibt dabei ungepaart und wird so für die Spleißreaktion positioniert (Query et al., 1994; Zhuang and Weiner, 1989). Zusätzlich wird die Verzweigungsstelle vom SF3b Protein p14 gebunden (Query et al., 1996). Das zuvor am Verzweigungspunkt gebundene Protein SF1/mBBP dissoziiert (Hartmuth et al., 2002). Weitere Proteine der SF3b Komponente des U2 snRNP kontaktieren die Umgebung der Verzweigungsstelle (Gozani et al., 1996). Zusätzlich wird der Komplex durch Wechselwirkungen der SR-Proteine stabilisiert (Fu and Maniatis, 1992). Eine Reihe von weiteren Proteinen ist spezifisch mit dem Komplex A, aber nicht mit den darauf folgenden Funktionszuständen des Spleißosoms assoziiert (Hartmuth et al., 2002). Wahrscheinlich interagiert unter in vitro Spleißreaktionsbedingungen der tri-snRNP mit der 5' Spleißstelle (Hartmuth et al., 2002; Maroney et al., 2000). Die Komplexbildung des tri-snRNP mit der prä-mRNA ist in der nativen Gelelektrophorese aber nicht nachweisbar. 

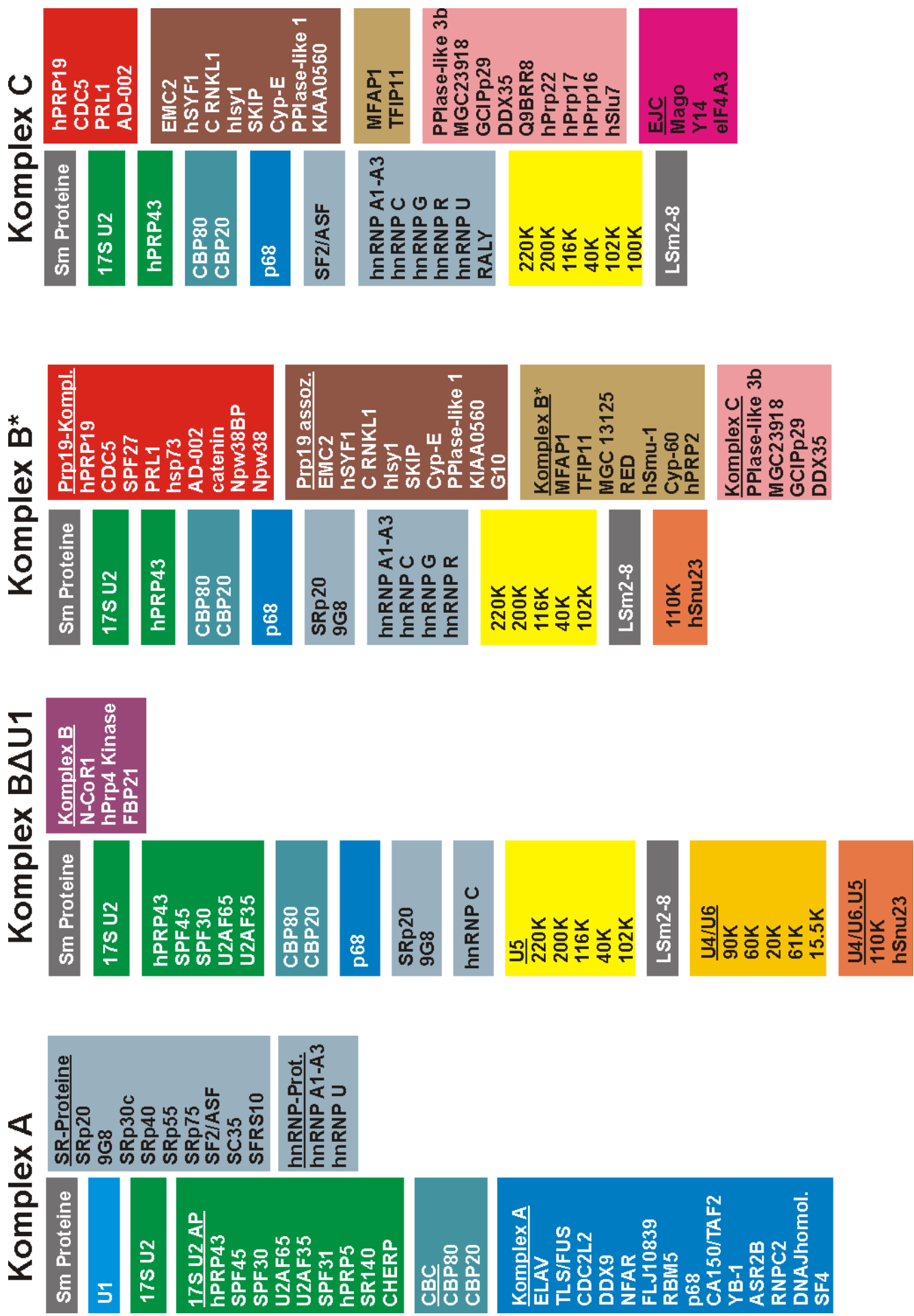

\section{Abbildung 2.8 Proteinzusammenssetzung des Spleißosoms}

Die Proteinzusammensetzung der spleißosomalen Komplexe A, B $\Delta \mathrm{U} 1, \mathrm{~B}^{*}$ und C wurde massenspektroskopisch bestimmt (Hartmuth et al., 2002; Jurica et al., 2002; Makarova et al., 2002; Makarova et al., 2001). Die Komplexe sind von links nach rechts entsprechend aufeinanderfolgender Stadien der Assemblierung des Spleißosoms angeordnet. Gezeigt sind Proteingruppen, die übereinstimmend in mehreren Aufreinigungen identifiziert wurden und charakteristisch für die spleißosomalen Komplexe sind. Die Namen der Proteingruppen sind nur beim ersten Erscheinen der Gruppe angegeben. Die Proteine des U1 snRNP und U2 snRNP sind zur Vereinfachung nicht einzeln aufgeführt (siehe Abbildung 2.6). 


\subsubsection{Integration des tri-snRNPs - Assemblierung des Komplexes B}

Im nächsten Schritt, der Bildung des Komplexes B, wird der tri-snRNP fest gebunden, so dass er in der nativen Gelelektrophorese einen Komplex mit der prä-mRNA bildet. In diesem prä-katalytischen Komplex liegt die U4/U6 snRNA noch basengepaart vor und das katalytische Zentrum der Spleißreaktion hat sich noch nicht gebildet (Nilsen, 1998) (Abbildung 2.9). Der U1 snRNP dissoziiert aus dem Komplex, wahrscheinlich vermittelt durch die DExH/D-Box Helikase U5 100K (Chen et al., 2001; Staley and Guthrie, 1999). Dieser Komplex ist als B $\Delta \mathrm{U} 1$ Komplex bezeichnet und biochemisch und massenspektrometrisch charakterisiert worden (Makarova et al., 2004). Durch die Dissoziation von U1 wird die Intron Sequenz der 5' Spleißstelle frei für Wechselwirkungen mit der U6 snRNA (Wassarman and Steitz, 1992). Die Zahl der im Komplex B identifizierten SR Proteine ist wesentlich geringer als im A Komplex (Abbildung 2.8). Im Komplex B wurden eine Reihe von Proteinen identifiziert, die bis jetzt nur in diesem Funktionszustand nachgewiesen werden konnten (Makarova et al., 2004). Bei der Integration des tri-snRNPs könnte der hPrp4 Kinase eine besondere Bedeutung zukommen, die in vivo essentiell für die Spleißreaktion ist (Schwelnus et al., 2001). Außerdem wurde das SPF30 (engl ,splicing factor 30 kDa') Protein mit der Integration des tri-snRNP in den Komplex B in Verbindung gebracht, da es sowohl mit dem U2 snRNP als auch mit dem tri-snRNP interagiert (Meister et al., 2001; Rappsilber et al., 2001).

\subsubsection{Katalytische Aktivierung - Bildung des Komplexes B*}

Die Bildung des aktiven Zentrums im aktivierten Komplex $\mathrm{B}^{*}$ bedingt eine bedeutende Änderung der Basenpaarung der snRNAs und eine Änderung der Zusammensetzung des Spleißosoms (Abbildung 2.8, 2.9). Der U4/U6 snRNA Duplex wird entwunden und die U6 snRNA kann mit der U2 snRNA eine Basenpaarung eingehen. Die U4 snRNA ist für die weiteren Schritte des Spleißens nicht notwendig und dissoziiert wahrscheinlich aus dem Komplex B (Yean and Lin, 1991). Der U4 snRNP übernimmt damit die Rolle eines RNA-Chaperons indem es erst im assemblierten Spleißosom die U6 snRNA für die Ausbildung des katalytischen Zentrums frei gibt. Die Sekundärstruktur der U6 snRNA ändert sich grundlegend (Abbildung 1.9). Der U4/U6 snRNA Duplex 1 ist basengepaart mit U2 snRNA, während die U6 Sequenzen des U4/U6 snRNA Duplex 2 eine intramolekulare U6 snRNA Haarnadelschleife ausbilden (Madhani and Guthrie, 1992). Das im U4/U6 Duplex ungepaarte 5' Ende der U6 snRNA bildet den U2/U6 Duplex 2 (Sun and Manley, 1995). Zudem interagiert die U6 snRNA mit der hoch konservierten ACAGAG Sequenz mit der 5’Spleißstelle (Lesser and Guthrie, 1993). 


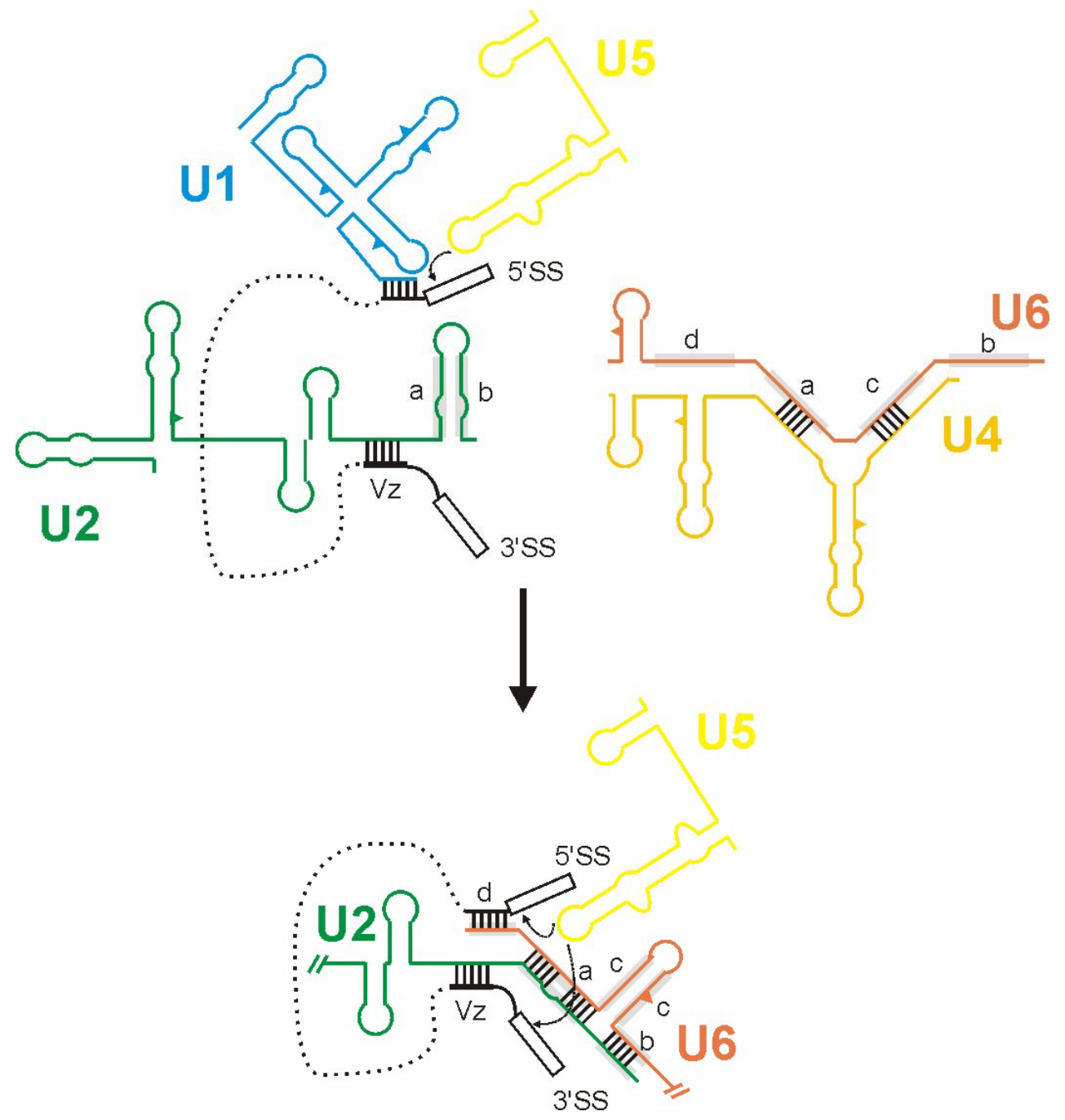

Abbildung 2.9 Umordnung des RNA-Netzwerks bei der katalytischen Aktivierung des Spleißosoms

Die Sekundärstruktur der snRNPs ist schematisch dargestellt: blau U1 snRNA, grün U2 snRNA, gelb U5 snRNA, orange U4 snRNA, rot U6 snRNA. Die prä-mRNA ist schwarz dargestellt: 5'SS - 5' Spleißstelle, 3'SS 3’ Spleißstelle, Vz -Verzweigungsstelle. Sekundärstrukturelemente, die bei der katalytischen Aktivierung neue Basenpaarwechselwirkungen eingehen sind grau unterlegt und die neu gebildeten RNA-Sekundärstrukturen sind mit a-d bezeichnet. Intermolekulare Basenpaare sind durch schwarze Balken hervorgehoben. Wechselwirkungen der U5 snRNA mit den Spleißstellen sind durch gestrichelte Pfeile gekennzeichnet (nach Staley and Guthrie, 1998; Wise, 1993).

An der Entwindung des U4/U6 Duplex sind das DExH/D-Box Protein U5 200K und die GTPase U5 116K beteiligt. Diese Proteine sind direkt oder indirekt an der Entwindung der RNA Helices oder Destabilisierung von Protein-RNA Wechselwirkungen beteiligt (Bartels et al., 2002; Laggerbauer et al., 1998). Die genaue Funktion der U5 DExH/D-Box Proteine ist aber noch nicht bekannt. Die genaue Abfolge der einzelnen Umlagerungen ist unklar und eventuell bestehen auch mehrere Reaktionswege (Frilander and Steitz, 2001; Nilsen, 1998). Das U5 220K Protein interagiert sowohl mit der DExH/D-Box Helikasen U5 200K und der 
GTPase U5 116K (Achsel et al., 1998) als auch mit der U5 und U6 snRNA, wie in S. cerevisiae U snRNPs gezeigt wurde (Dix et al., 1998; Vidal et al., 1999). Außerdem interagiert es mit der 5' Spleißstelle (Reyes et al., 1996). Ferner haben genetische Studien in S. cerevisisae gezeigt, dass U5 220K an der Entwindung des U4/U6 Duplex und der Dissoziation des U1 snRNA beteiligt ist (Kuhn et al., 1999; Staley and Guthrie, 1999). Das U5 220K Protein ist somit bei der Ausbildung des katalytischen Zentrums ein zentrales Element und ist wahrscheinlich für die Koordination der einzelnen Faktoren notwendig (Collins and Guthrie, 2000; Kuhn et al., 2002). Die Schleifen Region der Haarnadelschleife 1 der U5 snRNA interagiert sowohl mit dem U5 220K Protein als auch mit der 5' Spleißstelle (Sontheimer and Steitz, 1993; Wyatt et al., 1992). Diese Interaktion ist jedoch nicht essentiell für die Spleißreaktion. Die DExD/H Box Helikase hPrp2 vermittelt wahrscheinlich eine weitere konformationelle Umlagerung nach der Dissoziation von U4 snRNP, wie in S. cerevisiae gezeigt werden konnte (Kim and Abelson, 1996; Yean and Lin, 1991).

Die Proteinzusammensetzung des Komplex $B^{*}$ wurde massenspektrometrisch untersucht (Abbildung 2.8) (Makarov et al., 2002). Die Gruppe der U4/U6 Proteine ist nicht mehr nachweisbar und dissoziiert wahrscheinlich mit der U4 snRNA aus dem Komplex. Der für die Spleißreaktion essentielle Prp19 Komplex und assoziierte Proteine werden hingegen in das Spleißosom integriert (Makarov et al., 2002).

Quervernetzungsexperimente und NMR Strukturen haben einen ersten Einblick in die tertiären Wechselwirkungen der snRNAs gegeben. Die NMR Struktur der intramolekularen Haarnadelschleife der $S$. cerevisisae U6 snRNA ist in isolierter Form und im Kontext des U2/U6 Duplexes untersucht worden (Huppler et al., 2002; Sashital et al., 2004). Die Haarnadelschleife bildet einen Arm einer ,four-way junction', der wahrscheinlich auf einem weiteren Arm, dem U2/Verzweigungsstellen-Duplex, gepackt ist. Ebenfalls weisen Quervernetzungsdaten auf eine solche Anordnung von der U6 und U2 snRNA hin (Madhani and Guthrie, 1994; Sawa and Shimura, 1992). Ferner ist in S. cerevisiae eine Interaktion des 3' Endes des Introns mit der U6 snRNA beobachtet worden (Ryan et al., 2004). Eine solche Anordnung der snRNAs würde auch das im 1. Schritt der Spleißreaktion katalytisch aktive, an U6 snRNA gebundene Metallion, in räumliche Nähe zur Verzweigungsstelle bringen (Yean et al., 2000). Quervernetzungsexperimente an humanen U2/U6 Duplexe weisen auf eine ähnliche Anordnung der snRNAs in humanen Systemen hin (Valadkhan and Manley, 2000). Nachdem sich das katalytische Zentrum gebildet hat, katalysiert das Spleißosom die erste Transesterifizierungsreaktion. Die katalytisch aktiven Bestandteile sind dabei wahrscheinlich die snRNAs (Valadkhan and Manley, 2001). 


\subsubsection{Zweiter Schritt der Spleißreaktion - Bildung des Komplexes C}

Im Komplex C liegt das Intron in der Lariat-Form vor. Die 5' und 3' Spleißstelle treten im Komplex $C$ in eine enge Wechselwirkung. Das erste und letzte G Nukleotid des Introns interagieren über Nicht-Watson-Crick Wechselwirkungen (Parker and Siliciano, 1993). Diese Interaktion wird wahrscheinlich durch Wechselwirkung der 3' Sleißstelle mit der Schleifenregion der Haarnadelschleife 1 der U5 snRNA verstärkt (Newman, 1997). Die U5 snRNA Schleife wechselwirkt somit mit beiden Speißstellen und dient damit der Ausrichtung der aktiven Gruppen der zweiten Transesterifizierungsreaktion. Diese Interaktion ist essentiell für den zweiten Reaktionsschritt. Die Sequenzanforderungen an die U2 und U6 snRNA sind für den zweiten Reaktionsschritt wesentlich strikter als für den ersten Reaktionsschritt (Nilsen, 1998). Für die zweite Transesterifizierungsreaktion findet wahrscheinlich eine weitere konformationelle Umlagerung des U2/U6 Duplex statt (Staley and Guthrie, 1998). Die Proteinzusammensetzung des Komplex C wurde massenspektroskopisch bestimmt (Jurica et al., 2002)(Abbildung 2.8). An den Konformationsänderungen, die zur Ausbildung des Komplex C führen, ist die DExH/D-Box Helikase hPrp16 beteiligt (Staley and Guthrie, 1998). Mutationen in S. cerevisiae Prp16 führen zu einer verringerten Sensitivität gegenüber Mutationen an der Verzweigungsstelle, deshalb wurde dem Prp16 Protein eine Kontrollfunktion für die korrekte Ausbildung des aktiven Zentrums vor Beginn des zweiten Reaktionsschritts zugeschrieben (Burgess and Guthrie, 1993).

\subsubsection{Produkte der Spleißreaktion}

Nach der Katalyse des zweiten Reaktionsschritts wird die reife mRNA, vermittelt durch die DExD/H-Box Helikase Hrh1, freigesetzt und in das Zytoplasma transportiert (Burge et al., 1999). Die Exon-Exon-Übergänge sind dabei von dem sogenannten ,exon-junctioncomplex' (EJC) besetzt (Le Hir et al., 2000). Das Intron-Lariat liegt zunächst noch in einem Komplex mit der U2, U5 und U6 snRNA vor. Weitere Faktoren sind an der Dissoziation des Komplexes und am Abbau des Intron-Lariats beteiligt. Dabei treten Zwischenprodukte wie der $35 \mathrm{~S}$ U5 snRNP auf, in dem die U5 snRNA einen Komplex mit den kanonischen U5 Proteinen, dem Prp19 Komplex und weiteren Faktoren bildet (Makarov et al., 2002). Die snRNAs und die Proteinfaktoren der U snRNPs werden wieder zu den beschriebenen U snRNPs assembliert und einem weiteren Spleißzyklus zugeführt. 


\subsection{Strukturuntersuchungen an vollständig assemblierten Spleißosomen}

Aus den massenspektroskopischen Untersuchungen lässt sich die Masse eines spleißosomalen Komplexes B mit 3-5 MDa abschätzen (Makarov et al., 2002; Makarova et al., 2004). Komplexe dieser Größenordnung lassen sich nicht mehr mittels Kernspinresonanz untersuchen (Fernandez and Wider, 2003). Die dreidimensionale Strukturaufklärung mittels Röntgenkristallographie kann zwar zur Analyse makromolekularer Komplexe verwendet werden, wie die kristallographische Strukturbestimmung des Ribosoms zeigt (Yusupov et al., 2001), es ist aber häufig schwierig, Kristalle in ausreichender Qualität zu erhalten. Insbesondere können die großen Probenmengen und hohen Probenkonzentrationen, die benötigt werden, nicht in allen Fällen hergestellt werden. Elektronenmikroskopische Verfahren bieten den Vorteil, auch bei heterogenen Proben von geringer Konzentration ( $20 \mathrm{nM}$ ) angewendet werden zu können (Crowther and Prasad, 2004).

Ausgehend von in vitro Spleißreaktionen wurden durch Größenausschlusschromatographie spleißosomale Komplexe isoliert und elektronenmikroskopisch untersucht (Clark et al., 1988; Furman and Glitz, 1995; Reed et al., 1988). GlycerinGradientenzentrifugation von Kernextrakten wurde verwendet, um multimere spleißosomale Komplexe zu isolieren. Die dreidimensionale Struktur eines Monomers dieser Komplexe wurde kürzlich veröffentlicht (Azubel et al., 2004). Eine spezifische Aufreinigung von Komplexen ist über das Anbringen von Affinitätsmarkierungen an die RNA zu erreichen. Dazu wurde eine prä-mRNA mit RNA-Sequenzen, die das MS2 Protein binden, hergestellt. Ein Fusionsprotein aus dem MS2 Protein und dem Maltosebindenden Protein wurde verwendet, um die prä-mRNA Komplexe zu markieren und über einer Maltosematrix aufzureinigen (Das et al., 2000). Die erhaltenen Komplexe wurden durch RotationsMetallbedampfung elektronenmikroskopisch untersucht (Zhou et al., 2002). Über die Verwendung einer prä-mRNA mit einer Mutation am Verzweigungspunkt, die den zweiten Reaktionsschritt der Spleißreaktion verhindert, konnte der Komplex C isoliert werden (Jurica et al., 2002). Eine dreidimensionale Struktur wurde für einen minimalen Kernkomplex erhalten (Jurica et al., 2004).

\subsection{Einzelmolekül-Elektronenmikroskopie}

Mit der Einzelmolekül-Elektronenmikroskopie kann die Struktur asymmetrischer makromolekularer Komplexe von einer Größe von 200 kDa bis zu mehreren MDa bei einer Auflösung von bis zu 7 $\AA$ bestimmt werden (Frank and Agrawal, 2000; Orlova and Saibil, 2004; van Heel et al., 2000). 
Die Probenpräparation für die Einzelmolekül-Elektronenmikroskopie stellt verglichen mit Kristallographie weniger Anforderungen. Wenige Mikroliter einer verdünnten Lösung ( $~ 40 \mu \mathrm{g} / \mathrm{ml}$ ) werden auf einen Kohlefilm adsorbiert und eingebettet in einen dünnen Flüssigkeitsfilm schockgefroren (Adrian et al., 1984). Dies dient dazu, den nativen, hydrierten, Zustand des Partikels zu erhalten. Die alternative Einbettung der Partikel in Schwermetallsalze, negative Kontrastierung, hat den Vorteil eines höheren Kontrasts in den Partikelbildern (Adrian et al., 1998). Neuere Untersuchungen an makromolekularen Komplexen haben gezeigt, dass mit negativer Kontrastierung ebenso hohe Auflösungen wie mit der Einbettung in Eisfilmen zu erzielen sind (Golas et al., 2003).

Bei der Abbildung der Komplexe im Mikroskop werden Projektionsbilder der Partikel durch die Streuung der hochenergetischen Elektronen am Objektpotential erhalten. Die durch die elastische Streuung der Elektronen abgebildete Dichte entspricht weitgehend der Elektronendichte in der Röntgenkristallographie. Die im Vergleich zur Probendicke hohe Brennweite des Mikroskops führt dazu, dass alle Bereiche einer dünnen biologischen Probe ohne perspektivische Verzerrungen abgebildet werden. Die Abbildungen der Komplexe entsprechen deshalb nahezu idealen zweidimensionalen Projektionen der dreidimensionalen Dichte. Diese Art der Abbildung kann anschaulich mit einer medizinischen Röntgenaufnahmen verglichen werden. Allerdings verhalten sich dünne Präparate als schwache Phasenobjekte. Der Streu-Amplitudenkontrast, den die biologischen Proben erzeugen, ist relativ schwach. Der gebeugte Elektronenstrahl erfährt durch das Objektpotential hauptsächlich eine Phasenverschiebung, aber keine Amplitudenänderung gegenüber dem nicht gebeugten Nullstrahl. Phasenunterschiede können jedoch vom Photomaterial nicht detektiert werden. Die Phasenunterschiede können sichtbar gemacht werden, wenn der Nullstrahl und der gebeugte Strahl zur Interferenz gebracht werden. Im Elektronenmikroskop geschieht dies durch die sphärische Abberation der Linse und die Fokuslage. Wenn die Probe aus der Fokuseben gebracht wird (Defokus), kann so ein Phasenkontrast erzeugt werden. Die hochenergetischen Elektronen führen jedoch auch zur inelastischen Streuung und damit zur langsamen Schädigung des biologischen Materials. Deshalb muss die Strahlendosis möglichst gering gehalten werden. Diese Bedingung führt allerdings zu Bildern mit einem niedrigen Signal-Rausch-Verhältnis. Für die strukturelle Untersuchung von makromolekularen Komplexen ist es deshalb notwendig, die Einzelpartikelbilder von Komplexen, die in der gleichen Orientierung abgebildet wurden, zu mitteln.

Für die dreidimensionale Rekonstruktion von makromolekularen Komplexen werden hauptsächlich zwei Techniken verwendet. Die Technik des ,angular reconstitution` geht von 
mehreren gemittelten Projektionsbildern der Partikel aus (van Heel, 1987). Die relative Orientierung des Partikels in diesen Projektionsbildern ist zunächst nicht bekannt. Es ist jedoch möglich, die Projektionsrichtungen ausgehend von den Projektionsbildern zu berechnen. Die Technik des, random conical tilt’ geht von Paaren von Einzelpartikelbildern aus (Radermacher et al., 1987). Durch das Kippen der Probe im Mikroskop werden zwei Ansichten eines Moleküls erhalten. So können die Projektionsrichtungen von mehreren Ansichten bestimmt und zur Berechnung einer dreidimensionalen Struktur verwendet werden. Beide Techniken unterscheiden sich grundlegend von der Elektronentomographie, bei der von einem einzigen Objekt viele Ansichten in festgelegten Winkelabständen erhalten werden. Die mit der Elektronentomographie maximal zu erzielende Auflösung liegt zurzeit jedoch bei $50 \AA \AA-80 \AA$ (Beck et al., 2004; Plitzko et al., 2002).

\subsection{Aufgabenstellung}

In der hier vorgelegten Studie soll der Komplex B $\Delta \mathrm{U} 1$ untersucht werden (Makarova et al., 2004). Der Komplex wurde über einen gegen das U4/U6 Protein 61K gerichteten Antikörper aufgereinigt. Das 61K Protein wird in den aktivierten spleißosomalen Komplexen nicht mehr von den Antikörpern gebunden. So ist eine spezifische Aufreinigung eines Komplexes möglich, der einen Zustand unmittelbar nach der Integration des tri-snRNP, aber noch vor der katalytischen Aktivierung darstellt. Die dreidimensionale Struktur des Komplexes soll einen ersten Einblick in die strukturelle Organisation eines spleißosomalen Komplexes vor der katalytischen Aktivierung geben. Die Struktur soll die Grundlage für weitere strukturelle Untersuchungen bilden, die zu einem besseren Verständnis der Wechselwirkungen der spleißosomalen Proteine und der snRNAs mit der prä-mRNA beitragen sollen. Ferner sollen flexible Bereiche der Struktur beschrieben werden, die potentiell für die katalytische Funktion wichtig sind. Ein Vorbild sind hier die kristallographischen Studien an Ribozymen, die geholfen haben, die Struktur und Funktion verschiedener Konformationen der Ribozyme zu klären (Doherty and Doudna, 2001). Im Vergleich mit den Strukturen des Komplex A und des Komplex C soll es so in der Zukunft möglich werden, die Konformationswechsel des Spleißosoms während der Spleißreaktion zu beschreiben. 


\section{Material und Methoden}

\subsection{Material}

\subsubsection{Großgeräte}

Elektronenmikroskop CM200 FEG

Trommelscanner Primescan D7100

CCD Kamera F415A-HS2
Philips / Fei

Heidelberger Druckmaschinen

Tietz Video and Image Processing

\subsubsection{Feinchemikalien}

Alle Feinchemikalien wurden von den Firmen Merk, Sigma-Aldrich oder Fluka bezogen und besitzen den Reinheitsgrad pro analysis.

\subsubsection{Filme und Entwickler}

Entwickler Kodak D19

Eastman Kodak

Filme Kodak S0-163

Eastman Kodak

\subsubsection{Computerprogramme}

Amira 2.3

CorelDRAW 9

CorelPHOTO-PAINT

Exel 2000

Imagic-5

KaleidaGraph
TGS Europe

Corel

Corel

Microsoft

Image Science

Synergy Software

\subsection{Molekularbiologische Methoden}

Der spleißosomale Komplex B $\Delta \mathrm{U} 1$ und der 25S U4/U6.U5 tri-snRNP wurden von Dr. Makarov zur Verfügung gestellt (Makarova et al., 2004). Die Aufreinigung soll hier nur kurz beschrieben werden. 

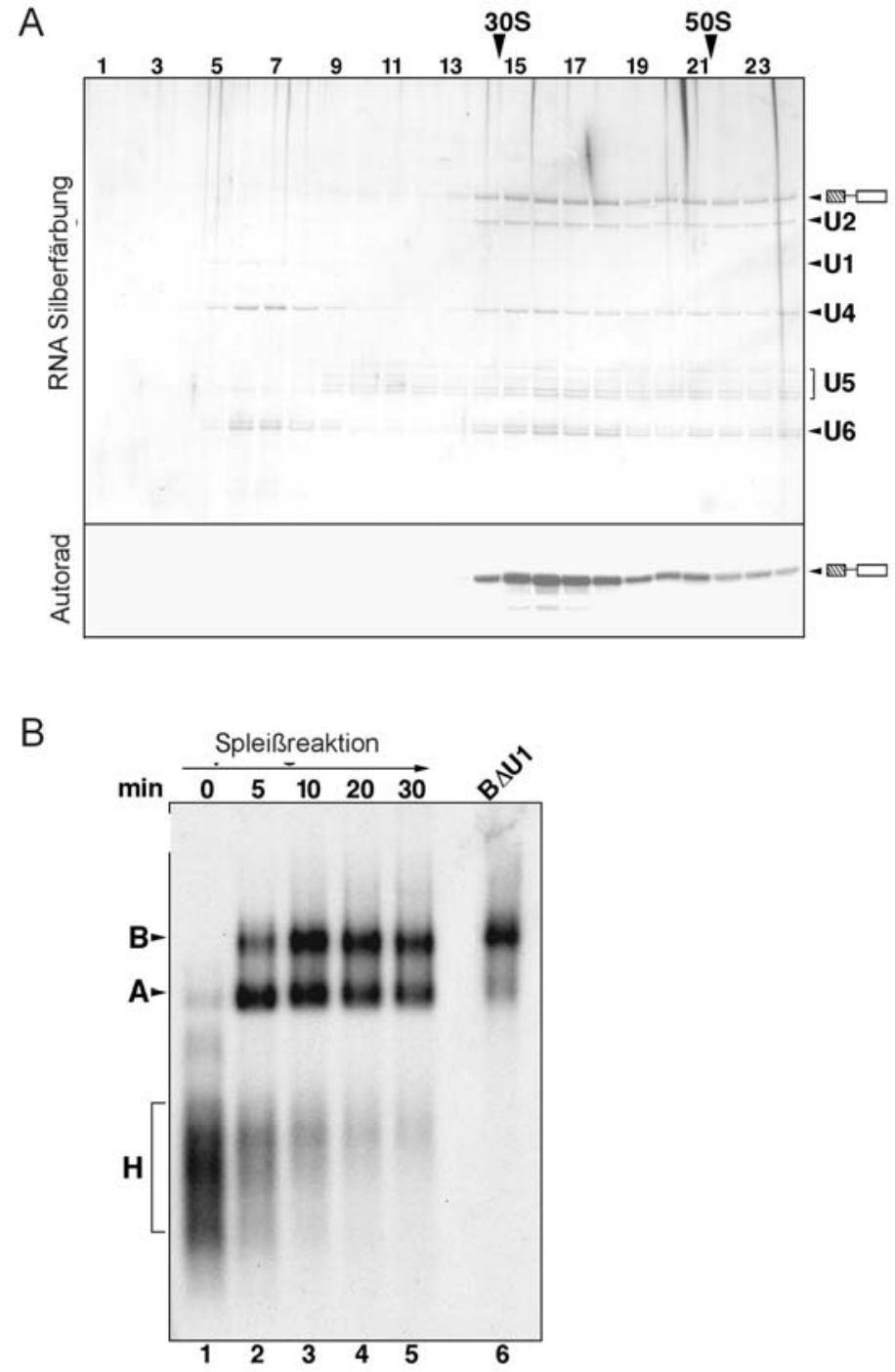

\section{Abbildung 3.1 Isolierung des Komplexes BAU1}

A) Sedimentationsverhalten des Komplexes B $\Delta U 1$. Das Eluat der Antikörperpräzipitation wurde auf einen 1030\% Glycerin Gradienten aufgetragen und die RNA-Zusammensetzung jeder Fraktion durch SDSGelelektrophorese und Silberfärbung analysiert. Die Laufhöhe der prä-mRNA und spleißosomalen snRNAs ist am Rand markiert. Der Komplex B sedimentiert bei 45S und enthält equimolare Konzentrationen an U2, U4, U5 und U6 snRNA. Autorad: Gradientenprofil der prä-mRNA. Autoradiogramm der prä-mRNA Banden des in (A) gezeigten Gels. Die höchste Konzentration der ${ }^{32}$ P-markierten prä-mRNA enthält Fraktion 16. B) Laufverhalten des isolierten Komplexes $\mathrm{B} \Delta \mathrm{U} 1$ in nativen Agarosegelen. 32P-markierte MINX prä-mRNA wurde unter Spleißreaktionsbedingungen mit HeLa Kernextrakt für 0-30 min inkubiert. Die Assemblierung von spleißosomalen Komplexen wurde auf einem 2\% Agarosegel zusammen mit isolierten Komplex B $\Delta \mathrm{U} 1$ analysiert. Die Laufhöhe des Komplexes H, A und B sind am Rand angegeben. Der Komplex B $\Delta$ U1 zeigt das gleiche Laufverhalten wie Komplex B. 


\subsubsection{Aufreinigung des spleißosomalen Komplexes $B \Delta U 1$}

Für eine Spleißreaktion wurden 2,8 nmol MINX ${ }^{32} \mathrm{P}$-markierte prä-mRNA in 1,4 ml 40\% (v/v) HeLa Kernextrakt für 10 Minuten bei $30^{\circ} \mathrm{C}$ inkubiert. Heparin wurde mit einer Endkonzentration von $0,5 \mathrm{mg} \mathrm{ml}^{-1}$ zugesetzt und die Inkubation weitere $5 \mathrm{~min}$ bei $30^{\circ} \mathrm{C}$ fortgesetzt. Alle weiteren Arbeitschritte wurden bei $4^{\circ} \mathrm{C}$ durchgeführt. Die Spleißreaktion wurde zehnfach mit IP Puffer (20 nM HEPES; pH 7,9; $150 \mathrm{mM} \mathrm{NaCl,} \mathrm{1,5} \mathrm{mM} \mathrm{MgCl}_{2}$; 0,5 MM DTT) versetzt mit 0,05\% (v/v) NP40 verdünnt. Speißosomale Komplexe wurden mit einem gegen das U4/U6 Protein 61K gerichteten Antikörper an Sepharose immobilisiert. Die immobilisierten spleißosomalen Komplexe wurden durch eine einstündige Inkubation mit 0,6 $\mathrm{mg} \mathrm{ml}^{-1}$ des zur Immunisierung verwendeten Peptids in 0,5 ml IP Puffer unter Zusatz von $5 \%(\mathrm{v} / \mathrm{v})$ Glycerin und 0,05\% (v/v) NP40 eluiert. 0,4 ml des Eluats wurden auf einem linearen $4 \mathrm{ml} \mathrm{10-30 \%} \mathrm{(v/v)} \mathrm{Glyceringradienten} \mathrm{in} \mathrm{IP} \mathrm{Puffer} \mathrm{aufgetragen} \mathrm{und} \mathrm{in} \mathrm{einem} \mathrm{TH-660} \mathrm{Rotor}$ für zwei Stunden bei 488.000 g zentrifugiert. Die Fraktion mit dem höchsten Gehalt an prämRNA sedimentierte bei 45S und enthielt den spleißosomalen Komplex B $\Delta U 1$ (Abbildung 3.1).

\subsubsection{Aufreinigung des 25S U4/U6.U5 tri-snRNP}

Der tri-snRNP wurde mit weitgehend der selbem Aufreinigungsprozedur, wie für den Komplex B $\Delta \mathrm{U} 1$ beschrieben, isoliert. Abweichend von der oben aufgeführten Aufreinigung wurde keine Inkubation mit Heparin durchgeführt.

\subsection{Elektronenmikroskopische Methoden}

\subsubsection{Herstellung negativ kontrastierter Proben}

Um den Kontrast der Komplex B $\Delta \mathrm{U} 1$ Partikel zu dem sie umgebenden Medium zu erhöhen, wurden die Probe in einer Schicht Uranylformiat mit der sogenannten DoppelKohlefolie-Technik eingebettet (Tischendorf et al., 1974). Die Probenlösung wurde in eine Teflonschale gefüllt. Ein dünner Kohlefilm, auf Glimmer aufgedampft, wurde auf die Oberfläche der Probenlösung abgeschwemmt, um die Probe an die Glimmerseite des Kohlefilms zu absorbieren. Der Kohlefilm wurde nach einer Minute von der Oberfläche abgenommen und in einer Teflonschale mit einer 2\% (w/v) Uranylformiatlösung wieder abgeschwemmt. Ein weiterer Kohlefilm wurde ebenfalls mit der Probe beschichtet und auf Kontrastmittel abgeschwemmt. Der erste Kohlefilm wurde mit einer perforierten Kohlefolie 
an ein Kupfernetzchen gebunden, dem Probenträger, von der Lösungsoberfläche abgenommen. Der auf dem Probeträger befindliche Kohlefilm wurde dann mit dem zweiten Kohlefilm überdeckt, so dass die Probepartikel im Kontrastmittel zischen den beiden Kohlefolien eingebettet werden. Überschüssiges Kontrastmittel wurde mit Filterpapier abgesaugt und das Präparat für 5-10 Minuten getrocknet. Ein Teil der Proben wurde anschießend in flüssigem Stickstoff schockgefroren (Golas et al., 2003).

\subsubsection{Elektronenmikroskopische Aufnahmen des Komplexes B $\Delta \mathrm{U} 1$}

Die Komplex B $\Delta$ U1 Präparate wurden in einem Philips CM200 FEG Mikroskop bei 160 kV Hochspannung mikroskopiert. Die elektronenmikrokopischen Bilder der Komplexe wurden bei 27.500 facher Vergrößerung auf Kodak S0-163 Film aufgenommen. Der Defokus betrug 1-2 $\mu \mathrm{m}$, so dass sich der erste Null-Durchgang der Kontrast-Transfer Funktion (CTF) bei 1/20 $\AA^{-1}$ befindet. Die Negative wurden für 12 Minuten in Kodak Entwickler entwickelt. Das CM200 FEG Mikroskop ist mit einem elektronisch steuerbaren Probenhalter ausgestattet, der Aufnahmen des Probenträgers in verschiedene Kippwinkeln zulässt. Es wurden Aufnahmen unter $0^{\circ}, 40^{\circ}$ und $55^{\circ}$ Kippwinkel erstellt.

\subsubsection{Digitalisierung der Negative}

Die Bilder wurden mit einem Trommelscanner mit einer Schrittweite von $21 \mu \mathrm{m}$ digitalisiert. Dies entspricht einer Pixelgröße von 7,7 $\AA$ in den Bildern des Komplexes B $\Delta U 1$. Die Pixelgöße P gibt die maximale Ortsfrequenz der in den digitalisierten Bildern enthaltenen Information. Sie wird als Nyquistfrequenz $f_{n}$ bezeichnet.

$$
f_{n}=1 /(2 \times P)
$$

Die maximal zu erreichende Auflösung einer dreidimensionalen Struktur liegt bei einer Pixelgröße von 7,7 $\AA$ bei ca. $23 \AA$, da in den Berechnungsschritten der Rekonstruktion Interpolationsfehler auftreten (Sander et al., 2003). Die Grauwertverteilung der digitalisierten Bilder umfasste etwa zwei Standardweichungen um den mittleren Grauwert.

\subsubsection{Auswahl und Bildverarbeitung der Einzelbilder}

Alle folgenden Bildverarbeitungsschritte wurden mit dem Programm Imagic-5 durchgeführt (van Heel et al., 1996). In den digitalisierten Negativen des Komplex B $\Delta U 1$ wurden die einzelnen Komplexe visuell lokalisiert und in einem quadratischen Rahmen von 72 Bildpunkten extrahiert. Die Einzelpartikelbilder wurden elektronisch auf eine 
Bildpunktgröße von 8,66 $\AA$ pro Bildpunkt umgerechnet um die Rechenzeit der Bildverarbeitungsschritte zu verkürzen. Insgesamt wurden $\sim 500$ Negative bei nicht gekipptem Probenträger aufgenommen. Aus diesen Aufnahmen wurden 20.000 Einzelpartikelbilder selektiert. Zusätzlich wurden Negative bei $40^{\circ}$ und $55^{\circ}$ gekippten Probenträgern aufgenommen. Aus diesen Aufnahmen wurden je 4000 Einzelpartikelbilder selektiert. Nachdem von einer Stelle des Probeträgers Aufnahmen bei $40^{\circ}$ gemacht wurde, wurde dieselbe Stelle nochmals bei nicht gekippten Probenträger abgebildet. Auf die Einzelpartikelbilder wurde ein Hochpassfilter angewendet, um Grauwertschankungen mit niedriger Frequenz (> 1/200 $\AA^{-1}$ ) in den Bildern zu unterdrücken, wie sie beispielsweise durch eine unterschiedliche Dicke der Kontrastmittelschicht hervorgerufen werden können. Zudem wurden ein Tiefpassfilter benutzt, um den Anteil hoher Frequenzen $\left(<20 \AA^{-1}\right)$ an der Bildinformation zu verringern, da in diesem Frequenzbereich lokale Dichteunterschiede der Kohlefolie die Bildinformation bestimmen. Auf die gefilterten Bilder wird eine Kreismaske angewendet, um die Bildinformation auf die Abbildung des Partikels zu begrenzen. Die mittlere Dichte wird auf eine Wert von Null und eine Varianz von 100 normalisiert um Intensitätsunterschiede der Grauwerte zwischen den Einzelbildern gering zu halten.

\subsubsection{Multivariate Statistische Analyse der Einzelbilder}

Das Signal der Partikel ist weit kleiner als das Hintergrundsignal in den Einzelbildern. Um Details der Komplexe zu erkennen ist es daher notwendig, mehrere identische Ansichten des Partikels zu mitteln. Bei einem Komplex unbekannter Struktur kann diese Mittelung auch ohne eine vorhergehende Information erfolgen, was als ,reference free alignment' bezeichnet wird (Dube et al., 1993). Dabei werden Methoden der multivariaten statistischen Analyse (MSA) angewendet.

Methoden:

- Ausrichtung der Bilder:

Die Ausrichtung eines Bildes nach einem Referenzbild kann durch Korrelationsberechnungen erfolgen. Dabei muß sowohl die Translation als auch die Rotation der beiden Bilder zueinander berücksichtigt werden. Für die Berechnung der TranslationsKreuzkorrelationsfunktion (CCF) gilt:

$$
C C F\left(r_{k}\right)=\sum_{i=1}^{N} d_{1}\left(r_{i}\right) d_{2}\left(r_{i}+r_{k}\right)
$$


Wobei $d_{1}\left(r_{i}\right)$ und $d_{2}\left(r_{i}\right)$ zwei Bilder mit $N$ Bildpunkten darstellen. Das Maximum der Kreuzkorrelationsfunktion ist um den selben Verschiebvektor $r_{k}$ verschoben wie das Bild und die Referenz. Das Bild wird entsprechend dem Verschiebevektors verschoben. Für die Rotationsausrichtung werden Bild und Referenz zuvor in Kreiskoordinaten umgewandelt und die Rotation der Bilder zueinander durch Berechnung der Rotations-Kreuzkorrelationsfunktion berechnet. Die Höhe des Maximum der Kreuzkorrelationsfunktion ist ein Maß für die Übereinstimmung beider Bilder und kann durch den Korrelationskoeffizienten C beschrieben werden:

$$
C=\frac{\sum_{i=1}^{N}\left(d_{1}\left(r_{i}\right)-\left\langle d_{1}\right\rangle\right)\left(d_{2}\left(r_{i}\right)-\left\langle d_{2}\right\rangle\right)}{\sum_{i=1}^{N}\left(d_{1}\left(r_{i}\right)-\left\langle d_{1}\right\rangle\right)^{2} \sum_{i=1}^{N}\left(d_{2}\left(r_{i}\right)-\left\langle d_{2}\right\rangle\right)^{2}}
$$

mit

$$
\left\langle d_{j}\right\rangle=\frac{1}{N} \sum_{i=1}^{N} d_{j}\left(r_{i}\right)
$$

- Eigenvektor - Eigenwert - Datenkomprimierung

Zentrierte Einzelbilder können mit Hilfe einer Korrespondenzanalyse und Klassifizierung in Gruppen ähnlicher Bilder eingeteilt werden (van Heel, 1989). Die Bildinformation eines Bilds kann durch einen Grauwertvektor von p Pixelwerten beschrieben werden und die Bildinformation aller Bilder $n$ ist so in $\operatorname{der} n \times p$ Matrix $X$ der Grauwertvektoren gegeben. Diese Matrix beschreibt einen p-dimensionalen Bildraum. Die Klassifizierung von Bildern in diesem p-dimensionalen Raum erfordert einen hohen Rechenaufwand. Um den Rechenaufwand zu reduzieren, wird der Bildraum in ein neues Koordinatensystem transformiert, in dem die Achsen parallel zu den orthogonalen Richtungen der Varianz zwischen den Bildern aufgespannt werden. Wird die Transformation auf Achsen beschränkt, die die signifikante Varianz der Partikelinformation beschreiben, so wird die Dimension des Bildraums reduziert und damit der Rechenaufwand. Diese neuen Achsen u werden durch eine Eigenwert-Eigenvektoranalyse gefunden:

$$
X_{T} N X M U=U \Lambda
$$

bei der Orthogonalisierungs Bedingung:

$$
U_{T} M U=I_{P}
$$


Wobei $I_{p}$ die Einheitsmatrix darstellt. Die Eigenvektoren u besitzen p-Elemente und können deshalb als Bild wiedergegeben werden. Sie bilden die Spalten der Eigenvektormatrix U (nach der absteigenden Höhe der Eigenwerte geordnet), während die entsprechenden Eigenwerte in der Eigenwertmatrix $\Lambda$ enthalten sind. Die Matrizen $M$ und $N$ geben die Metrik der Eigenwert-Eigenvektoranalyse, die hier als sog. ,modulation' Distanz (ähnlich der $\chi^{2}$ Metrik) gewählt wurden:

$$
\begin{aligned}
& n_{i}=\frac{1}{\left(\sum_{j=1}^{p} x_{i j}^{2}\right)^{1 / 2}} \\
& m_{j}=\frac{1}{\left(\sum_{i=1}^{p} x_{i j}^{2}\right)^{1 / 2}}
\end{aligned}
$$

\section{- Klassifizierung}

Die Klassifizierung der Bilder wurde nach der Methode der ,hierachical ascendant classification' (HAC) durchgeführt (Borland and van Heel, 1990; van Heel, 1984). Ausgangspunkt sind die Bildkoordinaten im durch Korrespondenzanalyse erhaltenen Bildraum. Bei dieser agglomerativen Clusterung werden ausgehend von den Einzelobjekten, hier Einzelbilder, schrittweise Einzelbilder und Gruppen von Einzelbildern zu größeren Clustern vereinigt. Für die Abstandsberechnung wurde Wards-Methode verwendet. Die Partition erfolgt so nach der geringsten Intra-Klassen-Varianz und maximiert die InterKlassen-Varianz. In einem weiteren Schritt, dem ,moving-elements-refinement', wird die Intra-Klassen-Varianz weiter minimiert. So wird eine verbesserte Partition erhalten, die im Sinne der Methode der kleinsten Quadrate optimal ist (van Heel, 1989). Der Abstand jedes einzelnen Bilds zu den erhaltenen Klassen im Bildraum wird nochmals berechnet und das Bild der Klasse mit dem geringsten Abstand zugeordnet. Nach einer erneuten Abstandsaktualisierung wird die Berechnung mit dem nächsten Bild fortgesetzt. Dieser Prozess wird iterativ wiederholt bis sich keine Veränderung der Partition mehr ergibt.

\section{Durchführung:}

Zunächst wurden die Abbildungen der Komplexe im Bildrahmen zentriert. Dazu wurde zunächst ein Summenbild aller Einzelpartikelbilder berechnet und radial gemittelt. Die Translations-Kreuzkorrelation von Summenbild und Einzelbild wurde berechnet und die Einzelbilder entsprechend auf das Korrelationsmaximum verschoben. Dieser Prozess wurde 
mit den verschobenen Bildern iterativ dreimal durchlaufen, um sukzessiv eine bessere Zentrierung der Bilder zu erreichen.

In dieser ersten Korrespondenzanalyse wurden 25 Eigenvektoren bestimmt und 15 Eigenvektoren, die den größten Anteil der Gesamtvarianz beschreiben, zur Klassifizierung verwendet. Die Klassifizierung wurde bei einer Gruppengröße von 20-30 Bildern abgebrochen. Die erhaltenen Gruppen Bildern wurden gemittelt, um so genannte Klassensummen zu erhalten.

\subsubsection{Verbesserung der Klassensummen}

Um eine bessere Ausrichtung der Einzelpartikelbilder zu erreichen wurden die erhaltenen Klassensummen zur Ausrichtung der Einzelpartikelbilder verwendet. In dieser Arbeit wurden zwei Verfahren verwendet: Die Multireferenz-,direct'-Ausrichtung (Steinkilberg and Schramm, 1980; van Heel and Stoffler-Meilicke, 1985) und die Multireferenz-Polarkoordinatenausrichtung (Joyeux and Penczek, 2002; Sander et al., 2003).

\section{Methoden:}

- Multireferenz-, direct'-Ausrichtung

Die dreidimensionale Struktur wurde in alle Raumrichtungen in $15^{\circ}$ Abständen ausprojiziert. Die 180 Rückprojektionen bilden die Referenzbilder für die weiter Ausrichtung der Bilder. Dazu wird die Multireferenz Ausrichtung verwendet (engl. ,multi reference alignment', MRA). Durch die Berechnung der Translations- und Rotations-Kreuzkorrelation werden die Bilder zunächst nach den ersten beiden Referenzen ausgerichtet und die Korrelationskoeffizienten bestimmt. In einem iterativen Prozess, der zwei bis fünfmal durchlaufen wird, folgt dabei auf eine Rotations-Ausrichtung und eine TranslationsAusrichtung und umgekehrt. Von den beiden ausgerichteten Bildern wird das Bild mit dem höheren Korrelationskoeffizienten auf die dritte Referenz ausgerichtet und wiederum der Korrelationskoeffizienten berechnet. Die Prozedur wird in dieser Weise für alle Referenzen wiederholt und somit Korrelationskoeffizienten der Einzelpartikelbilder für alle Referenzbilder erhalten.

- Polarkoordinaten-Ausrichtung

Die Partikelbilder werden zunächst für alle möglichen Partikelzentren in Polarkoordinaten transformiert. Die Rotations-Korrelation der transformierten Partikelbilder mit den Referenzen wird berechnet. Das Partikelbild wird nach der Referenz mit den höchsten Rotations-Korrelationskoeffizienten ausgerichtet. Die Zahl der Korrelationsberechnung für 
die Polarkoordinatenausrichtung liegt um ein vielfaches höher als für die MRA und erfordert deshalb sehr viel Rechenzeit. Die Genauigkeit der Ausrichtung ist aber besonders für Partikelbilder mit einem niedrigen Signal-Rausch-Verhältnis besser als in der MRA (Sander et al., 2003).

\section{Durchführung:}

Ein Datensatz von Einzelbildern wurde anhand von gut definierten Klassensummen erneut ausgerichtet. Die Zahl der ausgewählten Klassensummen lag bei 5-10 pro tausend Einzelbildern. In der MRA wurde die Korrelation der Einzelpartikelbilder mit den Referenzen der so genannten ,mutual'-Korrelationsfunktion (engl. ,mutual correlation funktion', MCF) berechnet. Die Verwendung der MCF führt gegenüber Kreuzkorrelationsfunktion zu einer Unterdrückung von Bildinformation niedriger Frequenz (van Heel, 1992). Auf die MRA folgte eine weitere MSA und die Bildung von Klassensummen. Dieser Zyklus wurde insgesamt fünfmal durchlaufen. Ab dem dritten Zyklus wurde die PolarkoordinatenAusrichtung anstelle der MRA verwendet.

\subsubsection{Dreidimensionale Rekonstruktion}

Bei der dreidimensionale Rekonstruktion von asymmetrischen Objekten erfordert die Berechnung der ersten Struktur besondere Sorgfalt. Wenn die ersten Zuordnung von Projektionswinkeln zu den Klassensummen zu ungenau ist, kann es zu einer Akkumulation von Fehlern in den weiteren Berechnungsschritten kommen. Es ist deshalb notwendig mehrere Startstrukturen zu berechnen und unterschliche Rekonstruktionsalgorithmen zu verwenden. Die dreidimensionale Rekonstruktion einer Startstruktur wurde mit drei unterschiedlichen Methoden, ,angular reconstitution' (van Heel, 1987), ,random conical tilt' (RCT) (Radermacher et al., 1987) und einem iterativen Berechnungsverfahren durchgeführt, um ein erstes dreidimensionales Modell des Komplexes B $\Delta \mathrm{U} 1$ für die weiter Verbesserung der Struktur zu erhalten. Die Rekonstruktion wurde im Kontext des EulerKoordinatensystems des Imagic-5 Programm durchgeführt (Abbildung 3.2) 


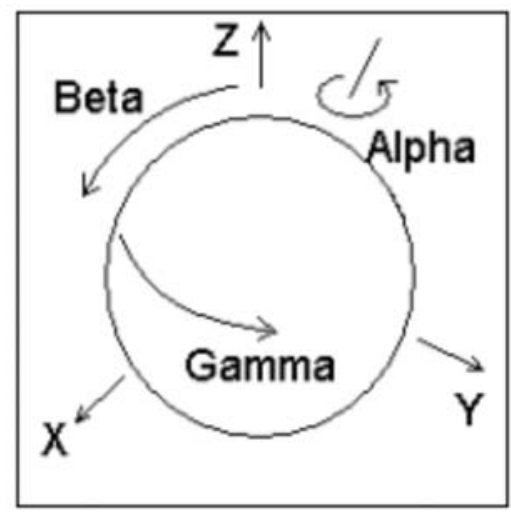

\begin{abstract}
Abbildung 3.2 Euler Koordinatensystem der Imagic-5 Software. Die Projektionsrichtung eines Bildes kann durch drei Winkel beschrieben werden. Um ein Bild in eine bestimmte Projektionsrichtung zu bringen müssen nacheinander drei Rotationen um diese Winkel ausgeführt werden. Der $\gamma$-Winkel beschreibt eine Rotation der Partikelbilder in der Bildebene um die z-Achse. Der $\beta$-Winkel beschreibt eine Rotation um die y-Achse. Der $\alpha$-Winkel beschreibt eine weitere Rotation in der Bildebene um die neue z-Achse des Bildes.
\end{abstract}

\title{
Methode:
}

- ,angular reconstitution'

Das Theorem der gemeinsamen Linienprojektion sagt aus, dass zwei Projektionsbilder eines dreidimensionalen Objekts eine gemeinsame Linienprojektion besitzen (Abbildung 3.3 A und B). Die Darstellung aller Linienprojektionen eines Projektionsbilds (in einem Bild) wird als Sinogramm bezeichnet (Abbildung 3.3 C und D). Die gemeinsame Linienprojektion wird durch die Berechnung der Korrelation für alle Linienprojektionen des ersten Projektionsbilds mit allen Linienprojektionen der zweiten Projektionsbilds ermittelt. In einem Diagramm, der so genannten Sinogramm-Korrelationsfunktion, der Linienprojektionen werden die Korrelationskoeffizienten aufgetragen und die Maxima der Korrelationskoeffizienten bestimmt (Abbildung 3.3 E). Die Maxima der Korrelationskoeffizienten geben die Lage der gemeinsamen Linienprojektion in den Projektionsbildern an. Die Richtung, in welche die Projektionen ausprojiziert wurden, liegt orthogonal zur der gemeinsamen Linienprojektion (Abbildung 3.4 A). In einer Gruppe von drei Projektionen können so für jede Projektion die beiden mit den jeweils anderen Projektionen gemeinsamen Linienprojektionen gefunden werden und somit die relativen Projektionsrichtungen bestimmt werden (Abbildung 3.4 B). 


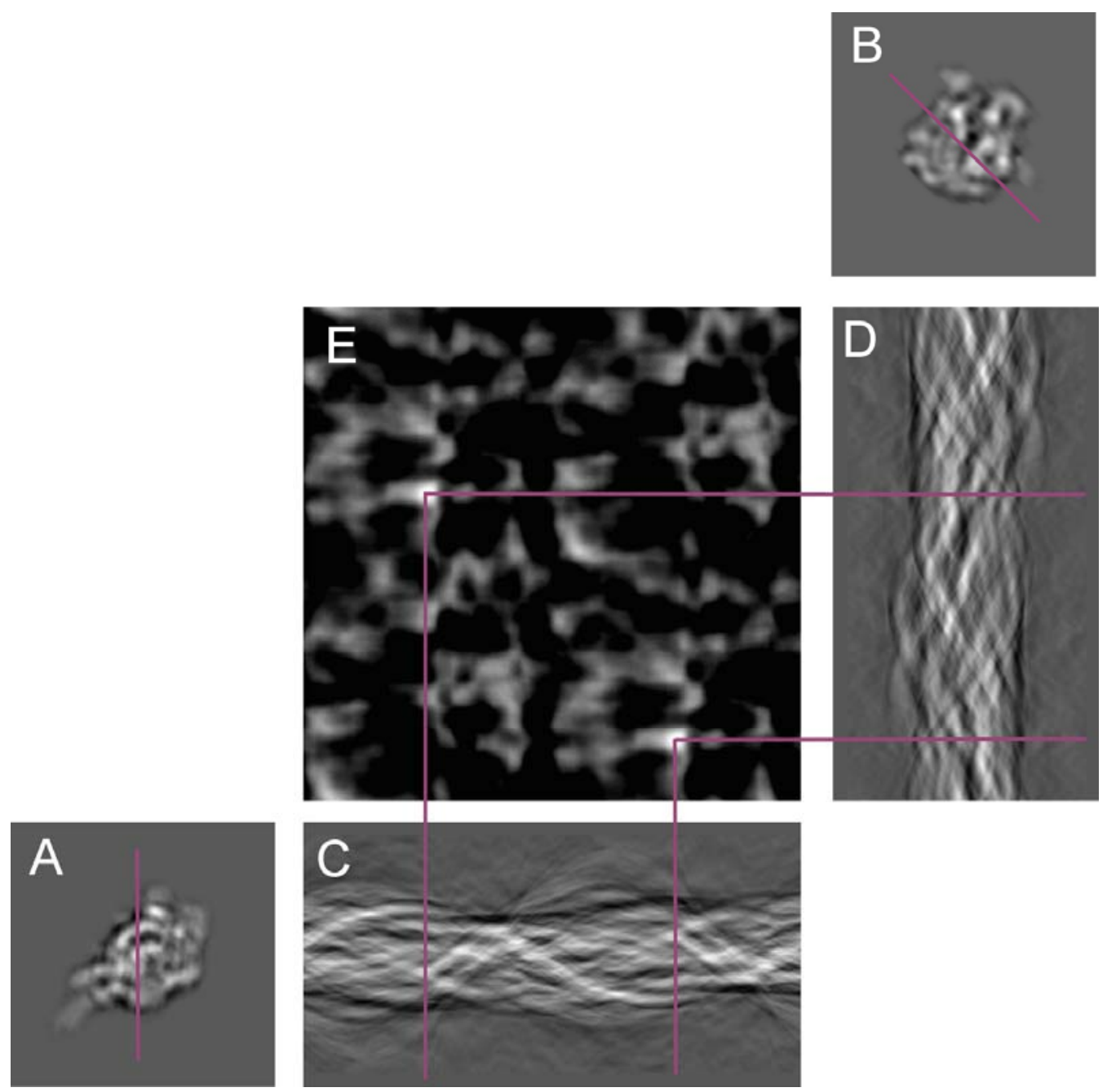

\section{Abbildung 3.3 Theorem der gemeinsamen Linienprojektion}

Dargestellt ist die Berechnung der gemeinsamen Linienprojektion der Projektionsbilder A und B, welche die Projektionen eines Objekts (hier 50S ribosomale Untereinheit (N. Fischer, unveröffentlichte Daten) darstellen. Die Linienprojektion der Bilder bilden untereinander abgebildet die Sinogramme C und D. Die Berechnung der Kreuzkorrelation aller Linienprojektionen des Bildes A und des Bildes B gibt ein Diagramm der Korrelationskoeffizienten, Sinogramm-Korrelationsfunktion genannt, die hier durch Grauwerte anschaulich dargestellt sind (weiß = hohe Korrelationskoeffizienten). Die Maxima Korrelationskoeffizienten zeigen die gemeinsamen Linienprojektionen der Bilder A und B auf (rote Linie). 
A

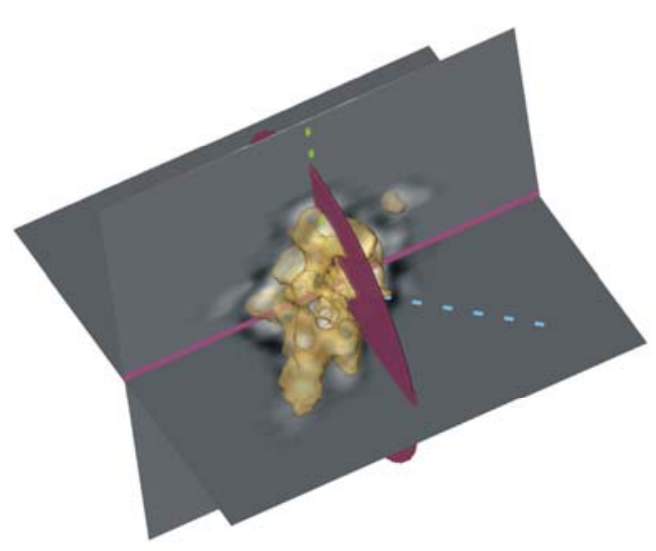

B

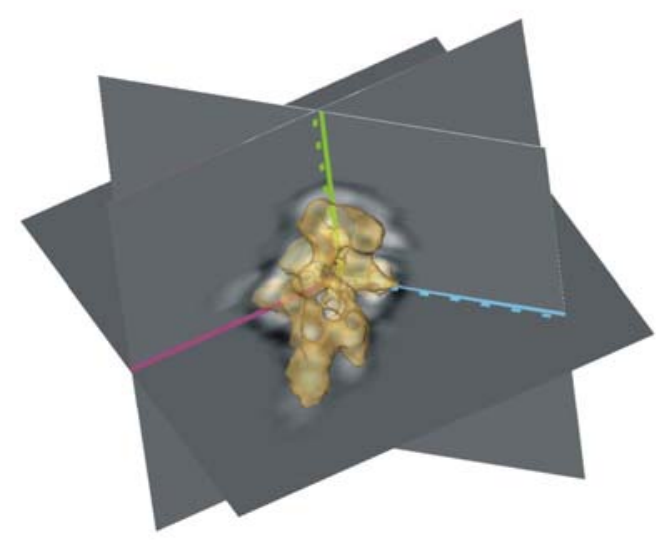

Abbildung 3.4 Anwendung des Theorems der gemeinsamen Linienprojektion für die dreidimensionale Rekonstruktion

A) Die Projektionsrichtungen, bzw. die Bildebene, der Bilder A und B (Bildrahmen gegenüber Abbildung 3.3 um $45^{\circ}$ in der Bildebene rotiert), liegen orthogonal $\mathrm{zu}$ der gemeinsamen Linienprojektion (rot). Die Projektionsrichtungen der Bilder liegen damit auf den rot dargestellten Kreis. B) Erst wenn die gemeinsame Linienprojektionen der Bilder A und B mit einem weiteren Bild (der gleichen Struktur) bestimmt werden (gemeinsame Linienprojektionen sind blau und grün dargestellt), sind die Projektionswinkel aller drei Bilder vollständig bestimmt.

\section{- Berechnung eines RCT- Startmodells}

Den bei $40^{\circ}$ Kippwinkel erhaltenen Einzelpartikelbildern werden jeweils die bei $0^{\circ}$ Kippwinkel erzeugten Einzelpartikelbilder zugeordnet und so genannte Kippwinkelpaare gebildet (Radermacher et al., 1987). Die $0^{\circ}$-Einzelpartikelbildern werden in Klassen gleicher Ansichten eingeteilt. Die zugehörigen $40^{\circ}$-Einzelpartikelbilder bilden dann einen Konus von Ansichten des Partikels (Abbildung 3.5). Die relativen Projektionsrichtungen der $40^{\circ}$ Einzelpartikelbilder sind durch die Rotation der $0^{\circ}$-Einzelpartikelbilder auf dem Probenträger bestimmt. Für die dreidimensionale Rekonstruktion muss die Kippachse in den $40^{\circ}$ Bildern senkrecht zur Normalen des Konus der Ansichten ausgerichtet sein. 


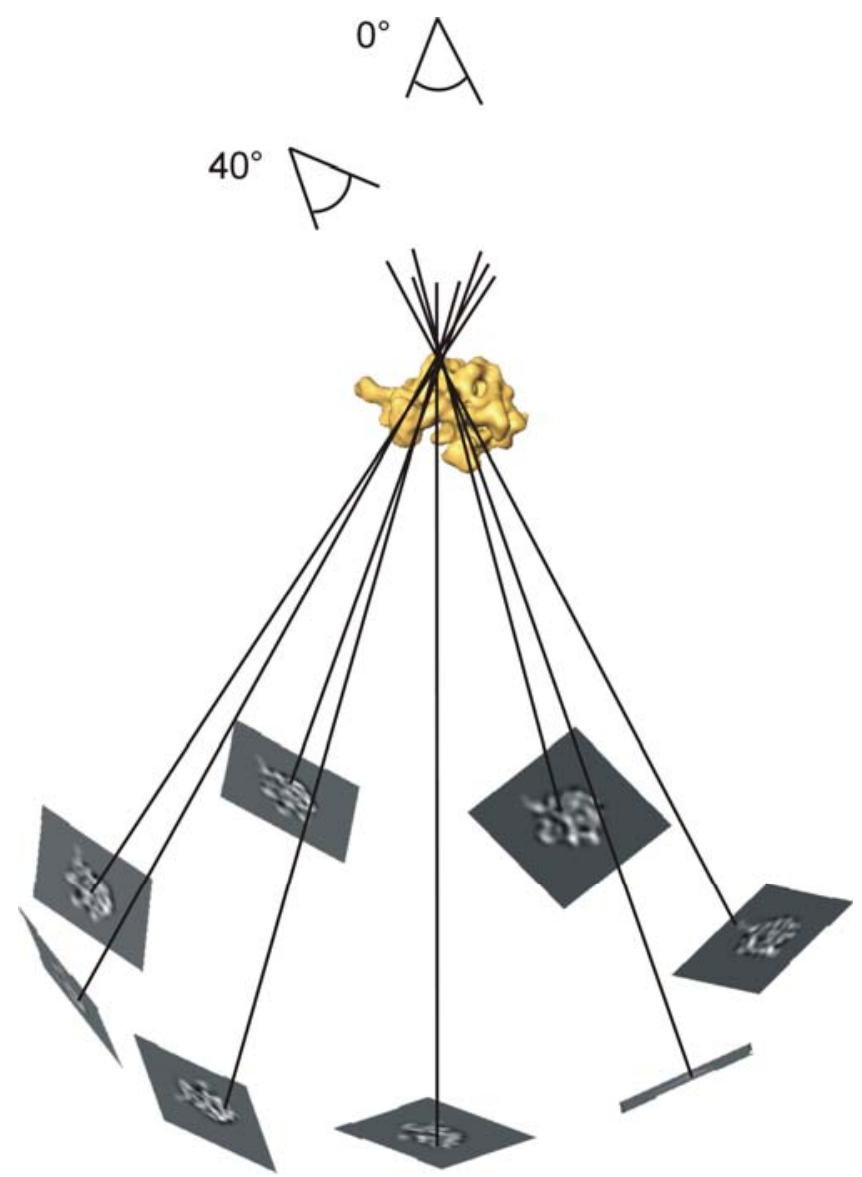

Abbildung 3.5 Schematische Darstellung der Datenaufnahme für eine konische Kippserie für die RCT

\section{Rekonstruktion}

Wenn ein Partikel eine bevorzugte Adsorbtionsorientierung auf dem Probenträger besitzt (gelbe Struktur), erscheint er in den $0^{\circ}$ Aufnahmen immer mit der gleichen Ansicht (Schematisch dargestelltes Auge $0^{\circ}$ ). Bei gekipptem Probenträger (schematisch dargestelltes Auge $40^{\circ}$ ) hingegen bilden die Einzelbilder nun einen Konus von Seitenansichten des Partikels (im Schema dargestellte Projektionen).

- Iterative Berechnung einer Startstruktur

Aus einem Satz von Projektionsbildern eines Objekts soll das ursprüngliche dreidimensionale Objekt rekonstruiert werden. Zur Rekonstruktion müssen die Projektionswinkel, hier die Winkel eines Eulersystems $\alpha, \beta$, $\gamma$, gewählt werden. Durch einen geeigneten Rekonstruktionsalgorithmus kann das Objekt rekonstruiert werden (siehe unten). Die Güte der Rekonstruktion kann durch die Korrelationskoeffizienten C der Korrelation der Projektion mit der Rückprojektion des Objekts bestimmte werden (Harauz and van Heel, 1984). Für hinreichend komplexe Objekte kann angenommen werden, dass sich die richtige dreidimensionale Struktur durch die höchste Summe der Korrelationskoeffizienten von Projektion und Rückprojektion auszeichnet (Harauz and van Heel, 1986; van Heel et al., 
2000). Eine zutreffende Rekonstruktion des Objekts sollte sich daher durch einen hohen mittleren Korrelationskoeffizienten $<\mathrm{C}>$ für alle Projektions-Rückprojektionspaare auszeichnen:

$$
\max <C(\alpha, \beta, \gamma)>
$$

Die dem Rekonstruktionsalgorithmus zugrunde liegende Funktion ist allerdings in Abhängigkeit von der Wahl der Winkel nicht linear (Harauz and van Heel, 1984; Penczek et al., 1996). Das Auffinden des globalen Maximums der Übereinstimmung von Projektion und Rückprojektion kann deshalb nur mit Hilfe der nichtlinearen Optimierung erhalten werden. Im Folgenden wurde der von Kirkpatrick vorgeschlagene stochastische Optimierungsansatz gewählt (Kirkpatrick et al., 1983). Der Ablauf der Berechnung kann schematisch dargestellt werden (Abbildung 3.6). Zunächst werden den Projektionen Zufalls-Projektionswinkel $\mathrm{P}_{1}$ zugeordnet und eine dreidimensionale Struktur $\mathrm{D}_{1}$ berechnet. Danach wird $\mathrm{zu}$ den Projektionswinkeln ein Winkelinkrement addiert und mit den so erhaltenen Projektionswinkeln $\mathrm{P}_{2}$ erneut eine Struktur $\mathrm{D}_{2}$ berechnet. Die Korrelationskoeffizienten der Korrelation der Projektionen mit den Rückprojektionen werden für beide Strukturen berechnet. Wenn die mit den Winkeln $\mathrm{P}_{2}$ erhaltene Struktur $\mathrm{D}_{2}$ einen höheren mittleren Korrelationskoeffizienten aufweist, so werden diese Winkel beibehalten und in einer erneuten Berechnung eingesetzt. So kann iterativ schrittweise der mittlere Korrelationskoeffizient maximiert werden. Wenn die mittleren Korrelationskoeffizienten für die Struktur $\mathrm{D}_{1}$ größer sind, werden die Winkel $\mathrm{P}_{2}$ mit einer bestimmten Wahrscheinlichkeit abgelehnt oder angenommen. Die Wahrscheinlichkeit nimmt exponentiell mit der Differenz der Korrelationskoeffizienten ab. Die Wahrscheinlichkeit wird ferner von einem Parameter T kontrolliert, der im Verlauf der Iteration immer kleinere Werte annimmt. Die Wahrscheinlichkeit für die Akzeptanz von Winkeln $\mathrm{P}_{2}$, die eine relativ starke Abnahme der Korrelationskoeffizienten gegenüber $\mathrm{P}_{1}$ bedeuten, verringert sich so im Verlauf der Iterationen. Die Iterationszyklen wurden nach einer festen Anzahl von Zyklen abgebrochen. Der Parameter T lässt dann nur noch wenige Winkelkombinationen zu und die Rechenzeit für eine Verbesserung der mittleren Korrelationskoeffizienten nimmt stark zu. Der Parameter T und die Art des Dekrements muss Problem spezifisch iterativ festgelegt werden. 


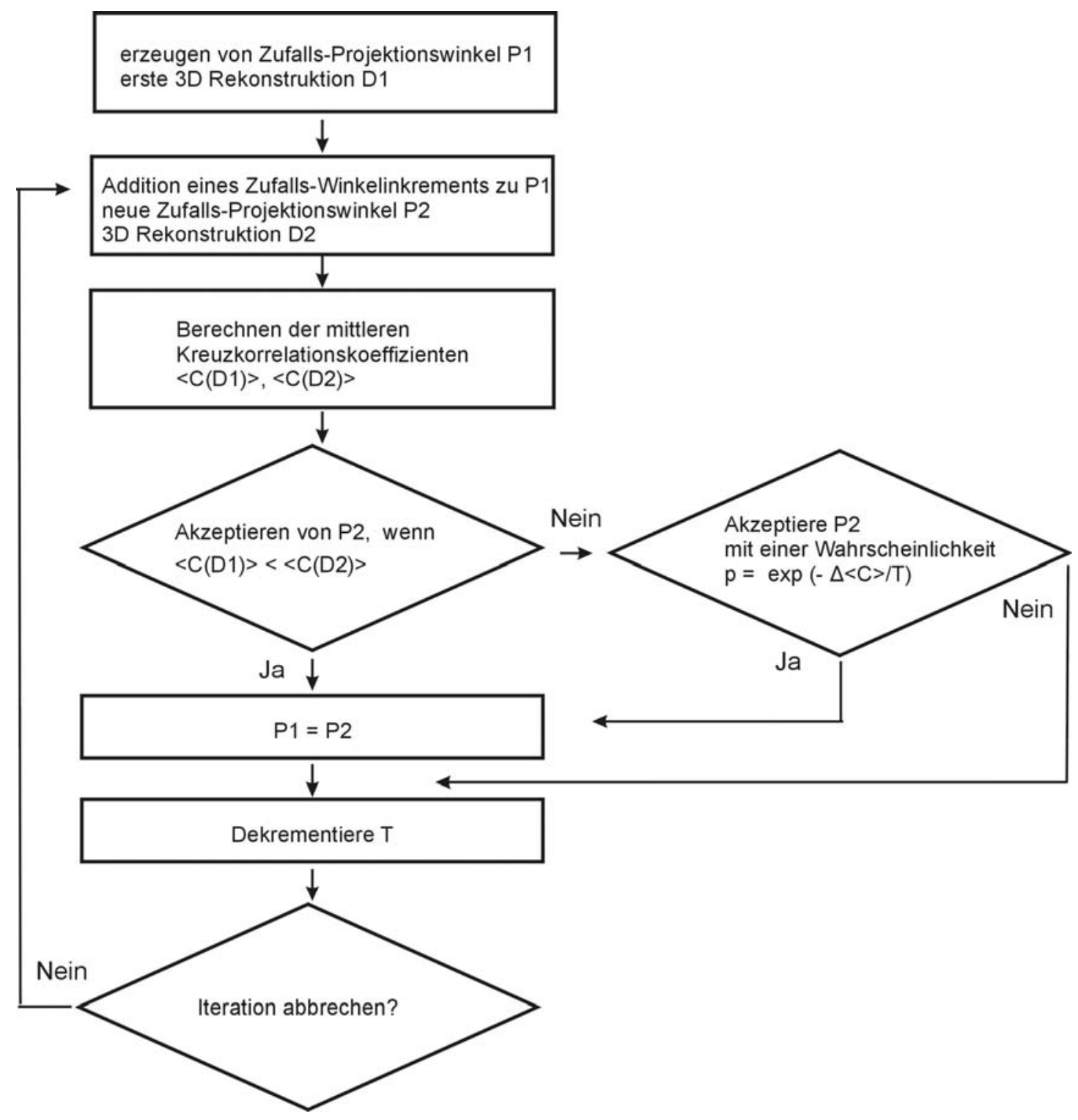

Abbildung 3.6 Flussdiagramm der iterativen Berechnung einer Startstruktur

Durchführung:

- ,angular reconstitution'

Für jeweils zwei Projektionen wurden in $1^{\circ}$ Abständen die Linienprojektionen berechnet und ein Sinogramm erstellt. Die erhaltenen Sinogramme wurden zur Berechnung der Sinogramm-Korrelationsfunktion verwendet. Aus den Maxima der Sinogrammkorrelationsfunktion wurde die Lage der gemeinsamen Linienprojektionen abgelesen. Die Projektionswinkel einer Gruppe von drei Projektionen wurden so bestimmt. 
- Berechnung eines RCT- Startmodells

Die Einzelpartikel wurden in den digitalisierten $40^{\circ}$-Aufnahmen markiert und die Koordinaten der Bilder auf die Position der Einzelpartikel in den $0^{\circ}$-Aufnahmen umgerechnet. Dazu wurden in beiden Bildern 3 auffällige Punkte, wie Staubpartikel, visuell gesucht und die Koordinaten der Partikel von beiden Bildern festgehalten. Diese Koordinaten wurden zur Berechnung der Transformationsmatrix verwendet. Es wurden zwei Datensätze von $40^{\circ}$ Einzelpartikelbildern und $0^{\circ}$-Einzelpartikelbildern erzeugt, in denen die $40^{\circ}$-Ansichten den $0^{\circ}$-Ansichten der Einzelpartikel zugeordnet sind. Insgesamt wurden so 2000 Kippwinkelpaare erhalten. Die $0^{\circ}$-Einzelpartikelbilder wurden wie in Abschnitt 3.3.5-3.3.6 beschrieben klassifiziert und Klassensummen berechnet. Eine Partikelansicht trat in den Klassensummen mit besonderer Häufigkeit auf. Die 100 Kippwinkelpaare dieser Ansicht wurden aus den Datensätzen extrahiert und die $40^{\circ}$-Einzelpartikelbilder zur Berechung der dreidimensionalen Struktur verwendet. Die $40^{\circ}$-Einzelpartikelbilder wurden zentriert, indem die $40^{\circ}$ Einzelpartikelbilder auf die radial gemittelte Summe der $0^{\circ}$-Ansichten ausgerichtet wurden. Die $0^{\circ}$-Einzelpartikelbilder wurden auf die Summe der Klassensummen ausgerichtet und so die relativen Rotationswinkel der $0^{\circ}$-Ansichten in der Probenträgerebene bestimmt. Zusammen mit dem Kippwinkel von $40^{\circ}$ sind dann die Projektionswinkel der $40^{\circ}$-Einzelpartikelbilder bestimmt. In dem Euler-Winkelsystem der Imagic Software bildet der Kippwinkel den $\beta$-Winkel und der Rotationswinkel der Ausrichtung der $0^{\circ}$-Ansichten den $\gamma$-Winkel (vgl. Abbildung 3.2). Der $\alpha$-Winkel entspricht den von der Kipp-Achse und x-Achse des Koordinatensystems eingeschlossenen Winkels.

Den $40^{\circ}$-Einzelpartikelbildern wurden so die relativen Projektionswinkel zugeordnet und eine erste dreidimensionale Struktur berechnet. Um eine verbesserte Zentrierung der $40^{\circ}$-Ansichten zu erreichen, wurde die Struktur rückprojiziert und diese Rückprojektionen zur Zentrierung der $40^{\circ}$-Ansichten verwendet. Aus den neu ausgerichteten $40^{\circ}$-Ansichten wurde dann eine dreidimensionale Struktur mit höherer Auflösung berechnet.

- Iterative Berechnung einer Startstruktur

In zwei separaten Berechnungen wurden die Klassensummen von $0^{\circ}$ gekippten und $40^{\circ}$ gekippten Probenträgern verwendet. Aus dem 20.000 Einzelbilder Datensatz wurden zwei 6000 Einzelbilder umfassende Datensätze extrahiert. Für beide Datensätze wurden separat Klassensummen berechnet und in zwei unabhängigen Berechnungen von Startmodellen verwendet. Aus einem Datensatz wurden 22 Klassensummen ausgewählt. Kriterium für die Auswahl war: (1) eine deutlich gegenüber dem Hintergrund abgegrenzte Kontur, (2) eine möglichst kontraststarke Struktur der Partikelansicht und (3) die Verwendung möglichst 
unterschiedlicher Ansichten des Komplexes. Die Klassensummen wurden entlang ihrer Kontur maskiert, sodass der Hintergrund außerhalb der Partikelansicht auf Null gesetzt wurde. Die Klassensummen wurden hochpass gefiltert und die Grauwerte oberhalb eines Schwellenwerts auf 1 und unterhalb des Schwellenwerts auf 0 gesetzt, sodass die Struktur des Partikels mit maximalen Kontrast erscheint. Für die iterative Berechnung wurden die Funktionen der Imagic5 Software verwendet. Die dreidimensionale Rekonstruktion wurde mit dem ,exact filtetered backprojection' Algorithmus durchgeführt (Harauz and van Heel, 1986). Für die Erzeugung von Zufallszahlen wurde ein Linear Kongruenter Generator verwendet (Blobel and Lohrmann, 1998). Die iterative Berechung wurde in gleicher Weise für den bei $40^{\circ}$ gekippten Probenhalter aufgenommenen Datensatz durchgeführt.

\subsubsection{Verbesserung der Projektionswinkelbestimmung}

Das mit der Methoden der iterativen Berechnung erstellte Startmodel wurde durch ,angular reconstitution' mittels ,anchor-set'-Winkelbestimmung verbessert. Das Startmodel wurde in alle Raumrichtungen in $40^{\circ}$ Abständen ausprojiziert, dem so genannten ,anchor-set' Diese Projektionen dienen zu einer , anchor-set' Winkelbestimmung der Klassensummen (van Heel et al., 1992).

\section{Methode}

- ,angular reconstitution' mittels ,anchor-set'-Winkelbestimmung

Wird einer Gruppe von Rückprojektionen, dem ,anchor-set', eines dreidimensionalen Objekts eine weitere Ansicht hinzugefügt, hier einer Klassensumme, so ergeben sich für alle Rückprojektionen gemeinsame Linienprojektionen mit denen der hinzugefügten Ansicht. Für einen bestimmten Projektionswinkel der hinzugefügten Ansicht ist die relative Lage dieser Linienprojektionen im ,anchor-set' bestimmt. Die Kreuzkorrelation der Linienprojektionen des ,anchor-sets' mit den Linienprojektionen der hinzugefügten Ansicht werden berechnet. Der höchste Korrelationskoeffizient wird für den Projektionswinkel der neuen Ansicht erwartet.

\section{Durchführung}

Allen Klassensummen wurden so Projektionswinkel zugeordnet und eine neue dreidimensionale Struktur berechnet, in der die Rückprojektionen eine höhere Übereinstimmung mit den Klassensummen aufwiesen. Um die Struktur wurde eine Maske gelegt. Die Dichte in den Randbereichen der Struktur, die Rauschen repräsentieren, wird von 
der Berechnung ausgeschlossen. Die Klassensummen wurden auf die Rückprojektionen der Struktur ausgerichtet, um eine bessere Zentrierung zu erreichen. Mit diesen zentrierten Klassensummen wurde eine weitere Struktur berechnet. Diese Struktur wurde dann wiederum zu einem neuen ,anchor-set' ausprojiziert und die Winkelbestimmung wiederholt. Diese Prozedur wurde iterativ fortgesetzt, bis sich keine wesentliche Verbesserung der Übereinstimmung von Rückprojektionen und Klassensummen durch eine neue Winkelbestimmung ergab.

\subsubsection{Iterative Verbesserung der Struktur}

In der dreidimensionalen Rekonstruktion ist die Bildinformation aller Klassensummen vereinigt. Die Rückprojektionen der Rekonstruktion besitzen daher ein wesentlich höheres Signal-Rausch-Verhältnis als die Klassensummen. Um eine bessere Ausrichtung der Einzelpartikelbilder zu erreichen, wird deshalb die erhaltene Struktur zur erneuten Ausrichtung der Einzelpartikelbilder verwendet. Nach erneuter MSA werden neue Klassensummen gebildet. Die Projektionswinkel dieser Klassensummen werden neu bestimmt und eine neue Struktur berechnet. Diese Prozedur wird mehrfach wiederholt (Abb. 3.7). Das Signal-Rausch-Verhältnis der Klassensummen nimmt dabei schrittweise zu, die Ausrichtung der Einzelpartikelbilder und die Projektionswinkelbestimmung der Klassensummen wird sukzessive genauer.

\section{Methode}

- Beschleunigung der Ausrichtungs-Prozedur

Wenn Einzelpartikelbilder erneut anhand eines Satz von gleichen oder nur leicht veränderten Rückprojektionen, Referenzen, derselben dreidimensionalen Struktur ausgerichtet werden sollen, so kann die Rechenzeit deutlich verringert werden. Die für die Ausrichtung eines Partikelbilds berücksichtigten Rückprojektionen, werden dabei auf die Rückprojektionsrichtungen beschränkt, die bereits in der vorhergehenden Ausrichtung hohe Korrelationskoeffizienten aufwiesen (Sander et al., 2003). Die Korrelationskoeffizienten der ersten Ausrichtung werden in einem Diagramm der Projektionswinkel $\beta$ und $\gamma$ als Grauwerte eingetragen. So wird für jedes Einzelbild ein interpoliertes Bild der Korrelationswertverteilung erzeugt, ein so genanntes Corrim. Nur Referenzen der Projektionswinkelkombinationen, für die die Grauwerte oberhalb einer bestimmten Standardabweichung liegen, werden in der erneuten Ausrichtung verwendet. 


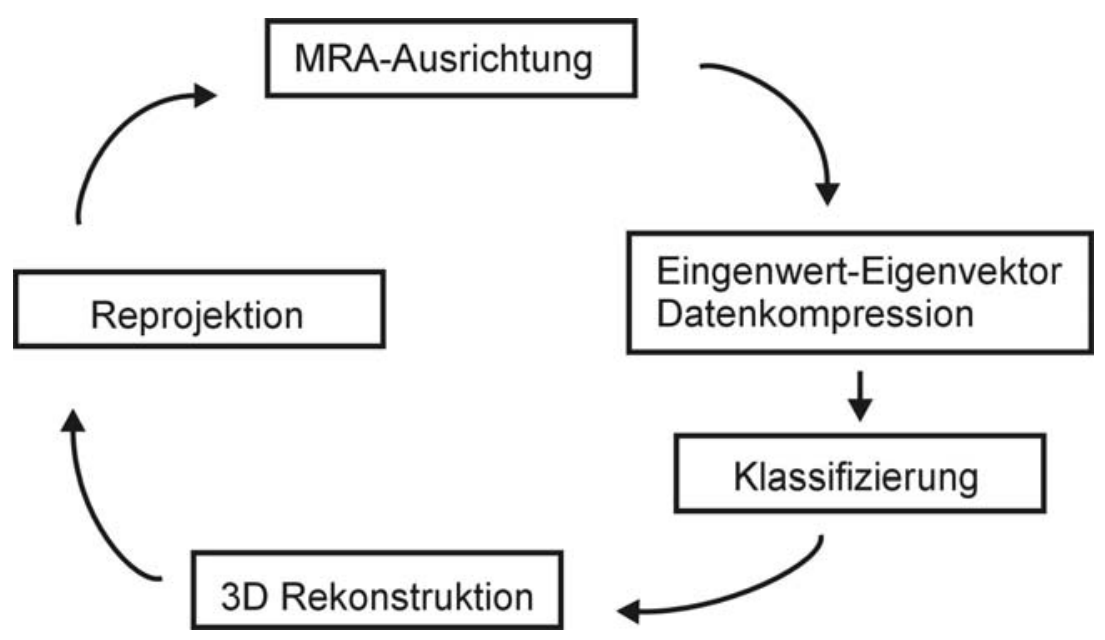

Abbildung 3.7 Schematische Darstellung der Abfolge der Berechnungsschritte bei der iterativen Verbesserung der Struktur.

Durchführung:

Die Startstruktur wurde in $15^{\circ}$ Winkelabständen rückprojiziert und die so erhaltenen Rückprojektionen in einer MRA als Referenzen verwendet. Der gesamte Datensatz von 20.000 Einzelpartikelbildern des Komplex B $\Delta U 1$ wurde nach diesen Referenzen ausgerichtet. Für alle Rückprojektionen wurden so Korrelationskoeffizienten erhalten und zur Berechnung von Corrims verwendet. In einer anschließenden Polarkoordinaten Ausrichtung der Bilder wurden nur Rückprojektionen berücksichtigt, die aus Projektionswinkebereiche stammen, die oberhalb der 1,2 fachen Standardabweichung der Grauwerte lagen.

Die so ausgerichteten Bilder wurden mittels einer MSA in Klassen von 20-30 Bildern eingeteilt und deren Klassensummen berechnet. Den Klassensummen wurden durch eine ,anchor set' Winkelbestimmung Projektionswinkel zugewiesen und eine neue dreidimensionale Struktur berechnet. Die Prozedur wurde ausgehend von dieser Struktur wiederholt. Die Auflösung der dreidimensionalen Struktur verbesserte sich dabei schrittweise. Der Winkelabstand der Referenzbilder wurde dabei sukzessiv bis auf $10^{\circ}$ verringert. Nach 15 Berechnungszyklen konnte keine weitere Verbesserung der Auflösung, bestimmt nach Fourier-Schalenkorrelationsfunktion (siehe 3.3.10), erreicht werden. 


\subsubsection{Auflösung der Struktur}

Die Zahl der für die Strukturberechnung verwendeten Klassensummen gibt eine untere Grenze für die zu ereichende Auflösung. Die tatsächlich erreichte Auflösung ist geringer als die erwartete Auflösung und kann durch den Vergleich zweier Rekonstruktionen mittels der Fourier-Schalenkorrelation bestimmt werden (Harauz and van Heel, 1986).

\section{Methode}

- Berechnung der maximal zu ereichenden Auflösung

Die minimale Anzahl n von gleichmäßig verteilten Projektionen, die zum Erreichen einer bestimmten Auflösung $f_{d}$ notwendig ist, ist durch die Überlappung der der ,central sections' bei der dreidimensionalen Rekonstruktion im Fourierraum bestimmt (DeRosier and Klug, 1968). Für eine Struktur mit dem Durchmesser D gilt:

$$
1 / f_{d} \leq \pi \times D / n
$$

Diese Formel gilt für ideale rauschfreie Projektionen, die gleichmäßig über aller Projektionswinkel verteilt sind, und ergibt beispielsweise für ein Objekt mit $300 \AA$ Durchmesser für eine Auflösung von 20 Å eine Zahl von 50 Projektionen.

Bei dreidimensionalen Rekonstruktionen von elektronenmikroskopischen Bildern ist die Auflösung der Klassensummen limitiert durch die Genauigkeit der Ausrichtung der Einzelbilder. Der Winkelabstand $\delta$ der Referenzbilder ist damit ausschlaggebend für die Genauigkeit der Ausrichtung (Frank et al., 1999):

$$
1 / f_{d} \leq \sin \delta \times D / 2
$$

Ein Winkelabstand der Referenzen von $15^{\circ}$, entsprechend 180 Referenzen, reicht aus um bei einem Objektdurchmesser von 300 Å eine Auflösung von 39 Å zu erreichen.

- Berechnung der Auflösung

Zur Berechnung werden zwei Rekonstruktionen aus separaten Datensätzen miteinander verglichen. Ein Maß für die Übereinstimmung der Strukturen in Abhängigkeit von der Raumfrequenz gibt die Fourier-Schalenkorrelation FSC (Harauz and van Heel, 1986).

$$
F S C(S)=\frac{\sum_{R=S} F_{1}(R) \times \sum_{R=S} F_{2}^{*}(R)}{\sqrt{\left(\sum_{R=S}\left|F_{1}(R)\right|^{2} \times \sum_{R=S}\left|F_{1}(R)\right|^{2}\right)}}
$$


Wobei F1 und F2 die Strukturfaktoren der beiden unabhängigen Rekonstruktionen sind und $S$ den Radius der Schale angibt.

Als Auflösung wird im Allgemeinen die Raumfrequenz angegeben, bei der die FSC unterhalb den dreifachen Wert fällt, der für die FSC von zwei Volumen von Rauschen mit einer Gaussverteilung erwartet wird.

Durchführung:

Die zur Berechnung der Rekonstruktion verwendeten Klassensummen wurden in zwei Gruppen geteilt und je eine Struktur berechnet. Die Strukturen wurden direkt, ohne Anwendung einer dreidimensionalen Maske, zur Berechnung der FSC verwendet.

\subsubsection{Visualisierung der dreidimensionalen Struktur}

Die Visualisierung einer Struktur kann durch eine Oberflächendarstellung vorgenommen werden, wie sie im Programm Amira implementiert ist. Dazu wird ein DichteSchwellenwert definiert und den Koordinaten dieses Schwellenwerts im rekonstruierten Volumen eine Oberfläche zugewiesen. Dichten unterhalb dieses Schwellenwerts werden als Rauschen betrachtet und nicht visualisiert.

\subsubsection{Analyse struktureller Heterogenität}

Strukturelle Heterogenitäten in Teilbereichen der Komplexe wurden mittels eines ,subdomain alignments' erfasst und Einzelpartikelbilder in Unterklassen unterschiedlicher Konformation und Zusammensetzung eingeteilt (Walz et al., 1998). Für die Analyse wurden die Einzelbilder einer häufigen Partikelansicht in einem Datensatz von 1200 Partikeln zusammengefasst und das Summenbild dieser Ansicht berechnet. Das strukturelle Element, das auf Heterogenität getestet werden soll, die Kopf Domäne, wird nun in allen Einzelbildern, die normalisiert sind, mit einer Null-Maske verdeckt. Diese maskierten Einzelbilder wurden auf die Summenansicht ausgerichtet. Die ausgerichteten Bilder wurden demaskiert und nach einer MSA in 20 Unterklassen aufgespalten (Abschnit 3.3.5). 


\subsubsection{Berechnung einer höher aufgelösten Sub-Struktur}

Wenn die Auflösung einer Struktur durch flexible Strukturelemente in einem Teilbereich limitiert ist, kann dieser Teilbereich durch Masken in den Berechnungen ausgeschlossen und eine verbesserte Ausrichtung der Partikelbilder erreicht werden. In dem Datensatz von 20.000 Einzelpartikelbildern wurde der Teilbereich der Struktur, der den Hauptanteil der Heterogenität zeigte, ausgeschlossen. Dazu wurde der homogene Teilbereich in der dreidimensionalen Struktur maskiert und das Volumen dieser Kontur in Projektionsrichtung der Referenzbilder rückprojiziert, und so zweidimensionale Konturmasken des homogenen Bereichs bestimmt. Die Einzelpartikelbilder, die auf eine Referenz ausgerichtet wurden, wurden mit der so erstellten zweidimensionalen Maske maskiert. Die so maskierten Bilder wurden in einem MRA mit Referenzen des verbleibenden Strukturteils ausgerichtet und mittels MSA klassifiziert (siehe 3.3.5). Eine neue Struktur des homogenen Strukturteils wurde berechnet und iterativ in 3 weitern Zyklen der dreidimensionalen Rekonstruktion verbessert (siehe 3.3.6-3.3.9) 


\section{Ergebnisse}

\subsection{Elektronenmikroskopische Aufnahmen des Komplexes B $\Delta \mathrm{U} 1$}

Der spleißosomale Komplex B $\Delta \mathrm{U} 1$ wurde durch eine Antikörperpräzipitation und anschließende Gradientenzentrifugation aufgereinigt (Makarova et al., 2004). Die Gradientenzentrifugation wies die höchste Konzentration an prä-mRNA in den Fraktionen 16 und 17 bei einem Sedimentationskoeffizienten von 45S auf. Die U2, U4, U5 und U6 snRNA lagen in diesen Fraktionen in einer 1:1 Stöchiometrie vor, wie es für den spleißosomalen Komplex B erwartet wird (Burge et al., 1999). Die Fraktionen 16 und 17 wurden elektronenmikroskopisch analysiert. Die Partikel wurden auf einem Kohlefilm adsorbiert und in einer Schicht von Uranlyformiat eingebettet.

Elektronenmikroskopische Bilder von diesen negativ kontrastierten Proben zeigen globuläre einzeln liegende Partikel ohne größere Aggregate (Abbildung 4.1 A). Es sind nur wenige kleinere Partikel vorhanden, die Bruchstücke der größeren globulären Partikel darstellen könnten. Damit scheinen die Partikel einzelne B $\Delta U 1$ Komplexe darzustellen.

\subsubsection{Ansichten einzelner Komplexe}

In einer Galerie von Bildern einzelner Partikel wird die charakteristische trapezförmige Struktur deutlich (Abbildung 4.1 B). Die Partikel besitzen eine maximale Ausdehnung von 300 bis 370 Å. Gruppen von drei Einzelbildern, welche die gleiche Kontur aufweisen, sind in Abbildung 4.1 dargestellt. In einigen Ansichten kann eine Linie von Kontrastmittel beobachtet werden, die das Trapez in einen globulären kleineren Teil und einen dreieckigen Teil trennt. In anderen Ansichten erscheint die Kontur in Form eines Omega. In diesen Projektionsbildern können neben einer zentralen Dichte zwei Dichtefortsätze gefunden werden. 
A

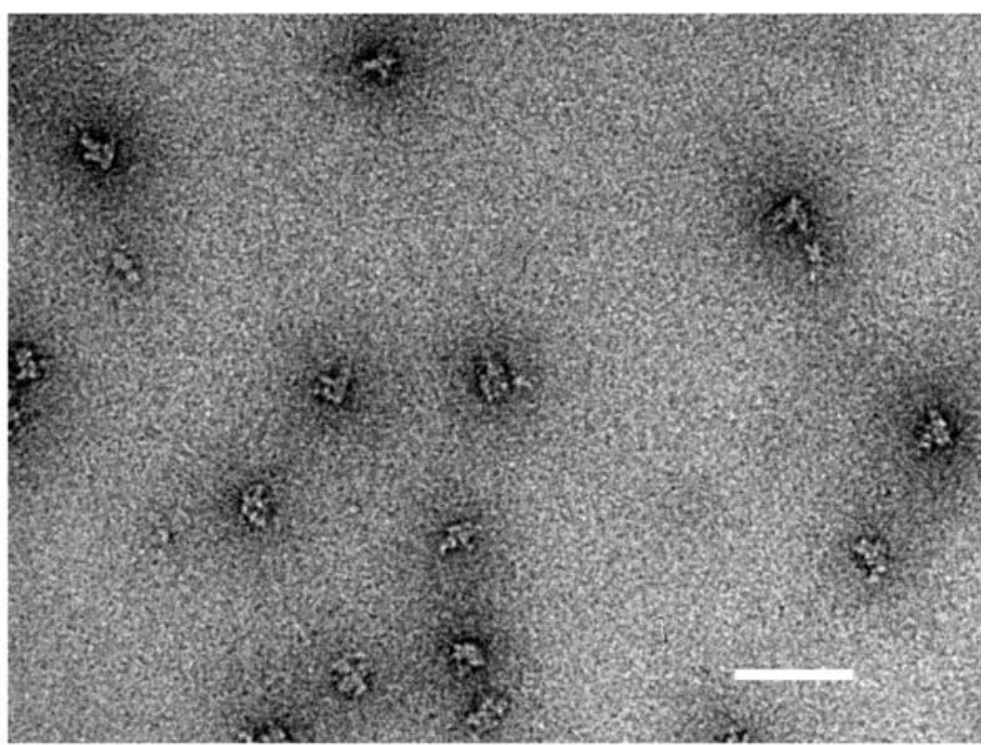

B

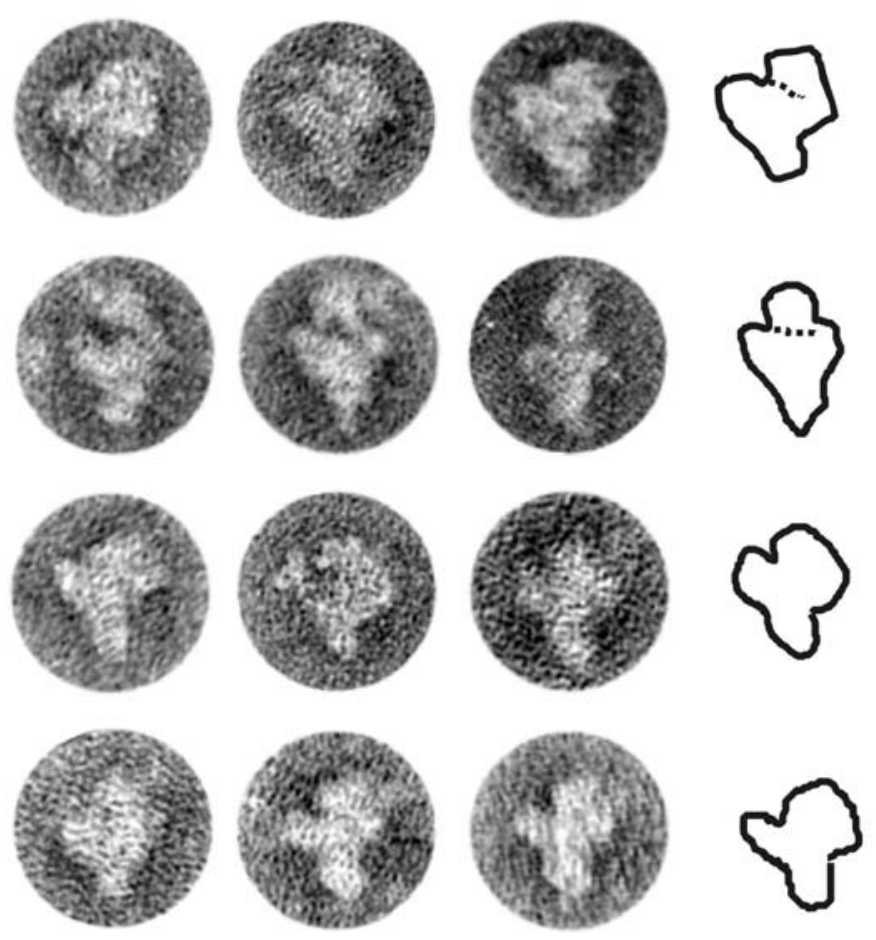

\section{Abbildung 4.1 Elektronenmikroskopische Aufnahmen des Komplexes BAU1}

A) Elektronenmikroskopische Aufnahme von negativ kontrastierten Komplex B $\Delta$ U1 Partikeln. Die Partikel wurden auf einem Kohlefilm adsorbiert in einer Schicht von Uranlyformiat eingebettet. Die Aufnahmen wurden bei 27.500facher Vergrößerung aufgenommen. B) Eine Galerie von Einzelpartikelbildern des Komplexes B $\Delta \mathrm{U} 1$. In den Reihen ist jeweils eine Gruppe von Ansichten gezeigt (links), die eine gemeinsame Kontur besitzen (rechts). In einigen Ansichten ist eine Linie von Kontrastmittelakkumulationen zu erkennen (durch gestrichelte Linien in den Konturen angedeutet) 


\subsection{Statistische Analyse der Einzelpartikelbilder}

\subsubsection{Berechnung von gemittelten Ansichten}

Insgesamt wurden 20.000 Projektionsbilder von Einzelpartikeln erhalten. Charakteristische zweidimensionale Ansichten mit verbessertem Signal-Rausch-Verhältnis wurden durch die Mittelung von 30 Einzelpartikeln erhalten. Nach einer referenzfreien Ausrichtung der Bilder (Dube et al., 1993), wurden die Bilder in Gruppen ähnlicher Bilder durch multivariate statistische Analyse (van Heel and Frank, 1981) und Klassifizierung (Borland and van Heel, 1990) eingeteilt. Die Bilder einer Gruppe werden zur so genannten Klassensumme gemittelt. Repräsentative Klassensummen sind visuell einzelnen Partikeln der Übersicht zugeordnet (Abbildung 4.2 A).

Auch in den Klassensummen fällt die trapezförmige Kontur der Partikel auf. Im Gegensatz zu den Einzelpartikelbildern wird in den Klassensummen aber auch die Feinstruktur des Partikels deutlich (Abbildung 4.2 B). Die Klassensummen zeigen häufig eine zentrale Dichte, die von vier äußeren Dichten umgeben ist. Die maximale Ausdehnung der größten Klasse liegt bei $370 \AA$ Å. In manchen Ansichten sind nur drei größere, äußere Dichten zu erkennen. Diese Ansichten zeigen wahrscheinlich das gleiche Partikel in einer anderen Orientierung, in der das vierte Dichtelement von der zentralen Dichte überlagert wird. Die grobe Struktur der Klassensummen zeigt eine gute Überstimmung mit Einzelpartikelbildern, wie es für eine zutreffende statistische Analyse erwartet wird. Allerdings zeigt die genauere Betrachtung aller Klassensummen (Vgl. Abbildung 4.2 B), dass die Kontur des Partikels an bestimmten Stellen weniger scharf von der Umgebung abgegrenzt ist, als für das restliche Partikelbild. Insbesondere erscheint die Kontur des Partikels im oberen Bereich verwischt. Dies deutet darauf hin, dass in der Klassensumme Partikel mit gleichem unterem Teil aber leicht unterschiedlichen oberen Teil gemittelt wurden. 
A

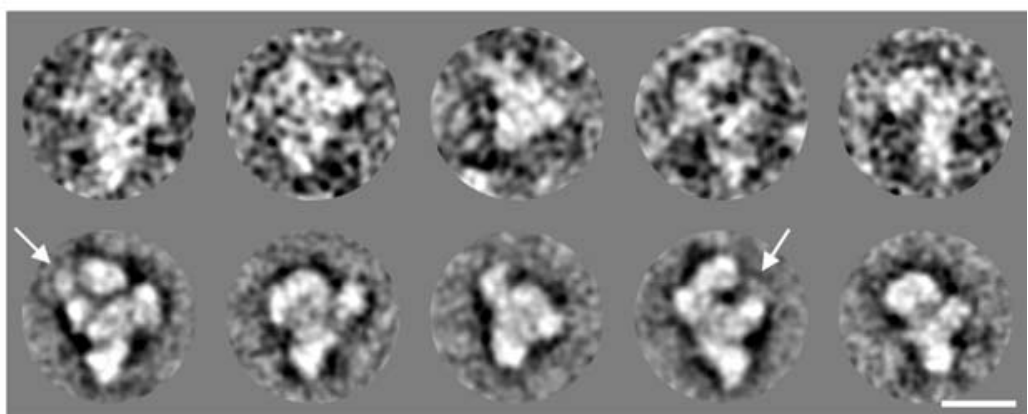

B

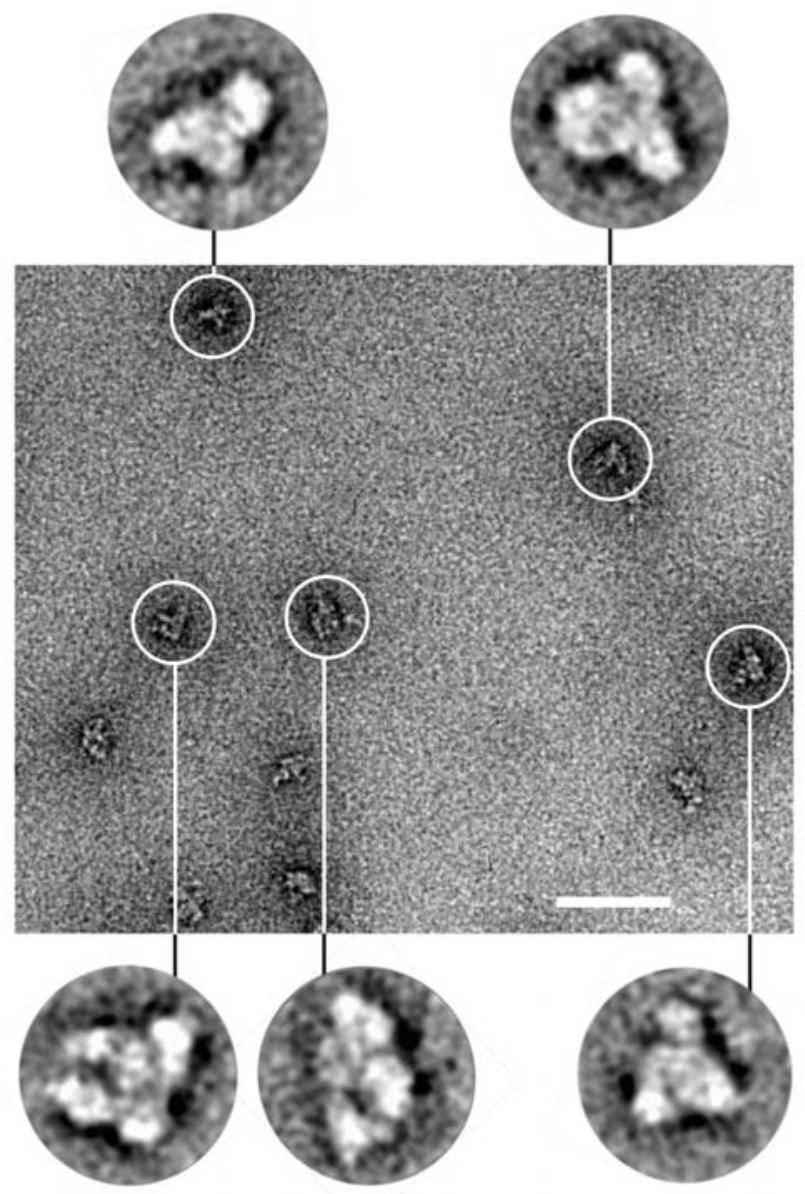

\section{Abbildung 4.2 Die Klassensummen des Komplexes BAU1 beschreiben eine Vielzahl von} Einzelpartikelansichten.

A) Einzelne Partikel einer elektronenmikroskopischen Aufnahme sind vergrößerten gemittelten Ansichten, Klassenssummen, zugeordnet. B) Galerie von Einzelpartikelbildern, die zur Berechnung der Klassensummen mit einem Bandpassfilter bearbeitet wurden (Reihe 1). Klassensummen des Komplexes B $\Delta U$ 1 (Reihe 2). Die Einzelpartikelbilder sind Mitglieder der in Reihe 2 gezeigten Klassensummen. (Größenmaßstab: $200 \AA$ ) 


\subsubsection{Analyse von Aufnahmen mit gekipptem Probenhalter}

Da der Komplex B $\Delta \mathrm{U} 1$ eine bevorzugte Ausrichtung auf dem Probenträger erfährt, erscheint in den Einzelpartikelbildern und den Klassensummen bevorzugt eine Ansicht. Für die weitere Analyse ist es notwendig zu ermitteln, ob die von dieser Ansicht abweichenden Klassensummen weitere Ansichten der Hauptpopulation oder Ansichten einer Subpopulation von Partikeln darstellen. Der Probenhalter kann im Mikroskop gekippt werden und ermöglicht so die Abbildung des Partikels aus weiteren Projektionsrichtungen (Abbildung 4.3). Mit der oben beschriebenen statistischen Analyse können Klassensummen gebildet werden. Diese Klassensummen stellen hauptsächlich die Seitenansichten des Partikels in der präferentiellen Orientierung, da nun die Seitenansichten des Partikels in der präferentiellen Orientierung gegenüber den Seitenansichten des Partikels in anderen Orientierungen überrepräsentiert sind. Aus Aufnahmen bei $40^{\circ}$ und $55^{\circ}$ gekippten Probenhalter wurden je 4000 Einzelpartikelbilder selektiert und statistisch ausgewertet. Es werden hauptsächlich dreieckige Ansichten erhalten in denen wahrscheinlich eines der vier äußeren Dichteelemente vom zentralen Dichteelement überlagert wird. Ähnliche Ansichten wurden auch bei den Klassensummen, die mit nicht gekipptem Probenträger erhalten wurden beobachtet. Damit scheinen diese Klassensummen verschiedene Ansichten einer Hauptpopulation von Partikeln darzustellen.

Wenn der Halter um $55^{\circ}$ gekippt wird, werden einige sehr schmale Ansichten in diesen 55-Aufnahmen erhalten. Es wurden zwar auch längliche Ansichten in den 55-Aufnahmen mit nicht gekipptem Halter beobachtet (Abbildung 4.2), diese Ansichten haben aber eine größere Ausdehnung senkrecht zur Längsachse. Wahrscheinlich kommt es bei der Probenpräparation mit der Doppelkohlefolie-Technik zu einer Abflachung der Partikel zwischen den beiden Kohlefilmen (Abbildung 4.4) (Frank, 1996; Kellenberger et al., 1982). Diese Abflachung der Partikel ist überwiegend isotrop, senkrecht zum Probenträger (M. M. Golas, unveröffentlichte Ergebnisse). Die bei gekipptem Probenhalter erhaltenen Ansichten stellen also gestauchte Formen der Ansichten eines Partikels in Lösung dar. Dagegen erscheinen solche Ansichten, die senkrecht zur Richtung der Abflachung von nicht gekippten Probenträgern aufgenommen wurden, weitgehend verzerrungsfrei. 


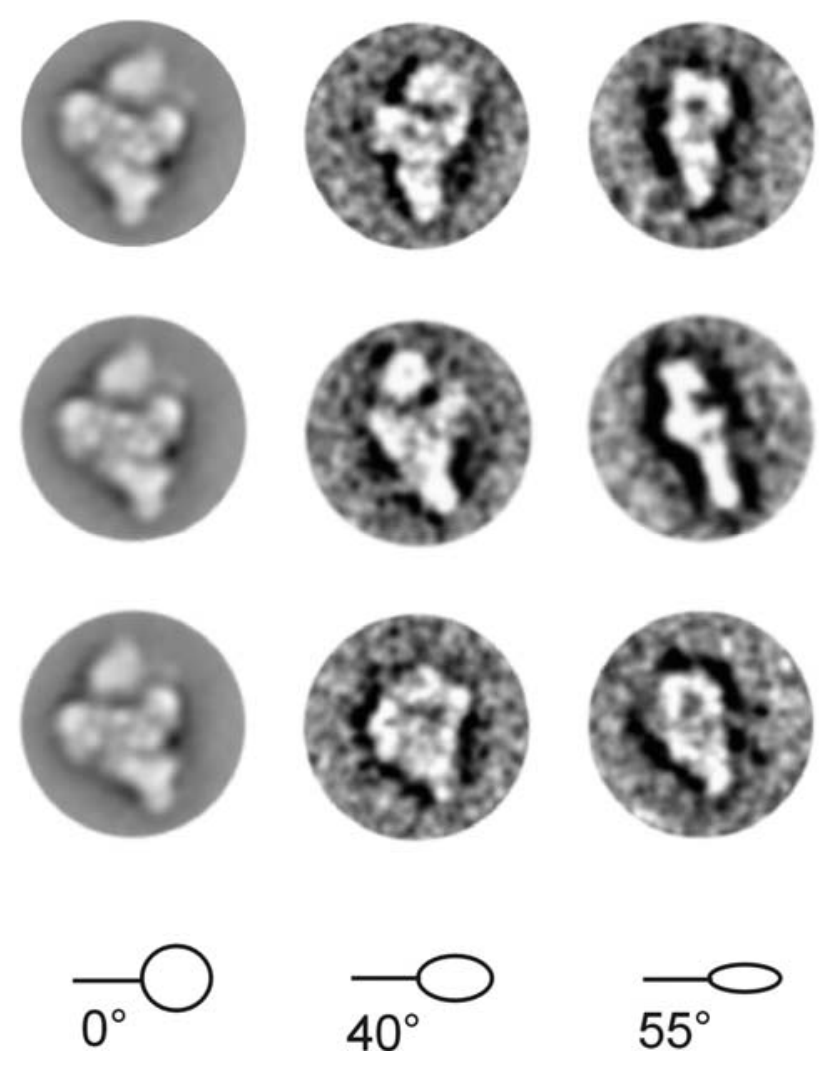

Abbildung 4.3 Serien von Partikelansichten unter verschiedenen Kippwinkeln

Die Klassensummen des Komplexes B $\Delta \mathrm{U} 1$ wurden nach statistischer Analyse der Aufnahmen von $40^{\circ}$ und $55^{\circ}$ gekipptem Probenträger erhalten und visuell Orientierungen der häufigsten Klassensumme auf $0^{\circ}$ Aufnahmen zugeordnet (siehe Text)

Ein erster Eindruck von der dreidimensionalen Struktur des Partikels ist bereits auf dieser Ebene möglich. Wenn die Klassensummen der $40^{\circ}$-Aufnamen, die Seitenansichten des präferentiell orientierten Partikels entsprechen, nebeneinander angeordnet werden. Man erhält so einen Kreis Ansichten, die den präferentiell orientierten Partikel darstellen, betrachtet aus einem Winkel von $40^{\circ}$ über der Ebene des Probenträgers (Abbildung 4.5).
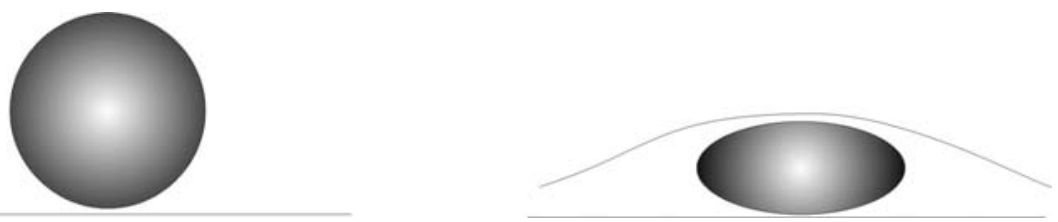

Abbildung 4.4 Schematische Darstellung der Abflachung von Partikeln bei der Sandwich-Präparation

Die Partikel, hier dargestellt als Kugel, können bei Trocknung der Kontrastmittelschicht zwischen den Kohlefolien komprimiert werden. 

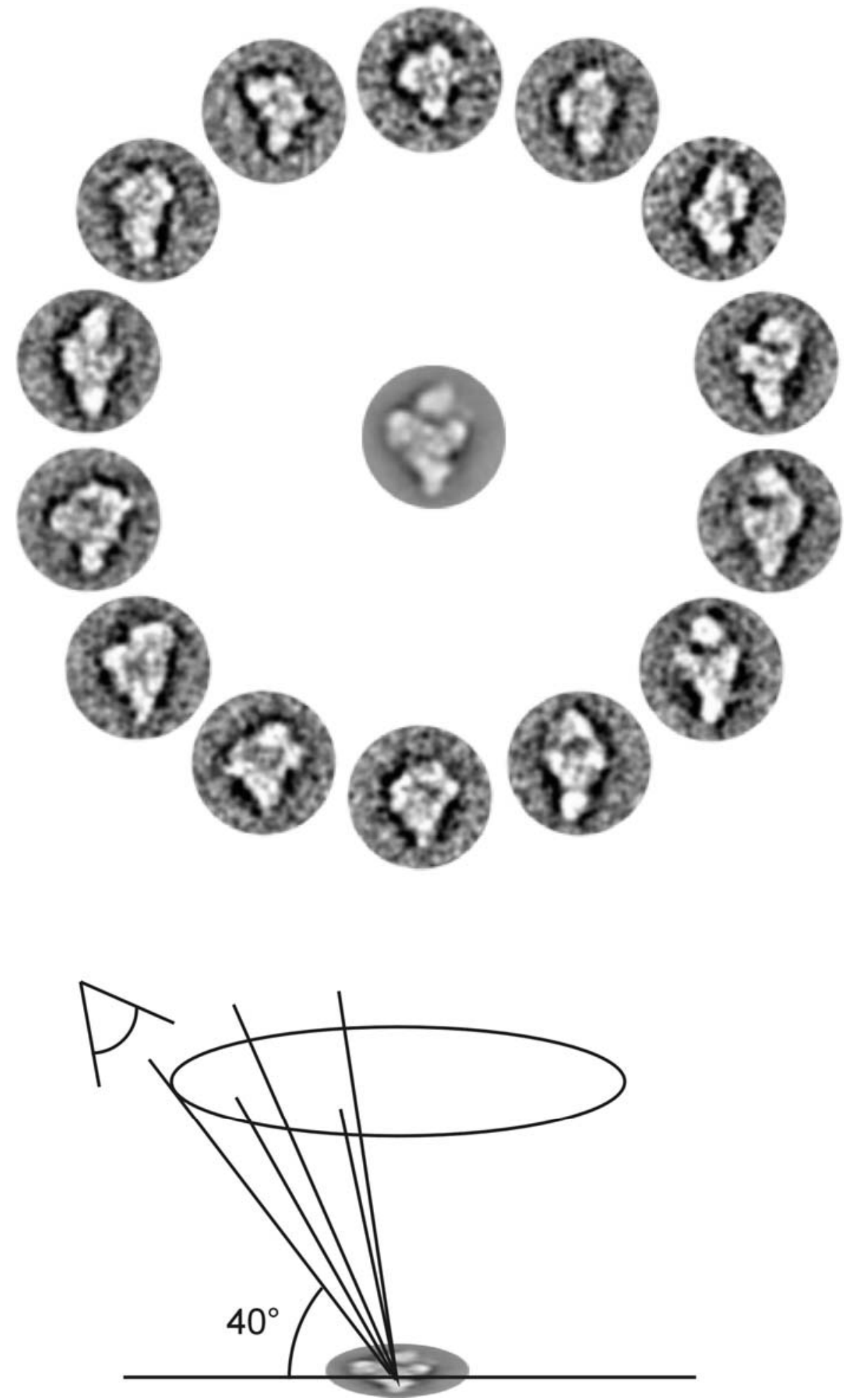

\section{Abbildung 4.5 Serie von Ansichten des Partikels aus $40^{\circ}$ Aufnahmen}

Die Klassensummen der $40^{\circ}$ Aufnahmen bilden einen Konus von Seitenansichten des Komplexes B $\Delta \mathrm{U} 1$ in der bevorzugten Adsorbtionsorientierung (häufigste Klassensumme in $0^{\circ}$ Aufnahmen, in der Mitte gezeigt). Die Klassensummen wurden visuell angeordnet. Die Geometrie der Anordnung der Klassensummen entspricht dem unten dargestellten Schema. 


\subsection{Startmodelle für die dreidimensionale Rekonstruktion}

Die dreidimensionale Rekonstruktion einer Startstruktur wurde mit drei unterschiedlichen Methoden, ,angular reconstitution' (van Heel, 1987), ,random conical tilt' (RCT (Radermacher et al., 1987)) und einem iterativen Berechnungsverfahren durchgeführt, um ein erstes dreidimensionales Modell des Komplexes B $\Delta \mathrm{U} 1$ für die weiter Verfeinerung der Struktur zu erhalten.

\subsection{1 ,Random Conical Tilt' - Rekonstruktion}

Die Methode des Random Conical Tilt erlaubt die Berechung niedrig aufgelöster dreidimensionaler Strukturen aus Bildpaaren eines Einzelpartikels von nicht gekippten und gekippten Probenträgern (Radermacher et al., 1987). Die Winkel der Partikelbilder von gekippten Teilchen sind dabei über die Orientierung der nicht gekippten Partikelbilder und den Kippwinkel definiert. Um ein Startmodel für die Strukturberechnung zu erhalten, wurden 2000 Bildpaare von nicht gekippten und $40^{\circ}$ gekippten Probenträgern aufgenommen. Die Einzelpartikelbilder vom nicht gekippten Probenträger wurden klassifiziert und Bilderpaare, die in die Klassensummen des präferentiell orientierten Partikels fielen, wurden zur Berechnung der Struktur verwendet (Abbildung 4.6). Die erhaltene Struktur ist in vielen Orientierungen den Klassensummen der 40-Aufnahmen (Abbildung 4.5) ähnlich. Die ungekippte Ansicht wird durch die Struktur in der groben Form wiedergegeben. Der obere Teil der Struktur gibt jedoch den oberen Teil der Klassensumme nicht vollständig wieder. Wenn diese Struktur allerdings um $90^{\circ}$ gedreht wird, wird deutlich, dass die Seitenansicht wesentlich breiter ist als die schmalen Ansichten des Partikels in Klassensummen von gekippten Proben. Die Verzerrung der Struktur in Projektionsrichtung der nicht gekippten Klassensumme wird durch das Fehlen von Ansichten für den Rekonstruktionsalgorithmus verursacht (Frank, 1996). 

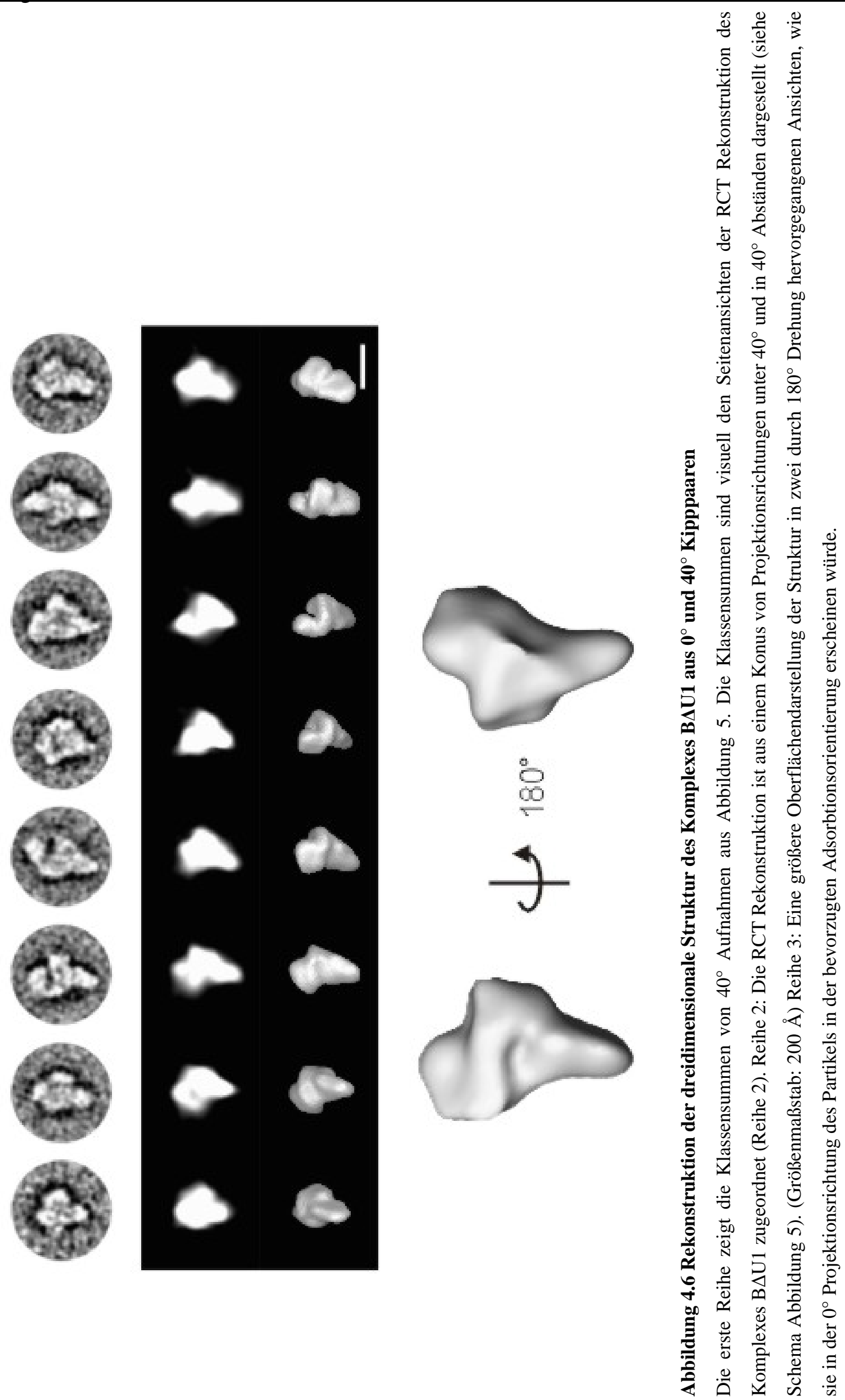


\subsection{2 ,Angular Reconstitution’ - Rekonstruktion}

Um die mit der RCT Methode verbundenen Artefakte der Strukturberechnung zu vermeiden, wurde eine weitere Möglichkeit zur Berechung eines Startmodells genutzt. Die Methode des Angular Reconstitution basiert auf dem Theorem der gemeinsamen Linienprojektion (van Heel, 1987). Es können so die relativen Projektionswinkel einer Gruppe von mindestens drei relativ rauschfreien Ansichten bestimmt werden. Die Sinogramkorrelationsfunktionen zeigten jedoch für die Klassensummen des Komplexes $\mathrm{B} \Delta \mathrm{U} 1$ keine eindeutigen Maxima. Außerdem müssen die auf diese Weise erhaltenen Winkel den Dreieckungleichungen der sphärischen Trigonometrie genügen. Für den Komplex B $\Delta \mathrm{U} 1$ konnten jedoch keine eindeutigen Lösungen gefunden werden. Wahrscheinlich ist die fehlerhafte Winkelbestimmung auf das relativ kleine Signal- Rausch-Verhältnis der Klassensummen zurückzuführen (Penczek et al., 1996; Serysheva et al., 1995). Weitere Fehlerquellen sind eine ungenügende Zentrierung der Partikel und strukturelle Heterogenität. Es ist daher eine erste visuelle Zuordnung von Projektionswinkeln zu den Klassensummen notwendig oder eine andere Bestimmung einer Startstruktur. Wenn eine Startstruktur vorliegt ist die Bestimmung der Projektionswinkel von Klassensummen über die Verwendung mehrerer rauschfreier Rückprojektionen der Startstruktur durch eine ,anchor-set'Winkelbestimmung möglich. Es ist aber insbesondere notwendig mehrere unabhängige Startmodelle zu verwenden um eine Beeinflussung der endgültigen Struktur durch das Startmodell erkennen zu können (Penczek et al., 1996; Yang et al., 2003). Um diesen Anforderungen zu erfüllen, wurde versucht durch eine automatische iterative Berechnung mehrere Startstrukturen zu erhalten.

\subsubsection{Iterative Berechnung von Startmodellen}

Eine erste Startstruktur kann iterativ ausgehend von einer zufälligen Verteilung der Projektionswinkel erhalten werden. Ein Maß für eine zutreffende Struktur ist eine hohe Übereinstimmung von Klassensummen und Rückprojektionen der Struktur, die als Kreuzkorrelation von Klassensumme und Rückprojektion beschrieben werden kann. Zusätzlich zu einem hohen Korrelationskoeffizienten aller Klassensummen zeichnet sich eine zutreffende Struktur auch noch durch die Beschreibung von möglichst vielen möglichst unterschiedlichen Ansichten aus. Ferner sollte die erhaltene Struktur eine zusammenhängende Dichte bilden. Die beiden letztgenannten Eigenschaften können visuell überprüft und eine geeignete Startstruktur gewählt werden. In der iterativen Berechnung wurde als Maß für die 
Güte der Struktur der mittlere Korrelationskoeffizient der Kreuzkorrelation von Rückprojektionen und Klassensummen verwendet (Details der Berechnung: siehe Methoden).

A
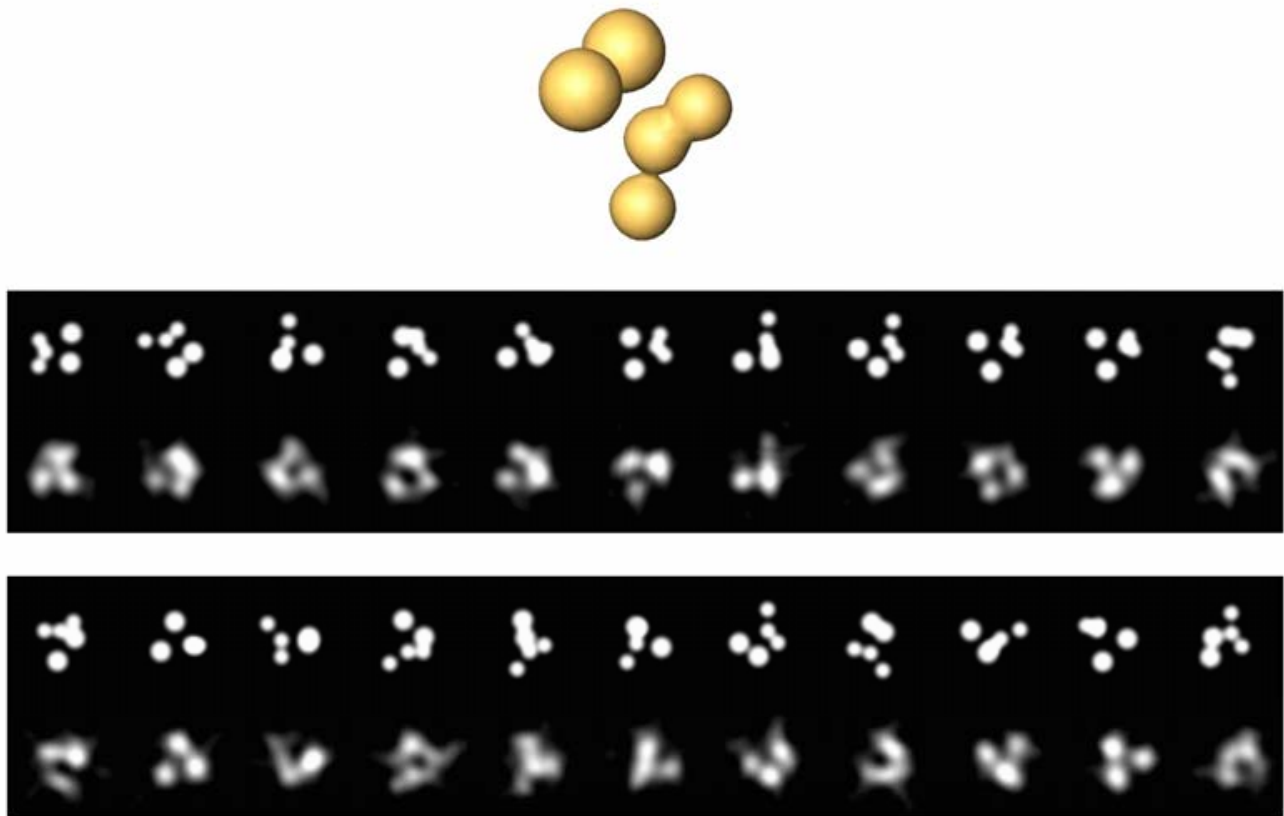

C
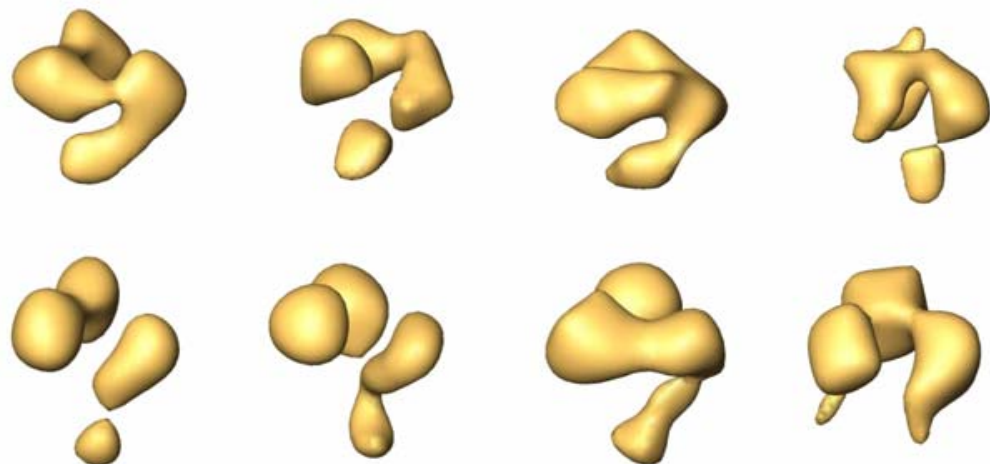

\section{Abbildung 4.7 Iterative Berechnung einer Struktur: Modellrechnung}

A) Ausgangsmodell bestehend aus fünf kugelförmigen Dichten. B) 1. und 3. Reihe: Projektionen des Modells in zufällig gewählte Projektionsrichtungen 2. und 4. Reihe: Rückprojektionen der nach der Iterativen Berechnung erhaltenen Struktur in den Projektionsrichtungen der Projektionen (Reihe 1 und 3). C) 1. Reihe: Die vier Strukturen aus der iterativen Berechung (vier Strukturen mit den höchsten Korrelationswerten von acht Strukturen) 2. Reihe: Ergebnis der nachträglichen Verbesserung der Struktur durch ,anchor-set'Winkelbestimmung 
Die iterative Berechnung wurde zunächst für ein Modelobjekt bestehend aus fünf kugelförmigen Dichten durchgeführt (Abbildung 4.7A). Das Modelobjekt wurde in 22 zufällig gewählte Raumrichtungen ausprojiziert (Abbildung 4.7 B). Aus diesen Rückprojektionen sollte das Objekt rekonstruiert werden. Dazu wurden den Rückprojektionen zufällig Projektionswinkel zugeordnet und zwei Startstrukturen berechnet. Die ersten beiden mit zufälligen Projektionswinkeln erzeugten Strukturen wurden verglichen und die Struktur mit dem kleineren Strukturberechnungsfehler wurde beibehalten. Ausgehend von dieser Struktur wurde nun eine weitere Struktur mit zufällig leicht veränderten Winkeln berechnet. Dieser Prozess wurde 10.000 Runden fortgesetzt und die Struktur mit der höchsten Summe der Kreuzkorrelationskoeffizienten wurde festgehalten (Abbildung 4.8). Die iterative Berechnung wurde dann noch achtmal mit einem neuen Startwinkeln wiederholt. Die vier Strukturen mit den höchsten Korrelationskoeffizienten wurden ausgewählt und mit der Ausgangsstruktur verglichen. Die Dichteverteilung der iterativ berechneten Strukturen stimmt mit dem Ausgangsmodel überein (Abbildung 4.7 C). Die Auflösung der Strukturen kann verbessert werden, indem die Rückprojektionen der iterativ berechneten Strukturen in einer ,anchor-set’ Winkelbestimmung für eine verbesserte Winkelbestimmung eingesetzt werden (Abbildung 4.9).

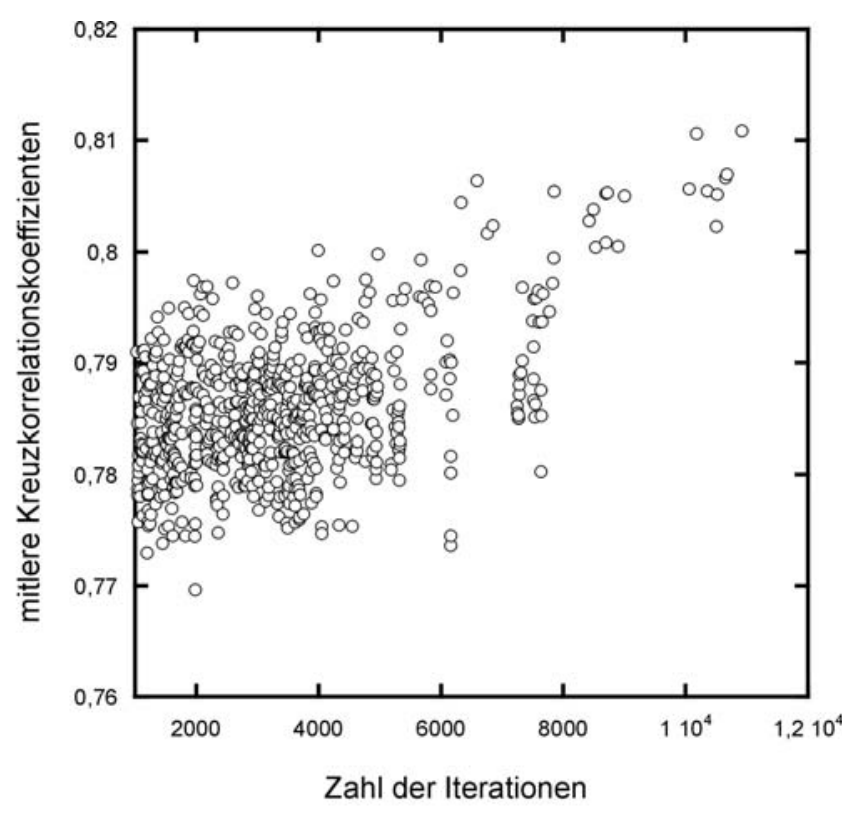

\section{Abbildung 4.8 Die iterative Berechnung führt zur Struktur mit den höchsten Korrelationswerten der Projektionen und Rückprojektionen}

Diagramm der mittleren Korrelationskoeffizienten der akzeptierten Strukturen in Abhängigkeit von der Gesamtzahl der Iterationen einer Berechnung. 
A

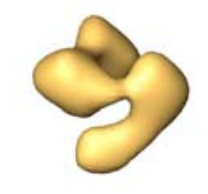

B

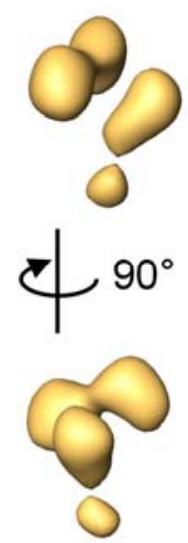

C
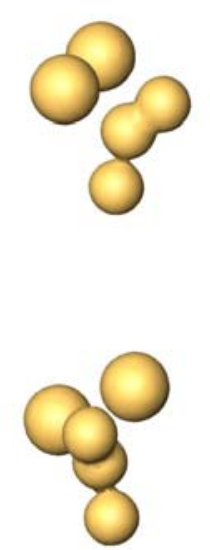

Abbildung 4.9 Iterative Berechnung einer Struktur aus Projektionen: Vergleich der berechneten Struktur mit der Ausgangsstruktur

Zwei um $90^{\circ}$ versetzte Ansichten der Struktur der iterativen Berechnung vor (A) und nach der Verbesserung der Struktur durch ,anchor-set' Winkelbestimmung (B). Zum Vergleich ist das Ausgangsmodell dargestellt (C).

Als ein Beispiel für eine Berechnung einer elektronenmikroskopischen Struktur mit realen Daten ist hier die Berechnung eines Startmodels für eine 50S ribosomalen Untereinheit (N. Fischer, unveröffentlichte Ergebnisse) gezeigt, deren dreidimensionale Struktur bekannt ist (Abbildung 3.10). 22 Rückprojektionen der dreidimensionalen Struktur wurden erzeugt und zur iterativen Berechnung eines Startmodels verwendet. Die gezeigte Struktur zeigte die höchste Korrelation von Rückprojektion und Klassensummen in sieben unabhängigen Berechnungen. Anhand der oben genannten Kriterien für eine zutreffende Struktur können so visuell mehrere Startmodelle für eine weitere Strukturberechnung gewählt werden. Die fortschreitende Verbesserung der Rechenleistung von PC-Systemen erlaubt die Berechung von 100.000 dreidimensionalen Strukturen pro Tag aus einem Satz von 20 Klassensummen auf einem einzelnen PC-System. Es ist deshalb trotz der sehr großen Zahl möglicher Kombinationen von Projektionsrichtungen der Klassensummen möglich eine zutreffende Struktur zu erhalten.

Die iterative Berechnung der Startmodelle hat den Vorteil, dass einzelne Klassensummen die nicht die dreidimensionale Struktur der größten Partikelpopulation wiedergeben nur einen geringen Einfluss auf die Startstruktur haben. Die iterative Berechnung führt zum Maximum der Kreuzkorrelationswerte für alle Klassensummen und führt damit zur Struktur, die die größte mögliche Zahl an Klassensummen beschreibt. 


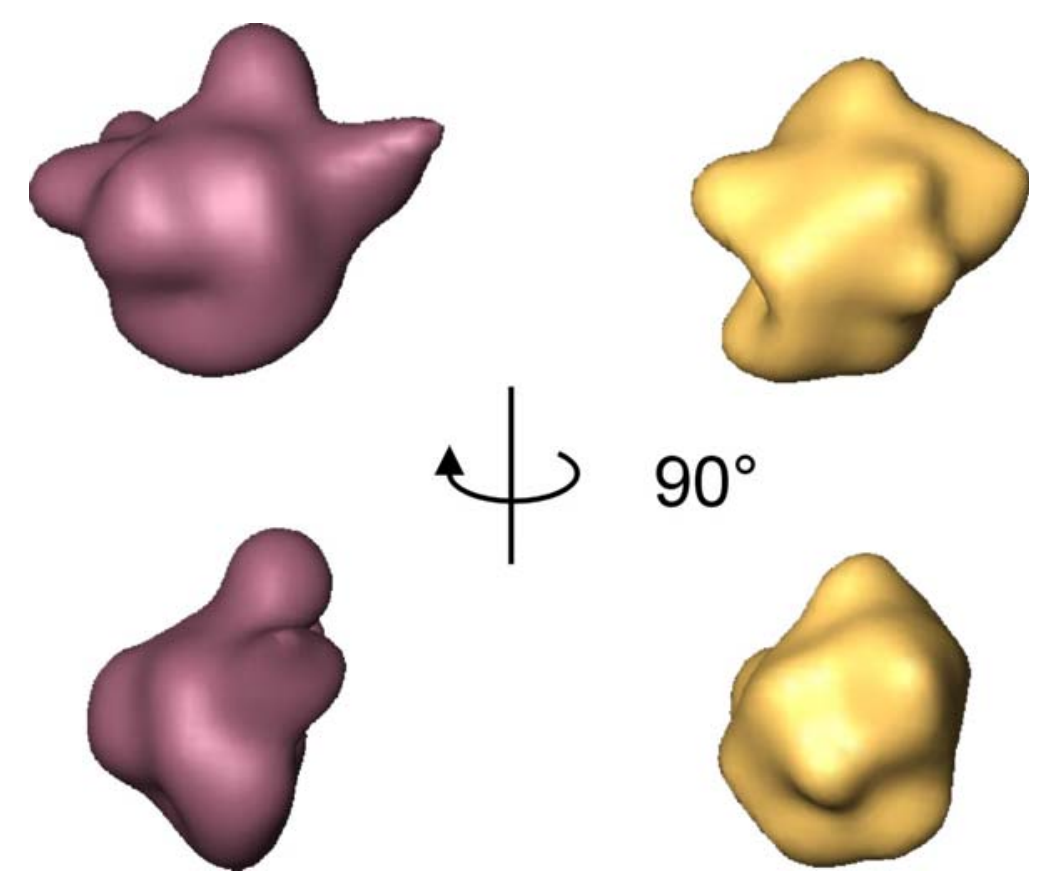

\section{Abbildung 4.10 Iterative Berechnung einer der Struktur der 50S Untereinheit}

Die Struktur der 50S Untereinheit (rot, links) wurde in zufällige Projektionsrichtungen ausprojiziert. Aus den Rückprojektionen wurde mittels iterativer Berechnung eine Modell neu berechnet (gelb, rechts). Beide Strukturen gleichen sich in den Dimensionen und groben Strukturmerkmalen und zeigen damit die Zuverlässigkeit der iterativen Berechnung für elektronenmikroskopische Strukturen.

\subsubsection{Vergleich der Startstrukturen des Komplexes B $\Delta \mathrm{U} 1$}

Die iterative Berechnung eines Startmodels wurde separat für die Klassensummen aus zwei kleineren 6000 Partikel umfassenden Datensätzen von Partikelbildern durchgeführt. Um den Effekt der Abflachung auf die Strukturbestimmung zu untersuchen, wurde eine iterative Berechnung ebenfalls mit Klassensummen von Bildern von gekippten Probenträgern durchgeführt. Aus den 6000 Einzelbildern umfassenden Datensätzen wurden 22 Klassensummen gebildet. Die nach der iterativen Berechnung erhaltene und visuell für die weitere Berechnung ausgewählte Startstruktur stimmt mit den Ansichten der Klassensummen in vielen Orientierungen überein (Abbildung 4.11). In weiteren iterativen Berechnungen wurden weitere Startstrukturen erhalten. Die Auflösung wurde mittels ,anchor-set'Winkelbestimmung verbessert. 

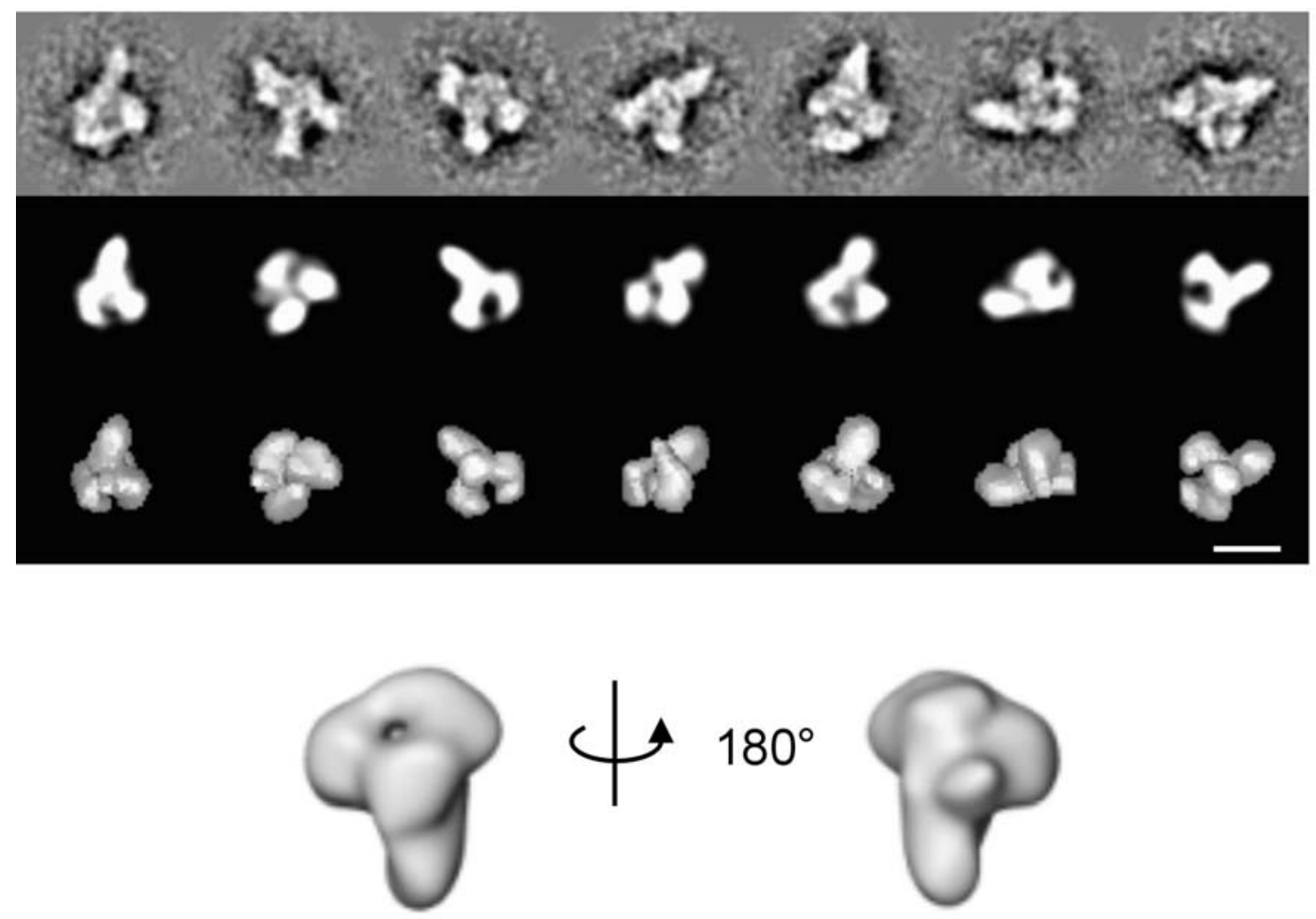

\section{Abbildung 4.11 Iterative Berechnung einer Startstruktur des Komplexes B $\Delta U 1$}

Aus einem 6000 Einzelpartikel umfassenden Datensatz wurden Klassensummen berechnet und für die iterative Berechnung ausgewählt (Reihe 1). Die Rückprojektionen der berechneten Struktur sind unter den Klassensummen dargestellt (Reihe 2); Oberflächendarstellung der Struktur betrachtet aus den Projektionsrichtungen der Rückprojektionen (Reihe 3). Zum Vergleich ist eine vergrößerte Oberflächendarstellung der Struktur in zwei durch $180^{\circ}$ Drehung hervorgegangene Ansichten dargestellt. (Größenmaßstab: $200 \AA$ )

Aus den beiden unabhängigen 6000 Einzelpartikel umfassenden Datensätzen wurden so zwei Startstrukturen erhalten, die schon eine übereinstimmende Domänenstruktur erkennen lassen (Abbildung 4.12 A und B). Den größten Teil des Komplexes B $\Delta \mathrm{U} 1$ macht eine dreieckige Dichte aus. Auf einer Seite dieser dreieckigen Dichte befindet sich eine weitere globuläre Dichte, die über eine relative dünne Verbindung mit einer Ecke der dreieckigen Dichte verbunden ist. Um den Effekt der Abflachung auf die Strukturbestimmung zu untersuchen, wurde eine iterative Berechnung ebenfalls mit Klassensummen von Bildern gekippter Probenträgern durchgeführt (Abbildung 4.12 C). 
A

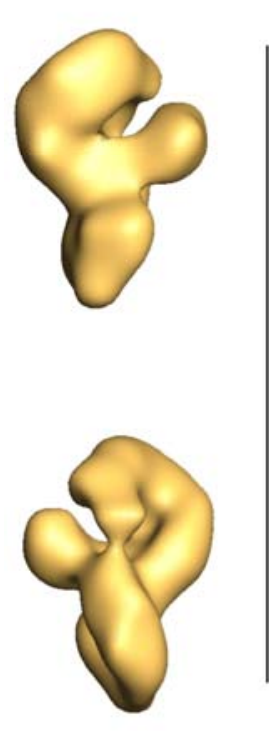

B

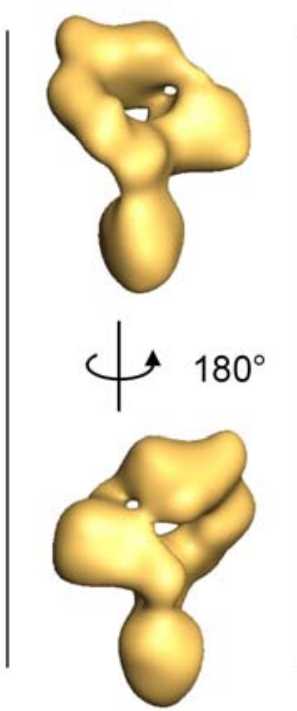

C

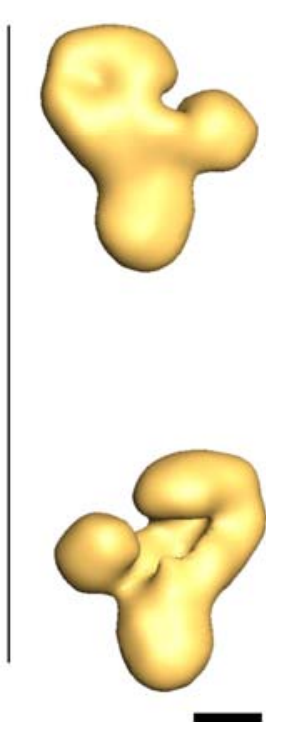

\section{Abbildung 4.12 Vergleich der durch Iterative Berechnung erhalten Startmodelle}

Zwei Startmodelle der iterativen Berechnung aus $0^{\circ}$-Aufnahmen sind darstellt (A und B). Die iterative Berechnung wurde auch für die $55^{\circ}$-Aufnahmen durchgeführt (C). Die Winkelzuordnung der Startstrukturen wurde durch eine, anchor-set ${ }^{\prime}$ Winkelbestimmung verbessert. Die Strukturen sind aus zwei durch $180^{\circ}$ Drehung hervorgegangene Richtungen dargestellt. (Größenmaßstab: $100 \AA$ )

Werden die mit verschiedenen Methoden bzw. aus unterschiedlichen Datensätzen erhaltenen Startmodelle verglichen so ist in allen die beschriebene Grundstruktur zu erkennen (Abbildung 4.13). Die Startmodelle nach iterativer Berechnung aus den Klassensummen bei gekipptem Probenträger, $40^{\circ}$-Startstruktur (Abbildung $4.13 \mathrm{C}$ ), und das Startmodell aus Klassensummen bei nicht gekipptem Probenträger, $0^{\circ}$-Startstruktur (Abbildung $4.13 \mathrm{~B}$ ), unterscheiden sich jedoch deutlich. Die $40^{\circ}$-Startstruktur ist senkrecht zur Projektionsrichtung der präferentiell orientierten Klassensumme bedeutend schmaler als die $0^{\circ}$-Startstruktur. Das deutet ebenfalls auf eine Abflachung der Partikel bei der Probenpräparation hin. Ferner ist diese Struktur in der maximalen Ausdehnung etwas kleiner. Auch dieser Unterschied kann mit der Abflachung der Struktur erklärt werden. So ist bei der Abflachung senkrecht zum Probenträger auch mit einer leichten isotropen Ausdehnung der Struktur in der Ebene des Probenträgers zu rechnen (Kellenberger et al., 1982; Lake, 1976). Die Struktur aus den RCT Rekonstruktion (Abbildung $4.13 \mathrm{~A}$ ) ist dem hingegen wesentlich breiter als die erhaltene $0^{\circ}$-Startstruktur. Das weist ebenfalls auf die bereits beschriebene Verzerrung der Struktur senkrecht zur Ebene des Probenträgers hin. Die erhaltenen $0^{\circ}$-Startstrukturen sind damit die Strukturen, die den Komplex $\mathrm{B} \Delta \mathrm{U} 1$ mit den geringsten Verzerrungen wiedergeben. Die in 
Abbildung 4.12B gezeigte Struktur wurde für die weitere Strukturberechnung verwendet, um eine höher aufgelöste Struktur zu erhalten.

A

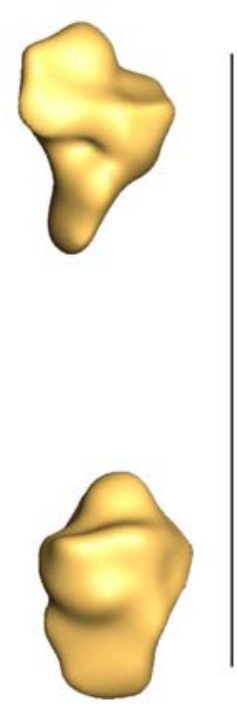

B

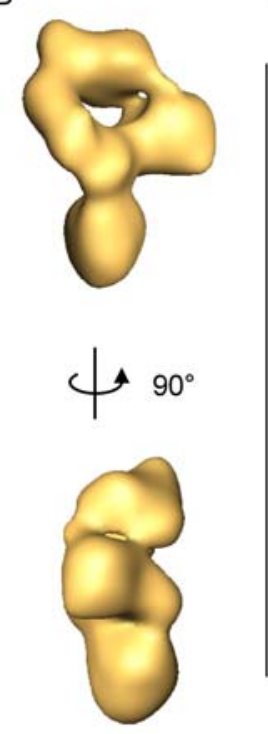

C
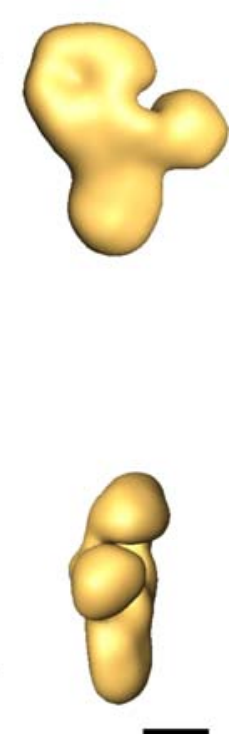

Abbildung 4.13 Vergleich der Startstrukturen von verschiedenen Berechnungsverfahren

Die RCT Struktur (A) ist im Vergleich zu den Startstrukturen der iterativen Berechnung aus $0^{\circ}$ Aufnahmen (B) und $55^{\circ}$ Aufnahmen (C) dargestellt. Die zwei Ansichten sind durch $90^{\circ}$ Drehung der Strukturen um die Längsachse entstanden. (Größenmaßstab: $100 \AA$ )

\subsection{Struktur des Komplexes B $\Delta \mathrm{U} 1$}

\subsubsection{Verbesserung der Auflösung der dreidimensionalen Struktur}

Die von den Klassensummen bei nicht gekipptem Probenhalter erhaltene Startstruktur wurde als Referenz für die Ausrichtung der Einzelpartikelbilder des Datensatzes mit 20.000 Partikelbildern verwendet. In aufeinander folgenden Zyklen von Klassifizierung, Strukturberechnung und Ausrichtung der Partikel anhand der neu erstellten Struktur nahm die Übereinstimmung der Rückprojektionen der dreidimensionalen Struktur und den Klassensummen schrittweise zu (Abbildung 4.14). Klassensummen, die Partikel ohne innere Struktur oder ohne scharfe Konturen aufwiesen, wurden aus der Berechnung ausgeschlossen. Diese Klassensummen repräsentieren wahrscheinlich Bruchstücke oder schlecht kontrastierte Partikelbilder, die ungenügend auf die Referenzen der dreidimensionalen Struktur ausgerichtet wurden. 
A

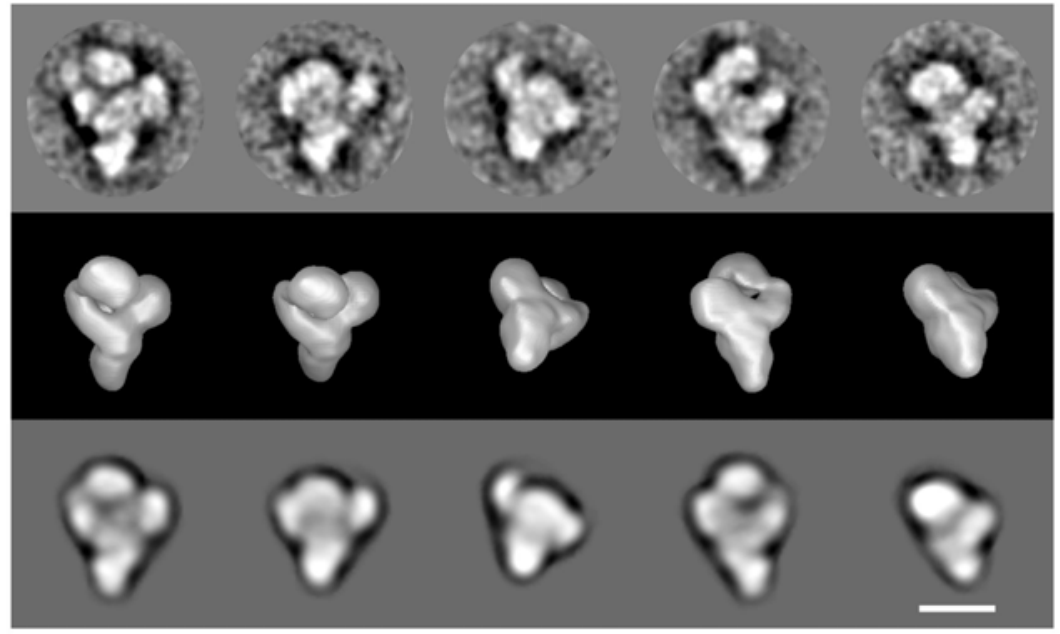

B
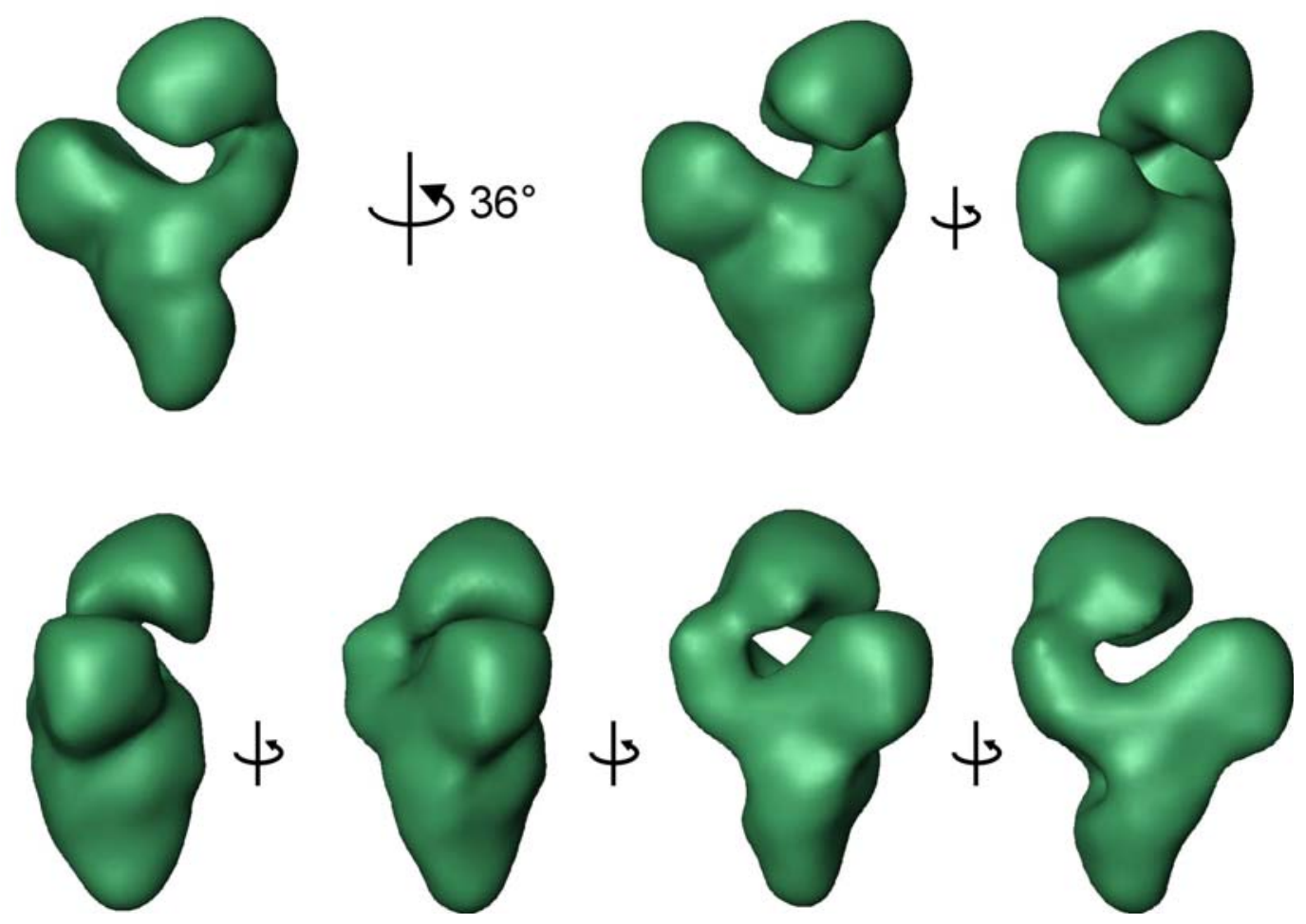

\section{Abbildung 4.14 Dreidimensionalen Struktur des Komplexes BAU1}

A) Vergleich von Klassensummen mit Ansichten der dreidimensionalen Struktur des Komplexes B $\Delta$ U1. Eine Galerie von Klassensummen (Reihe 1) ist im Vergleich zu Oberflächenansichten der dreidimensionalen Struktur (Reihe 2) und Rückprojektionen der dreidimensionalen Struktur (Reihe 3) dargestellt. Die Oberflächenansichten und die Rückprojektionen sind aus dem Projektionswinkel gezeigt, der den Klassensummen zugeordnet wurde. B) Oberflächendarstellung der dreidimensionalen Struktur des Komplexes B $\Delta U 1$. Die Struktur wurde um die Längsachse in $36^{\circ}$ Abständen rotiert 
Die iterative Berechung wurde nach 15 Zyklen abgebrochen, als keine weitere Verbesserung der Auflösung der Struktur und der Übereinstimmung von Rückprojektionen und Klassensummen zu beobachten war. Für die letzte Berechung der so erhaltenen Struktur wurden 182 Klassensummen verwendet (Abbildung 4.14). Die Klassensummen decken einen weiten Bereich der Projektionsrichtungen ab (Abbildung 4.15 A). Die Auflösung der Struktur liegt bei $40 \AA$, wie durch die Berechnung der Fourier-Schalenkorrelation bestimmt wurde (Abbildung 4.15 B). Die Klassensummen stimmen gut mit den Rückprojektionen der Struktur bei allen Projektionsrichtungen überein.

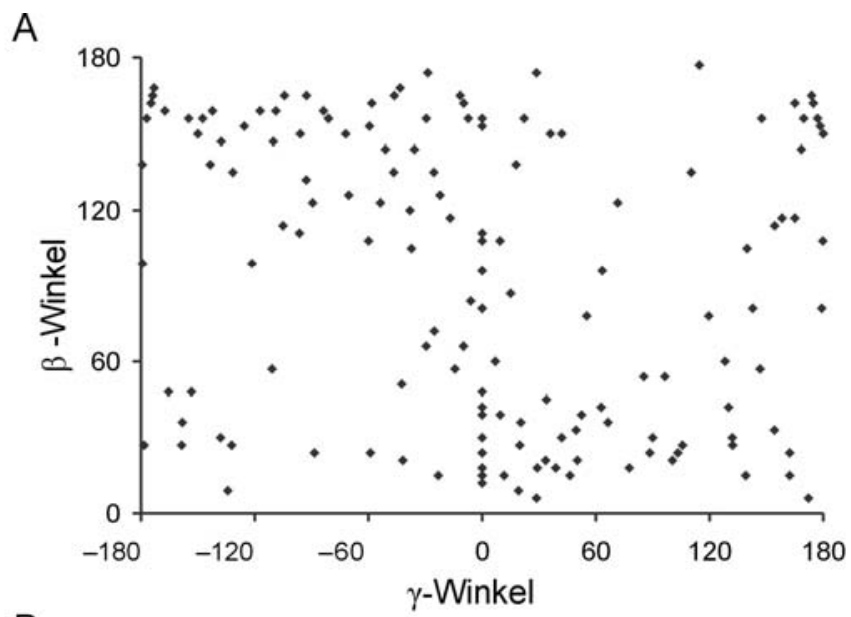

B

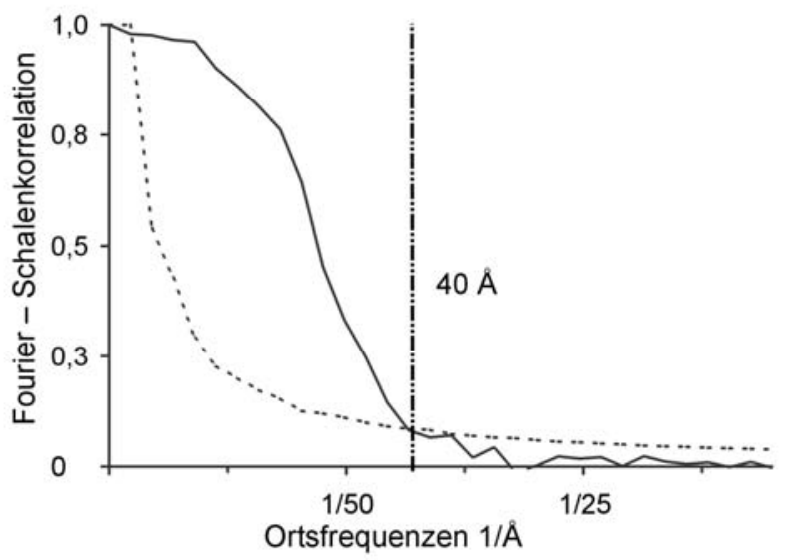

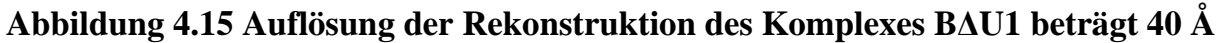

A) Die Projektionsrichtungen der Klassensummen sind über alle Projektionsrichtungen verteilt. Diagramm der Euler-Projektionswinkel, die den 182 in der endgültigen Struktur verwendeten Klassensummen zugeordnet wurden. Jede Klassensumme wird durch einen Punkt im $\beta, \gamma$-Winkelkoordinatensystem dargestellt. B) Diagramm der Fourier-Schalenkorrelationsfunktion berechnet von zwei unabhängig erstellten Rekonstruktionen (durchgehende Linie) und der $3 \sigma$ Kurve, die die Fourier-Schalenkorrelation von Rauschen repräsentiert. Der Schnittpunkt beider Kurven gibt eine Auflösung von $40 \AA$. 


\subsubsection{Strukturelle Organisation des Komplexes B $\Delta \mathbf{U} 1$}

Die Händigkeit der durch ,angular reconstitution` mit Hilfe des Startmodels erzeugten Struktur ist zunächst nicht bestimmt. Die Struktur und die zu ihr spiegelverkehrte Struktur hätten beide der Struktur in Lösung entsprechen können. Im Gegensatz dazu, ist durch das vorgegebene Winkelsystem in der RCT Rekonstruktion die Händigkeit der Struktur bestimmt. Durch einen Vergleich der RCT Rekonstruktion mit der durch ,angular reconstitution' bestimmten Struktur kann der letzt genannten die richtige Händigkeit zugewiesen werden (Abbildung 4.16). Der obere Teil erscheint in der RCT Rekonstruktion kleiner als in der durch ,angular reconstitution' bestimmten Struktur. Schon anhand des Vergleichs mit Klassensummen war beobachtet worden, dass der obere Teil der Struktur wahrscheinlich nicht die gesamte Dichte des Komplexes in diesem Bereich wiedergibt.

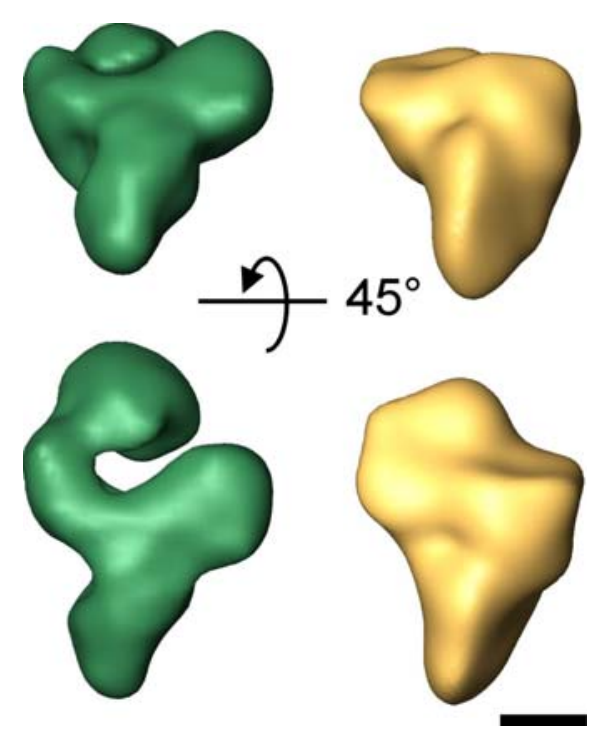

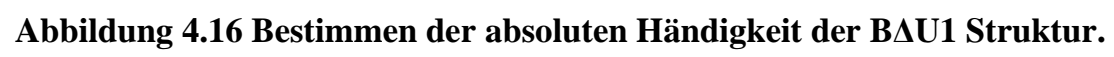

Die dreidimensionale Struktur des Komplexes B $\Delta \mathrm{U} 1$ wird mit der RCT Rekonstruktion verglichen. Die Händigkeit der B $\Delta U 1$ Struktur konnte von der Händigkeit der RCT Struktur abgeleitet werden.

Für die Oberflächendarstellung des Komplexes ist es notwendig einen Grenzwert für die dargestellte Dichte zu wählen. Dichte die unterhalb dieses Grenzwerts liegt wird als Rauschen betrachtet und nicht visualisiert. Wenn der Grenzwert zu niedrig gewählt wird, ist die resultierende Darstellung der Struktur mit zufälligen Dichtefluktuationen überlagert. Falls der Grenzwert zu hoch gewählt wird, wird ein Teil der Dichte des Komplexes selber abgeschnitten und nicht visualisiert. In der Literatur wird der Grenzwert im Allgemeinen so gewählt, dass das eingeschlossene Volumen bei gleichförmiger Ausfüllung mit Protein oder 
Nukleinsäure der bekannten molekularen Masse des Komplexes entspricht (van Heel et al., 2000). Im Fall des Komplexes $B \Delta U 1$ ist die Masse aber nicht mit hinreichender Genauigkeit bestimmt (Makarova et al., 2004). In der massenspektrometrischen Analyse der Proteinzusammensetzung kann die Stöchiometrie der Proteine nicht direkt bestimmt werden. Der Grenzwert für die Visualisierung wurde deshalb visuell angepasst (Abbildung 4.17). Der Grenzwert wurde zunächst so niedrig gewählt, dass Rauschen dominierte. Der Grenzwert wurde dann schrittweise angehoben bis die Konturen eines zusammenhängenden Partikels sichtbar wurden. Bei diesem Grenzwert entsprach das scheinbare Volumen des Partikels einem Molekulargewicht von 6,5 MDa. Der Grenzwert wurde weiter angehoben, so dass die äußeren Regionen zunehmend als potentielles Rauschen abgeschnitten wurden. Bei einem Grenzwert entsprechend einer molekularen Masse von 4,5 MDa bildeten die verbleibenden Dichten kein zusammen hängendes Objekt mehr, was der Beobachtung eines globulären Partikels widerspricht. Für eine repräsentative Visualisierung der Struktur wurde deshalb ein mittlerer Grenzwert entsprechend einem eingeschlossenen Volumen von 5,5 MDa gewählt.
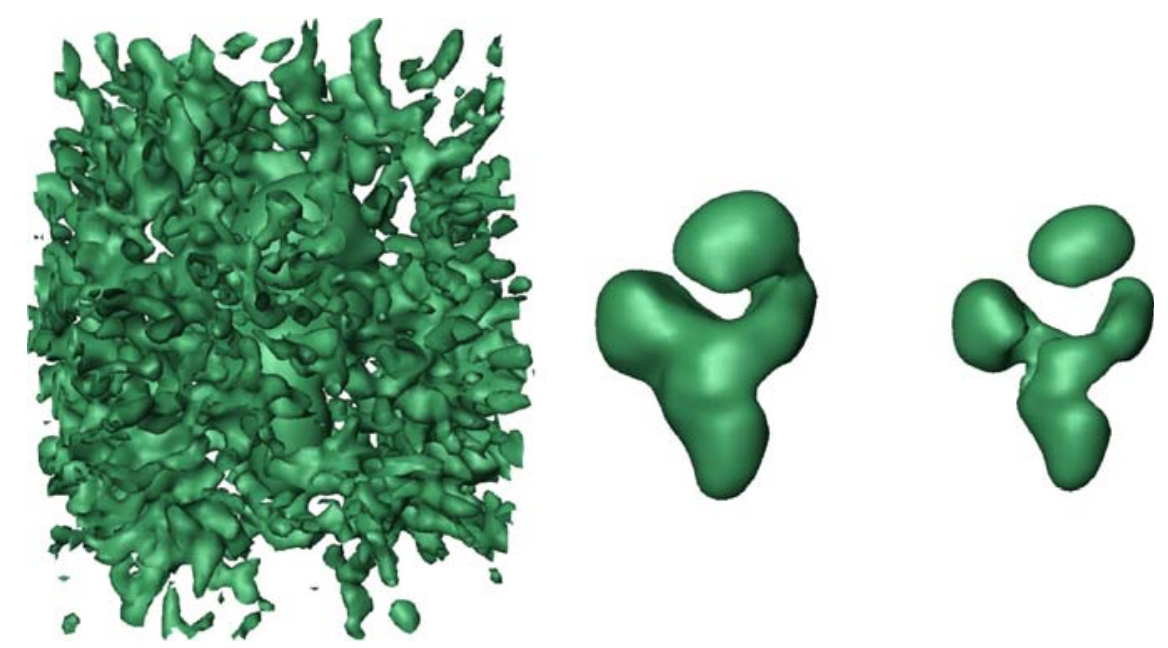

Abbildung 4.17 Wahl des Dichtegrenzwerts zur Oberflächendarstellung der Struktur

Von A nach C wurden zunehmend höhere Grenzwerte der dargestellten Dichte gewählt. Bei niedrigen Grenzwerten enthält das dargestellte Volumen Anteile von Rauschen (links), die Struktur grenzt sich nicht von der Umgebung ab. Bei zu hohen Grenzwerten sind die Dichten der Struktur nicht mehr miteinander verbunden (rechts).

Die so erstellte Oberflächendarstellung des Komplexes $\mathrm{B} \Delta \mathrm{U} 1$ besteht aus einer dreieckigen Domäne mit Seitenlängen $310 \times 310 \times 270 \AA$ und einer maximalen Dicke von $170 \AA$ (Abbildung 4.18). Diese dreieckige Domäne ist mit einem Dichtevorsatz, dem so genannten ,Kopf', verbunden, was der gesamten Struktur eine maximale Ausdehnung von 370 Å verleiht. Die dreieckige Domäne bildet eine zentrale Dichte in einer Ebene, umgeben 
von drei weiteren Dichten, die ,foot', ,stump' und ,neck' bezeichnet werden (Bezeichnet mit $\mathrm{f}, \mathrm{s}$ und $\mathrm{n}$ in Abbildung 4.18).

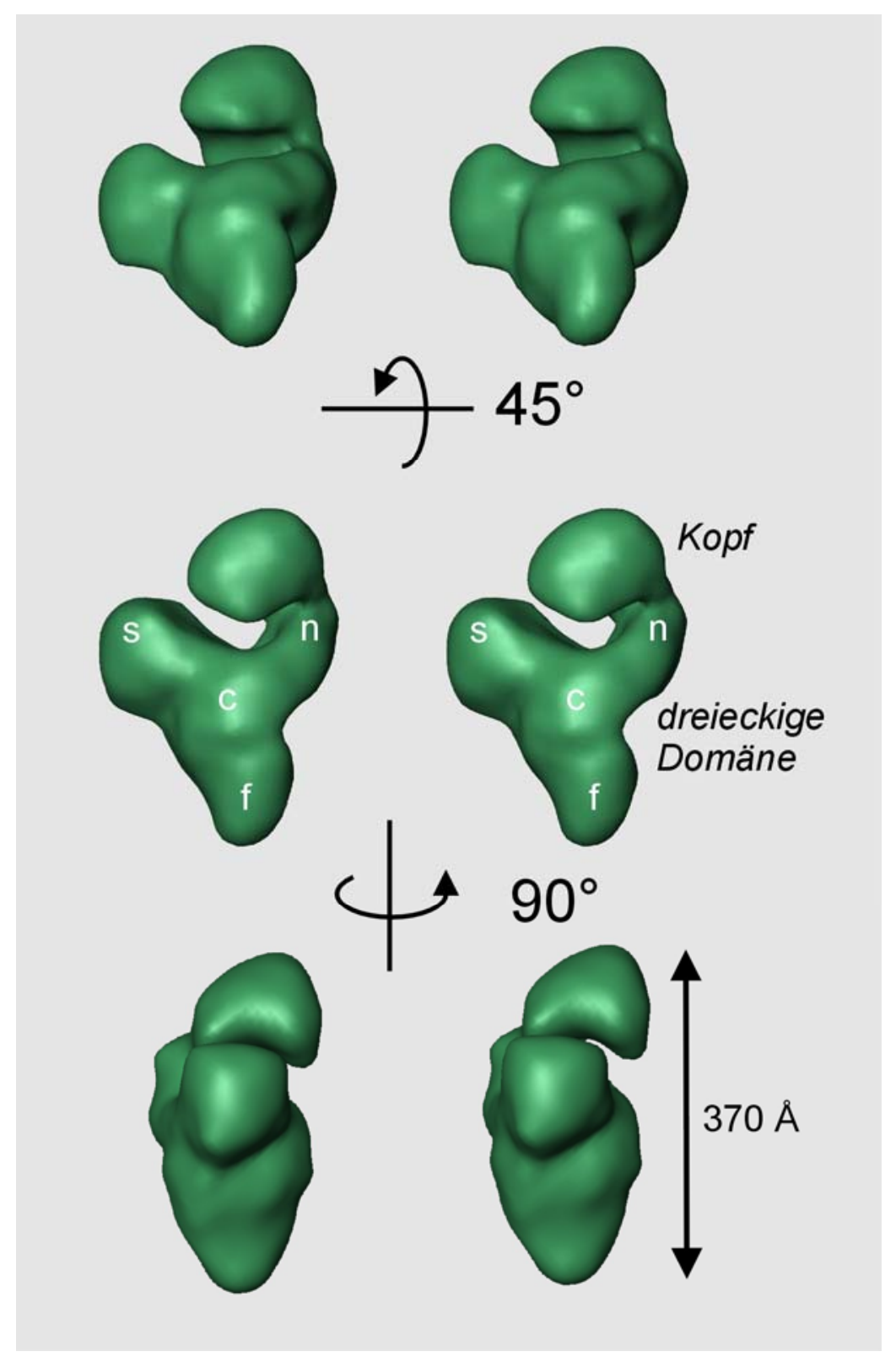

\section{Abbildung 4.18Stereopaare der Oberflächendarstellng des Komplexes BAU1.}

Stereobildpaare zeigen den Komplex in drei verschiedenen Orientierungen. Die Struktur wurde tiefpass auf eine Auflösung von $40 \AA$ gefiltert. Die Struktur kann in eine Kopfdomäne und eine dreieckige Domäne eingeteilt werden. Die dreieckige Domäne setzt sich aus vier Dichteelementen zusammen: foot,f ; zentrale Dichte, c; stump, s; und neck, n. 


\subsubsection{Flexible Domänen des Komplexes B $\Delta \mathrm{U} 1$}

Die dreidimensionale Strukturberechnung mit einen Datensatz von 20.000 Einzelbildern reicht bei homogenen und strukturell einheitlichen Partikelpopulationen für eine Auflösung von weit unter $20 \AA$, wie an vielen Beispielen von prokaryotischen und eukaryotischen Ribosomen gezeigt werden kann (Stark, 2002). Die Klassensummen des Komplexes B $\Delta U 1$ zeigen zum Teil Details von einer Auflösung von 20-30 Å, die Berechnung einer höher aufgelösten Struktur sollte also mit dem vorhandenen Datensatz möglich sein. Ferner decken die zur Berechnung der Struktur verwendeten Klassensummen den gesamten Projektionswinkelbereich ab. Die Auflösung der Struktur ist damit wahrscheinlich nicht durch das Fehlen von Klassensummen aus einem bestimmten Projektionswinkelbreich limitiert. Die Auflösung der Struktur könnte jedoch durch strukturelle Heterogenität begrenzt sein. Dabei kann es sich sowohl um Unterschiede in der Zusammensetzung der einzelnen Partikel handeln als auch um unterschiedliche Konformationszustände der Komplexe. Bei der Analyse der Klassensummen wurde bereits auf strukturelle Heterogenität im Bereich der Kopfdomäne hingewiesen. Außerdem finden sich in diesem Bereich auch die größten Unterschiede zwischen den durch ,angular reconstitution' und RCT erstellten Strukturen, was ebenfalls auf Heterogenität der B $\Delta \mathrm{U} 1$ Probe zurückgeführt werden konnte.

Um eine genauere Analyse der Heterogenität, ihres Umfangs und Art, zu bekommen, kann ein ,subdomain alignment' verwendet werden (Walz et al., 1998). Die Ansichten einer häufigen Projektionsrichtung, der Klassensumme mit den meisten Mitgliedern, werden dabei in Unterklassen aufgespalten. Für die Analyse des Komplexes wurde die trapezförmige Ansicht gewählt, die die Klassensummen mit den meisten Mitgliedern bildet. Außerdem ist in dieser Ansicht die Region des Komplexes in der die Heterogenität vermutet wird, die Kopfdomäne, nicht von der dreieckigen Domäne verdeckt. Alle Einzelbilder dieser Klassensummen wurden zu einem Datensatz von 1200 Partikeln zusammengefasst, der ein Summenbild der trapezförmigen Ansicht ergibt (Abbildung 4.19 B). Der Bereich der Kopfdomäne, der auf Heterogenität getestet werden soll, wird nun in allen Einzelbildern, die normalisiert sind, mit einer Null-Maske verdeckt. Diese maskierten Einzelbilder wurden dann auf die dreieckige Domäne der Summenansicht ausgerichtet. Die ausgerichteten Bilder wurden demaskiert und nach einer multivariaten statistischen Analyse in 20 Unterklassen aufgespalten (Abbildung 4.19 A). 
A
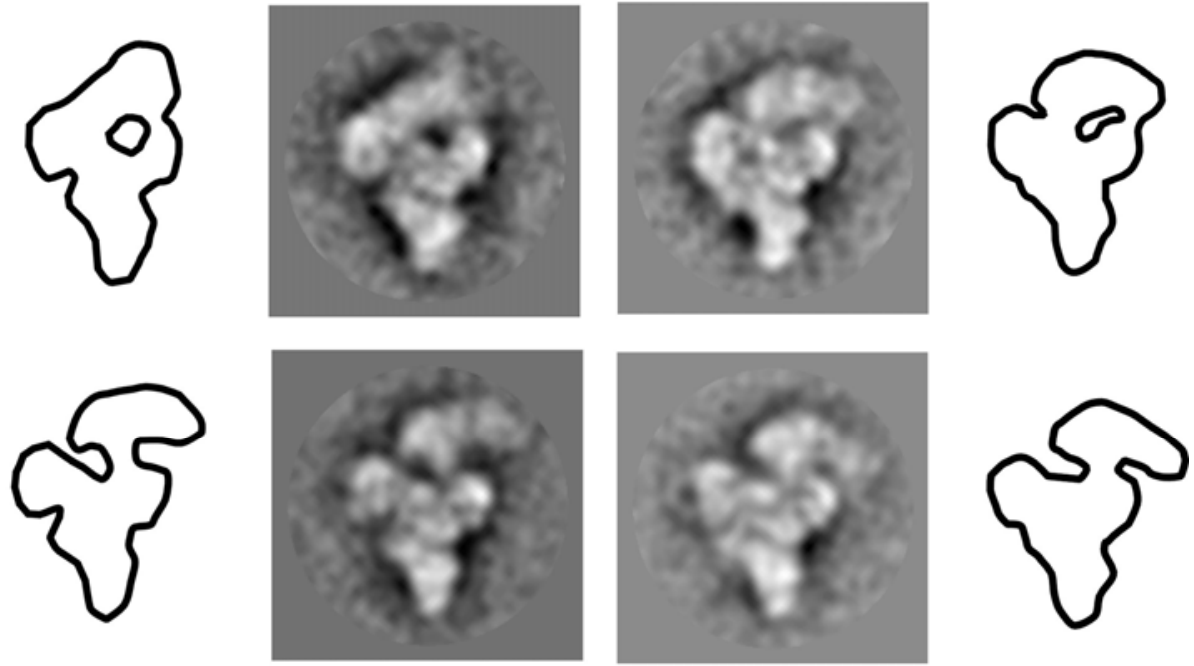

B

C
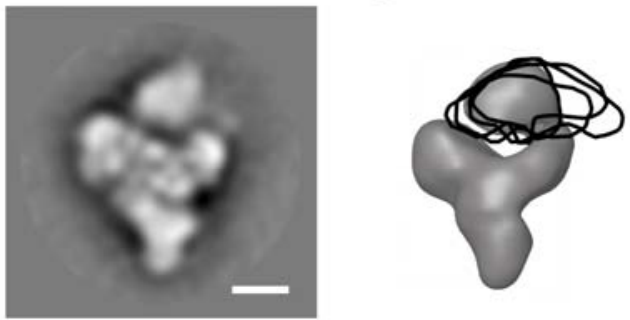

$\mathrm{D}$
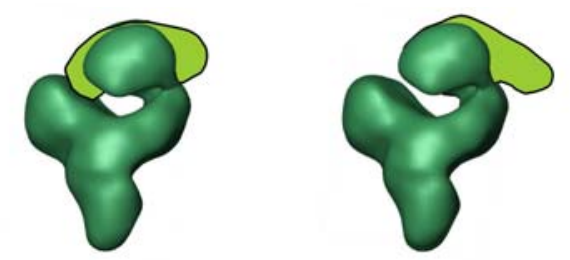

\section{Abbildung 4.19 Analyse der strukturellen Heterogenität des Komplexes BAU1}

A) Darstellung von vier repräsentativenKlassensummen des Komplexes in ähnlicher Orientierung, die nach der statistischen Analyse der Flexibilität erhalten wurden. Zum Vergleich sind die Konturen der Komplexe neben den Klassensummen gezeigt. Der untere Teil des Komplexes ist ähnlich in allen Klassensummen, der obere Teil ist strukturell heterogen. B) Darstellung der Summe der 1200 in der Analyse der Heterogenität ausgewerteten Einzelpartikelbilder. Die strukturelle Heterogenität führt zur Mittelung über alle Konformationen. Die Kopfdomäne erscheint deshalb in der Summenansicht zu klein. C) Die vier Konturen des oberen Teils der in A dargestellten Klassensummen sind auf eine Oberflächenansicht der Komplexe gelegt. Im Bereich der Überschneidung der Konturen erscheint die Kopfdomäne. Die Kopfdomäne wird nicht vollständig in der Struktur dargestellt. D) Zwei Konformere der Kopfdomäne (hellgrün) sind im Vergleich zur dreidimensionalen Struktur des Komplexes B $\Delta \mathrm{U} 1$ (dunkelgrün) dargestellt. Dir Kopfdomäne scheint eine stabile Domäne zu bilden, die flexibel an die dreieckige Domäne gebunden ist. (Größenmaßstab $200 \AA$ ) 
Der Vergleich der Unterklassensummen zeigt, dass der untere Teil in allen Klassen ähnlich ist während sich der obere Teil von Unterklassensumme zu Unterklassensumme deutlich unterscheidet. Dies zeigt deutlich die strukturelle Heterogenität im oberen Teil der $\mathrm{B} \Delta \mathrm{U} 1$ Struktur, der Kopfdomäne (Abbildung 4.19 C). Die Größe und Form der Kopfdomäne sind in den meisten Unterklassensummen ähnlich. Die Dichte erscheint jedoch in unterschiedlicher Position, relativ zur dreieckigen Domäne. Die Kopfdomäne scheint daher eine stabile Einheit zu bilden, die relativ zur dreieckigen Domäne flexibel gebunden ist. Aus den Unterklassensummen kann eine minimale Distanz von $60 \AA ̊$ bestimmt werden, die bei einer Überführung der zwei Konformationszustände von der Kopfdomäne zurückgelegt werden müssten. Allerdings kann nicht ausgeschlossen werden, dass sich auch die Zusammensetzung der Kopfdomäne in beiden Zuständen unterscheidet.

Für die gezeigte Oberflächendarstellung der B $\Delta \mathrm{U} 1$ Struktur bedeutet die Flexibilität der Kopfdomäne, dass der Kopf vergleichsweise zu klein dargestellt ist. Wenn bei der Strukturberechnung über alle Konformationen gemittelt wird, erscheint in der endgültigen Struktur die Dichte für den Kopf nur an der Stelle der Überlagerung aller Strukturen. Einen Eindruck von der Struktur des Komplexes B $\Delta \mathrm{U} 1$ mit der vergrößerten Kopfdomäne in zwei unterschiedlichen Konformationen ist in Abbildung 4.19 D gegeben. Ferner bedeutet diese Mittelung über aller Konformationen auch, dass nur eine geringe Auflösung für die Kopfdomäne zu erzielen ist und diese weitgehend unstrukturiert erscheint. Allerdings begrenzt die Heterogenität in der Kopfdomäne nicht nur die Auflösung dieser Domäne, sondern beeinflusst auch die Auflösung der Gesamtstruktur. So werden die verschiedenen Klassensummen unterschiedliche relative Anordnungen von Kopfdomäne und dreieckiger Domäne wiedergeben. Werden diese Klassensummen dann für die Berechnung einer dreidimensionalen Struktur verwendet, wird die Zuordnung der Projektionswinkel durch die Anordnung beider Domänen bestimmt. Es gehen dann über die Mittelung der unterschiedlichen Komformationen die feinen Strukturdetails verloren.

\subsubsection{Berechnung einer höher aufgelösten Struktur der dreieckigen Domäne}

Um eine höher aufgelöste Struktur der dreieckigen Domäne zu erhalten wurde die Kopfdomäne in allen Bildern maskiert. Die maskierten Bilder wurden in einer iterativen Berechnung der dreidimensionalen Struktur der dreieckigen Domäne verwendet (Abbildung 4.20). Die Auflösung erhöhte sich auf $33 \AA \AA$ nach FSC (Abbildung 4.21). Es sind nun feinere Details der dreieckigen Domäne zu erkennen. Insbesondere trennt sich die ,stump’ Dichte nun deutlich vom Rest des Domäne ab und ist mit der zentralen Dichte über zwei relativ dünne Dichtebrücken verbunden. 

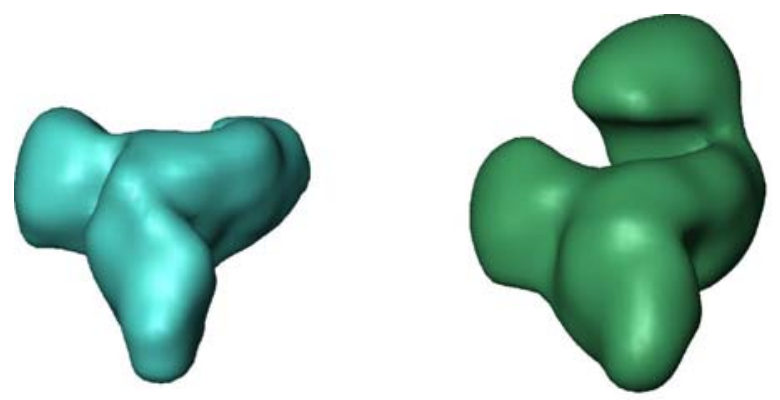

\section{$\eta 45^{\circ}$}
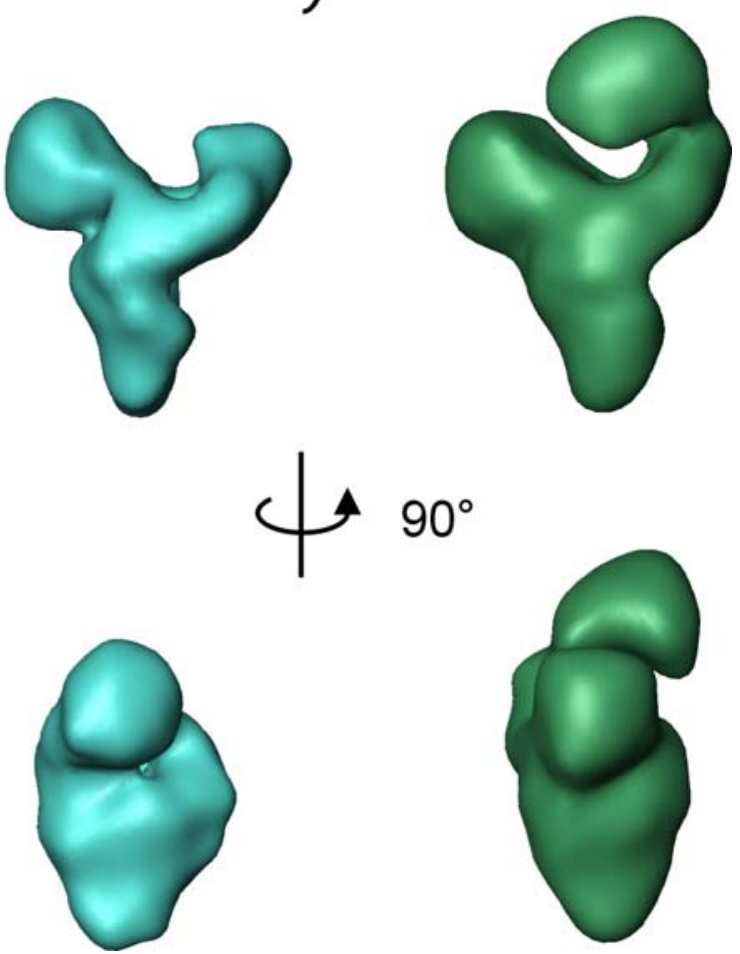

\section{Abbildung 4.20 Strukturverbesserung der dreieckigen Domäne}

Die verbesserte Struktur der dreieckigen Domäne (blau) ist in drei Orientierungen im Vergleich zum gesamten Komplex B $\Delta \mathrm{U} 1$ (grün) dargestellt. Die Kopfdomäne wurde aus der Berechnung ausgeschlossen und die Struktur der dreieckigen Domäne verbessert. Die Auflösung der Struktur beträgt 33 Å. 


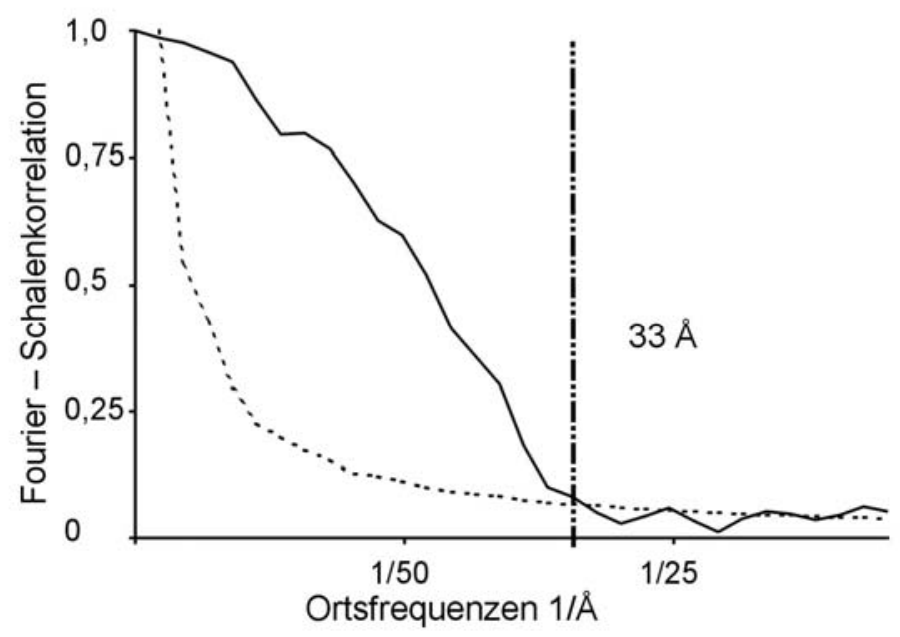

\begin{abstract}
Abbildung 4.21 Auflösung der verbesserten Struktur der dreieckigen Domäne
Diagramm der Fourier-Schalenkorrelationsfunktion berechnet von zwei unabhängig erstellten Rekonstruktionen (durchgehende Linie) und der $3 \sigma$ Kurve, die die Fourier-Schalenkorrelationsfunktion von Rauschen repräsentiert. Der Schnittpunkt beider Kurven gibt eine Auflösung von 33 Å.
\end{abstract}

\title{
4.5 Lokalisierung des Tri-snRNPs
}

Die dreieckige Kontur der unteren Domäne des Komplexes B $\Delta \mathrm{U} 1$ ist in Größe und Form den Klassensummen des U4/U6.U5 tri-snRNPs ähnlich (Fabrizio et al., 1994). Der U4/U6.U5 trisnRNPs ist der größte Bestandteil des Komplexes B. Um einen besseren Vergleich der beiden Komplexe zu ermöglichen, wurde der U4/U6.U5 tri-snRNPs nach einem der Aufreinigung des Komplexes B $\Delta$ U1 ähnlichen Protokoll aufgereinigt. Der U4/U6.U5 tri-snRNPs wurde aus Kernextrakt mit einem gegen das 61K U4/U6 Protein gerichteten Antikörper isoliert. Abweichend von der Isolierung des Komplexes $\mathrm{B} \Delta \mathrm{U} 1$ wurde allerdings kein Heparin zugesetzt. Elektronenmikroskopische Aufnahmen des U4/U6.U5 tri-snRNPs zeigen hauptsächlich dreieckige Partikelansichten mit einer Größe von $310 \times 280 \times 230 \AA$ (Seitenlänge) (Abbildung 4.22 A). Die Übereinstimmung in Größe und Form der dreieckigen Domäne des tri-snRNP und des Komplexes B $\Delta \mathrm{U} 1$ lassen vermuten, dass der tri-snRNP den Hauptbestandteil dieser Domäne bildet (Abbildung 4.22 B). Außerdem ist kein anderer Teil des Komplexes $\mathrm{B} \Delta \mathrm{U} 1$ groß genug um den tri-snRNP aufnehmen zu können. 
A

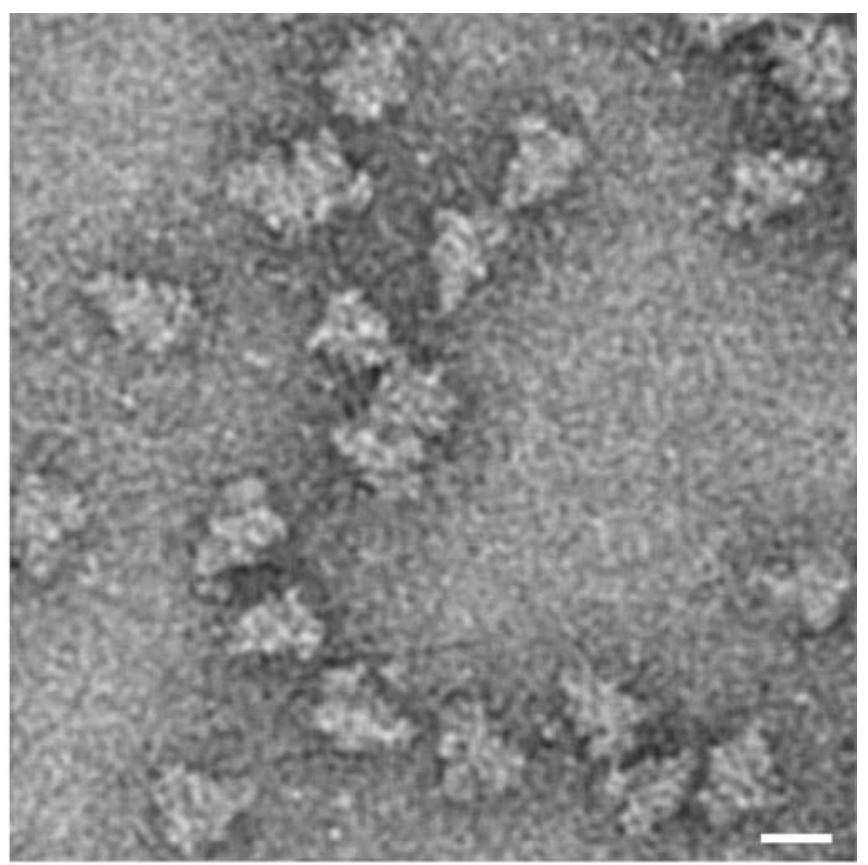

B
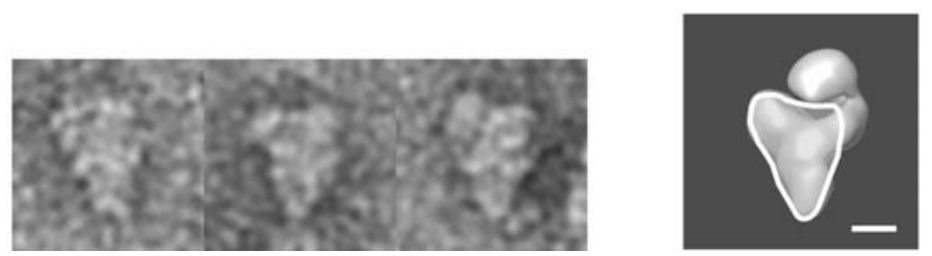

\section{Abbildung 4.22 Elektronenmikroskopische Visualisierung des U4/U6.U5 tri-snRNP}

A) Elektronenmikroskopische Aufnahme von U4/U6.U5 tri-snRNPs die in der Sandwich-Methode mit Uranylformiat negativ kontrastiert wurde. Die Aufnahme wurde bei 38.000facher Vergrößerung bei Raumtemperatur aufgenommen (Größenmaßstab: $200 \AA \AA$ ). B) Links: Galerie von U4/U6.U5 tri-snRNPs Einzelpartikelbildern. Der U4/U6.U5 tri-snRNPs besitzt eine dreieckige Form mit einer Kantenlänge von $310 \times$ $280 \times 230 \AA$ Rechts: Überlagerung der dreieckigen Kontur des U4/U6.U5 tri-snRNPs mit der dreieckigen Domäne der BAU1 Struktur (Größenmaßstab: $200 \AA$ ). 


\section{Diskussion}

\subsection{Die Struktur des Komplexes B $\Delta \mathrm{U} 1$}

Die Auflösung der Struktur des Komplexes B $\Delta \mathrm{U} 1$ von $40 \AA$ erlaubt einen ersten Einblick in die strukturelle Organisation des Spleißosoms. Die dreidimensionale Struktur des Komplexes B $\Delta \mathrm{U} 1$ ist gekennzeichnet durch einen dreieckigen Körper und eine Kopfdomäne, die durch eine relativ dünne Verbindung mit dem Körper verbunden ist. Die Domänenstruktur ermöglicht Rückschlüsse auf die Organisation der U snRNPs im Spleißosom. Die Flexibilität der Kopfdomäne erlaubt erste Rückschlüsse auf die Konformationswechsel bei der katalytischen Aktivierung des Spleißosoms.

\subsubsection{Lokalisation der U snRNPs}

Die biochemische Analyse ergab, dass die tri-snRNP Komponente noch nicht die für die katalytische Aktivierung notwendige Umlagerung vollzogen hat (Makarova et al., 2004). In Psoralen-Quervernetzungsstudien des Komplexes B $\Delta \mathrm{U} 1$ konnte eine Quervernetzung von U4 und U6 beobachtet werden, die charakteristisch für den tri-snRNP ist. Dies ist auf eine Basenpaarung von U4 und U6 snRNA zurückzuführen, die mit der Ausbildung der U2/U6 Helix 1 nicht vereinbar ist. Somit hat sich das RNA-Netzwerk des katalytisch aktivierten Komplexes noch nicht ausgebildet. Die strukturelle Einheit des isolierten in Lösung vorliegenden tri-snRNP ist deshalb wahrscheinlich noch im Komplex B $\Delta U 1$ erhalten. Elektronenmikroskopische Aufnahmen des isolierten tri-snRNP zeigen Partikel mit einer charakteristischen dreieckigen Ansicht, deren Konturen mit der unteren dreieckigen Domäne des Komplexes B $\Delta U 1$ übereinstimmen. Dieser Teil des Komplexes B $\Delta U 1$ kann deshalb dem tri-snRNP zugeordnet werden. Es ist im Moment aber noch keine Aussage möglich, ob noch weitere Bestandteile des Komplexes B $\Delta \mathrm{U} 1$ zur Struktur der dreieckigen Domäne beitragen.

Die Lokalisation des U2 snRNP ist nicht über den Vergleich mit Ansichten des isolierten U2 snRNP möglich, da sich die Konformation des U2 snRNP bei der Integration in das Spleißosom ändert. Die Interaktionen des U2 snRNP mit der prä-mRNA verändern sich deutlich bei der Umwandlung des Komplexes E in Komplex A, wenn die U2 snRNA mit der prä-mRNA am Verzweigungspunkt eine Basenpaarung eingeht (Ares and Weiser, 1995; Perriman et al., 2003; Reed, 2000). Auch die Struktur der isolierten U2 snRNP Komponente SF3b im isoliertem Zustand und integriert im U11/U12 di-snRNP weist auf eine dynamische Umordnung des U2 snRNP hin (Golas et al., 2003; Golas et al., 2005). So öffnet sich die schalenförmige Struktur des SF3b bei der Integration in den U11/U12 di-snRNP. Diese 
Konformationsänderung verlagert das Protein p14, welches den Verzweigungspunkt bindet, an die Oberfläche des Komplexes.

\subsubsection{Strukturelle Organisation des Komplexes B $\Delta \mathbf{U} 1$}

Die charakteristische Form des tri-snRNP lässt eine Zuordnung zur dreieckigen Domäne zu. Die dreieckige Domäne ist mit $170 \AA$ relativ dünn, sodass anzunehmen ist, dass der tri-snRNP den Hauptanteil der dreieckigen Domäne ausmacht. Es ist allerdings auf dieser Ebene nicht möglich die genaue Orientierung des tri-snRNPs in der dreieckigen Domäne zu bestimmen. So stellt die Zuordnung der Einzelpartikelbilder in Abbildung 22 nur eine von mehreren möglichen Orientierungen dar.

Die Kopfdomäne kann nicht mit Sicherheit bestimmten Komponenten des Komplexes $\mathrm{B} \Delta \mathrm{U} 1$ zugeordnet werden. Die Kopfdomäne und die dreieckige Domäne bilden jeweils stabile strukturelle Einheiten, die miteinander flexibel verbunden sind. Da bei der Bildung des Komplexes B zwei strukturelle Einheiten in Wechselwirkung treten, der tri-snRNP und der Komplex A, können die Kopfdomäne und die dreieckige Domäne spekulativ mit diesen strukturellen Einheiten identifiziert werden. Die Ausmaße der Kopfdomäne, wie sie nach der Auftrennung in unterschiedliche Konformere erscheint, betragen $250 \times 100 \AA \AA$. Der U11/U12 di-snRNP könnte in seiner strukturellen Organisation der strukturellen Organisation von U1 und U2 snRNP in spleißosomalen Komplexen entsprechen (Golas et al., 2005). Der U2 snRNP und assoziierte Proteine bilden den Hauptteil des Komplexes A, sodass der Verlust des U1 snRNP an den Proportionen des Komplexes nur eine geringere Veränderung bewirken sollte. Die Ausmaße des di-snRNP sind $260 \times 150 \AA$ und stimmen damit in den Proportionen mit den Ausmaßen der Kopfdomäne überein. Insofern könnte ein Hauptbestandteil der Kopfdomäne der an den Verzweigungspunkt gebundene U2 snRNP sein. Wird der Komplex $\mathrm{B} \Delta \mathrm{U} 1$ so spekulativ in einen tri-snRNP und einen U2 snRNP Teil unterteilt, so sollte der U4/U6 di-snRNP an der Verbindung beider Domänen im oberen Teil der dreieckigen Domäne lokalisiert sein.

Der Vergleich der unterschiedlichen Konformere der Kopfdomäne zeigt, dass die Kopfdomäne in allen Fällen von der Halsdichte der dreieckigen Domäne überlagert ist. Die Kopfdomäne ist deshalb wahrscheinlich über die Halsdichte mit der dreieckigen Domäne verbunden. Da die Kopfdichte eine stabile strukturelle Einheit zu bilden scheint, kann die Halsdichte als Scharnierregion beschrieben werden, die einer Bewegung der dreieckigen Domäne und Kopfdomäne zulässt.

Zwischen den Komplex A Bestandteilen, dem tri-snRNP und der prä-mRNA sind verschiedene RNA-RNA Interaktionen beschrieben worden. Die Quervernetzungs- 
experimente zeigen eine Basenpaarung von U2 und U6 snRNA sowie der prä-mRNA und U6 snRNA, zusätzlich zur Interaktion der U4 und U6 snRNA im di-snRNP (Makarova et al., 2004). Die U2/U6 snRNA Quervernetzungen können auf die Ausbildung der U2/U6 Helix 2 zurückgeführt werden, die zeitgleich mit den U4/U6 Helices existieren kann (Hausner et al., 1990). Zudem interagiert wahrscheinlich U5 snRNA mit prä-mRNA der 5' Spleißtelle (Wassarman and Steitz, 1992). Die U6 snRNA verbindet also die an der 5'-Spleißstelle gebundene U5 snRNA mit der U2 snRNA, die mit der Verzweigungsstelle interagiert. Dies lässt auf ein Netzwerk von Interaktionen zwischen den Komplex A Komponenten und dem tri-snRNP schließen. Die Flexibilität der Kopfdomäne und der relativ kleine Scharnierbereich der Bewegung sind zunächst nur schwer mit einem Netzwerk von RNA-RNA Interaktionen zu vereinen. Die basengepaarten Bereiche umfassen jedoch für jede Interaktion nur wenige Nukleotide und könnten deshalb von nur geringer Stabilität sein.

Dem Geflecht von RNA-RNA Interaktionen stehen nur wenige Interaktionen der Proteinkomponenten der snRNPs gegenüber. Die meisten Mutationen von Proteinen in S. cerevisiae, die die Assemblierung des Komplexes B blockieren, wirken über die Destabilisierung des tri-snRNP und blockieren nicht spezifisch die Bindung des tri-snRNP (Blanton et al., 1992). Die Bildung des Komplex B konnte durch Antikörper gegen das U5 220K Protein und das U4 60K Protein blockiert werden (Banroques and Abelson, 1989; Brown and Beggs, 1992). Die tri-snRNP Proteine 110K und 65K sind für die Assemblierung des Komplex B essentiell (Makarova et al., 2001). Es ist aber in beiden Fällen nicht sicher, dass es sich um eine direkte Interaktion handelt. Für das Protein SPF30 ist in Kernextrakten von HeLa-Zellen eine essentielle Funktion bei der Integration des tri-snRNP in den Komplex B beschrieben worden, die auf eine direkte Interaktion des Proteins mit dem U2 snRNP und dem tri-snRNP zurückzuführen ist (Meister et al., 2001; Rappsilber et al., 2001). In vivo interagiert SPF30 mit U2 snRNP und wurde somit in die Gruppe der U2 snRNP assoziierten Proteine eingeordnet. In vitro konnten Interaktionen mit dem tri-snRNP nachgewiesen werden, die wahrscheinlich durch das U4/U6 Protein 90K vermittelt werden (Meister et al., 2001; Rappsilber et al., 2001). Die Abwesenheit von Daten über weitere direkte Protein-Protein Interaktionen weist auf eine relativ kleine Region der stabilen Wechselwirkung von tri-snRNP und Komplex A hin. Spekulativ könnte es sich deshalb bei SPF30 um ein Protein handeln, das in der Scharnierregion des Komplexes B $\Delta U 1$ liegt und den U2 snRNP mit dem U4/U6 di-snRNP verbindet. 


\subsubsection{Bedeutung der Flexibilität der Kopf-Domäne}

Makromolekulare Komplexe besitzen in vielen Fällen eine für ihre Funktion wichtige Flexibilität (Alberts, 1998). Die zweidimensionale Analyse der Flexibilität des Komplexes B $\Delta \mathrm{U} 1$ ergibt eine Bewegung von mindestens $60 \AA$ für die Bewegung der Kopfdomäne. Die hier beschriebene Bewegung gehört zu den größten die an anderen makromolekularen Komplexen mittels Elektronenmikroskopie untersucht wurden (Chacon et al., 2003; Saibil, 2000). Die Flexibilität beschränkt sich dabei häufig nicht auf die strukturelle Domäne, die eine Reaktion katalysiert, sondern betrifft die strukturelle Organisation des gesamten Komplexes. An makromolekularen Komplexen, wie dem Ribosom und der RNA-Polymerase aus E. coli, wurde beschrieben, dass die Bewegungen ganzer Domänen von entscheidender Bedeutung für die katalysierten Reaktionen sind (Darst et al., 2002; Frank and Agrawal, 2000). Es ist daher zu vermuten, dass auch die im Fall des Komplexes B $\Delta U 1$ beobachtete Bewegung für die Spleißreaktion von Bedeutung ist. Die beobachtete Flexibilität könnte zur Integration des Prp19 Komplexes und weiterer Proteinfaktoren notwendig sein, die für die Ausbildung des katalytischen Zentrums notwendig sind (Makarova et al., 2004). Der Prp19 Komplex und weitere Faktoren könnten so die relative Orientierung der U2 und der tri-snRNP Komponenten koordinieren.

\subsubsection{Strukturelle Dynamik des Komplexes B BU1}

Die für den Komplex $\mathrm{B} \Delta \mathrm{U} 1$ beobachtete strukturelle Heterogenität kann mit biochemischen Daten über die Dynamik der RNA-RNA Interaktionen in Verbindung gebracht werden. Wie oben beschrieben existiert im Komplex BAU1 ein Netzwerk von RNA-RNA Interaktionen. Die U6 snRNA verbindet die an der 5'-Spleißstelle gebundene U5 snRNA mit der U2 snRNA, die mit der Verzweigungsstelle interagiert.

Die veröffentlichten biochemischen Untersuchungen am Komplex B $\Delta \mathrm{U} 1$ schließen die Bildung der U2/U6 Helix 1 sowie eine teilweise Entwindung der U4/U6 Helix nicht aus. Studien am U12 abhängigen Spleißosom haben gezeigt, dass diese Interaktionen gleichzeitig möglich sind (Frilander and Steitz, 2001). Sie sind unabhängig von den U6 prä-mRNA Interaktionen und somit existieren wahrscheinlich mehrere Wege zur Ausbildung des katalytischen Zentrums. Untersuchungen in S. cerevisiae weisen darauf hin, dass verschiedene Sequenzen der U6 snRNA mit der 5'-Spleißstelle interagieren, bevor es zu einer stabilen Wechselwirkung der ACAGAG-Box mit der 5'-Spleißstelle kommt (Johnson and Abelson, 2001). Ebenfalls wurden Interaktionen der U4 RNA mit der 5'-Spleißstelle identifiziert (Johnson and Abelson, 2001). Es scheint deshalb wahrscheinlich, dass verschiedene Regionen der U6 und U4 RNA unabhängig voneinander mit der 5'-Spleistelle interagieren. 
Zusammengenommen scheint es somit mehrere Wege zur katalytischen Aktivierung des Spleißosoms zu geben, die durch unterschiedliche Basenpaarungen der U4 und U6 snRNA mit der U2 snRNA charakterisiert sind.

Die biochemischen Verfahren zur Isolierung spleißosomaler Komplexe, Gradientenzentrifugation und Affinitätsaufreinigung, können nicht zur Auftrennung unterschiedlicher Konformere der verschiedenen Reaktionswege dienen, wenn sich die Konformere wenig unterscheiden oder in einem sich schnell einstellenden Gleichgewicht befinden. In der elektronenmikroskopischen Analyse kann aber zwischen einzelnen Molekülen und ihren Zuständen unterschieden werden. Diese Technik liefert daher Informationen über einzelne Moleküle und deren Konformation. Einzelmolekültechniken haben im Fall kleiner Ribozyme einen Einblick in die dynamischen Konformationswechsel der RNA gegeben. Einzelmolekül- Floureszenzenergietransfer (FRET) Studien am Hairpin Ribozym haben gezeigt, dass einzelne Moleküle eine Vielzahl von reversiblen Umlagerungen eingehen bis es zur Katalyse der Reaktion kommt (Zhuang et al., 2002). Der hier beschriebenen Flexibilität des Komplex B $\Delta \mathrm{U} 1$ könnte somit ebenfalls ein Ensemble von Zuständen zugrunde liegen. Es lässt sich aber nicht ausschließen, dass durch die Verwendung von Heparin stabilisierende Interaktionen im Komplex gestört wurden. Die hier beschriebene Flexibilität könnte deshalb in der Abwesenheit von Heparin geringer ausfallen.

\subsubsection{Stöchiometrie der Bestandteile des B $\Delta U$ U1 Komplexes}

Zur Visualisierung der Struktur wurde ein Volumen von 5,5 MDa dargestellt. Dieser Wert ist allerdings mit einem Fehler von mindestens 1 MDa belastet. Der Grenzwert für die Dichte zur Visualisierung lässt sich nicht exakt festlegen, da es kein genaues Kriterium zur Unterscheidung der Dichte der Struktur und Dichte der Umgebung gibt (Frank, 1996). Die Flexibilität der Domänen des $\mathrm{B} \Delta \mathrm{U} 1$ Komplexes lässt nur eine ungenaue Bestimmung der molekularen Masse zu. Auf der einen Seite bedingt die Flexibilität der Kopfdomäne, dass nur eine kleine gemittelte Struktur der Kopfdomäne in der Struktur erscheint. Die molekulare Masse des Komplexes könnte also größer sein, als durch das eingeschlossene Volumen zunächst berechnet. Auf der anderen Seite könnte die molekulare Masse auch zu hoch berechnet sein. So erscheint die Dichteverteilung der Struktur kontinuierlich. Zu erwarten wäre allerdings, wie der Vergleich mit anderen spleißosomalen Komplexen (Golas et al., 2003) oder dem Ribosom nahe legt (Stark, 2002), eine schwammartige Dichteverteilung. Die kontinuierliche Erscheinung der Dichteverteilung ist auf die relativ geringe Auflösung zurück zuführen. Diese geringe Auflösung kann wiederum mit der Flexibilität des Komplexes 
begründet werden. Die molekulare Masse des Komplexes kann deshalb nur mit einem relativ großen Fehler von $1 \mathrm{MDa}$ angegeben werden.

Aus der massenspektrometrischen Analyse des Komplexes kann eine molekulare Masse von 4,8 MDa für eine stöchiometrische Bindung aller Proteine mit einer Kopie berechnet werden (Makarova et al., 2004). Einige Proteine werden allerdings substöchiometrisch gebunden sein. Da die molekulare Masse nach der elektronenmikroskopischen Analyse höher zu sein scheint als 4,8 MDa, könnte der Komplex also einige Proteine in mehreren Kopien enthalten. Die biochemische Charakterisierung der molekularen Masse ist wegen der Komplexität des Spleißosomes noch nicht gelungen. Genauere Auskunft über die Stöchiometrie der Proteinzusammensetzung könnten quantitative massenspektrometrische Analysen geben, wie sie für den U1 snRNP durchgeführt wurden (Hochleitner et al., 2005).

\subsubsection{Vergleich mit strukturellen Daten anderer spleißosomaler Komplexe}

Der Vergleich mit anderen strukturellen Daten spleißosomaler Komplexe ist nur auf der Basis der allgemeinen Architektur der Komplexe möglich, da die Komplexe mit unterschiedlichen Methoden isoliert und der Funktionszustand meist nur wenig charakterisiert wurde. Aufreinigungen, die ohne eine spezifische Markierung oder Antikörper-Präzipitation vorgenommen wurden, ergaben eine Vielzahl von unterschiedlichen strukturellen Grundformen.

Die dreieckige Form spleißosomaler Komplexe wurde schon in einer früheren Arbeit beschrieben. In vitro Spleißsysteme von HeLa Zellen Kernextrakt wurden benutzt um spleißosomale Komplexe anzureichern, bei denen der zweite Spleißschritt durch Hitzebehandlung der Kernextrakte inhibiert wurde (Reed et al., 1988). Die Komplexe wurden durch Größenausschlusschromatographie von anderen großen makromolekularen Komplexen getrennt. Nach Rotationsmetallbedampfung wurden Komplexe mit einer maximalen Ausdehnung von 400-600 $\AA$ Länge und $250 \AA$ Breite visualisiert, die eine V-förmige pseudosymmetrische Struktur besaßen. Diese V-förmige Grundstruktur könnte mit der hier beschriebenen dreieckigen Domäne übereinstimmen. Auch die Beschreibung von drei bis sechs Domänen ist mit der hier beschriebenen Struktur in Einklang zu bringen, wenn die kompositionelle Heterogenität der Probe in Betracht gezogen wird. So ist die Hitzeinaktivierung in späteren Studien als wenig reproduzierbar beschrieben worden, sodass der Funktionszustand der abgebildeten Komplexe nicht eindeutig bestimmt ist (Gozani et al., 1994). Ferner enthielt nur der kleinere Teil der Komplexe die in vitro transkribierte definierte 
prä-mRNA, sodass die abgebildeten Komplexe auch Komplexe der endogenen prä-mRNA darstellen, in denen eventuell mehrere Introns enthalten sind.

Die Dimensionen der Kopfdomäne können mit den Dimensionen des Komplex A verglichen werden. Komplex A ist aus einem in vitro Spleißsystem von HeLa Kernextrakten isoliert worden, indem die Bindung an den tri-snRNP durch ein Antisense Oligonukleotid blockiert wurde (Furman and Glitz, 1995). Die Komplexe wurden durch GrößenausschlussChromatographie aufgereinigt und zeigen in negativ kontrastierten Aufnahmen zweigeteilte globuläre Partikel von $230 \times 270 \AA$ Durchmesser. Die maximale Dimension der Partikel stimmt mit den Dimensionen der Kopfdomäne überein. Es bestehen aber auch hier Zweifel an der Reinheit der Komplexe. Die Komplexe wurden als Durchflussfraktion einer Größenausschluss-Chromatographie erhalten und sind potentiell mit höhermolekularen Komplexen verunreinigt (Boehringer, nicht veröffentlichte Ergebnisse)(Clark et al., 1988).

Diese strukturellen Daten und die strukturelle Organisation des Komplexes B $\Delta \mathrm{U} 1$ stehen im Kontrast zu strukturellen Untersuchungen an endogenen spleißosomalen Komplexen aus HeLa Kernextrakten (Azubel et al., 2004). Diese spleißosomalen Komplexe wurden durch Gradientenzentrifugation multimerer spleißosomaler Komplexe gewonnen, die einen Sedimentationskoeffizienten von 200 S besitzen. Diese multimeren Komplexe wurden in einzelne spleißosomale Komplexe dissoziiert und mittels Elektronenkryomikrosopie ohne Kontrastierung abgebildet. Die dreidimensionale Rekonstruktion der Komplexe zeigt eine zweigeteilte globuläre Struktur von $280 \AA$ maximalem Durchmesser. Der funktionelle Zustand der spleißosomalen Komplexe wurde biochemisch nicht näher charakterisiert und wahrscheinlich repräsentieren die Komplexe alle Stadien der Spleißosomenassemblierung. Die berechnete Struktur kann also nur zutreffend sein, wenn diesen Komplexen eine gemeinsame Struktur zugrunde liegt. Diese Hypothese wurde durch die Beschreibung des Penta-snRNPs in S. cerevisiae gestärkt (Stevens et al., 2002). Die biochemischen Arbeiten über die Assemblierungsstadien des Spleißosoms im HeLa Kernextrakt stehen aber nicht im Einklang mit dieser Hypothese. Die Qualität der Klassensummen, die schlecht definierte Konturen besitzen, weisen auf die Mittelung mehrerer unterschiedlicher Partikelansichten in einer Klassensumme hin. Auch die Dimensionen der Untereinheiten können nicht mit den Abmessungen der Ansichten der snRNPs in Einklang gebracht werden. Die größere Untereinheit besitzt die Maße $240 \times 220 \times 170 \AA$ und hat damit nicht die Dimensionen des tri-snRNP. Die Lokalisierung des tri-snRNP bleibt damit ungeklärt. Auch Ferner bleibt ungeklärt, ob durch die beschriebene Aufreinigung nichtspleißosomale, hochmolekulare, 
Komplexe des Kernextrakts abgetrennt werden können (Clark et al., 1988) (Boehringer, nicht veröffentlichte Ergebnisse).

Die Struktur des Komplex B $\Delta \mathrm{U} 1$ ist ebenfalls nicht mit den veröffentlichten Daten von S. cerevisiae spleißosomalen Komplexen vereinbar (Clark et al., 1988) obwohl die große Homologie der snRNAs und spleißosomalen Proteine eine große strukturelle Ähnlichkeit vermuten lässt. Ein in vitro Spleißsystem in Hefe wurde benutzt, um mit einer Kombination von Gradienten bei hohen und niedrigen Salzkonzentrationen spleißosomale Komplexe aufzureinigen (Clark et al., 1988). Durch Kontrastierung der Probe mit Uranylacetat wurden elliptische Strukturen elektronenmikroskopisch visualisiert. Die Strukturen wiesen einen von der Salzkonzentration abhängigen Durchmesser auf, der bei 100 mM KCl bei 200-230 Å lag. Diese Strukturen sind von Größe und Struktur nur schwer mit der hier dargestellten Struktur in Einklang zu bringen. In späteren Studien ist aber nachgewiesen worden, dass eine Gradientenzentrifugation bei hohen Salzkonzentrationen (400 mM KCl) zum Verlust vieler Proteine des Spleißosoms führt (Kastner and Lührmann, 1999), was einem Kollaps der Struktur bedingen könnte.

Die Isolierung spleißosomaler Komplexe auf definierten prä-mRNAs ist durch die Verwendung von RNA ,Tags' (zusätzlichen Sequenzen der prä-mRNA, die zur Bindung an eine Matrix dienen) möglich geworden. Die Homogenität der Probe lässt sich so verbessern und die Kontaminationsgefahr der Probe verringern. Die strukturelle Organisation des Komplexes B $\Delta \mathrm{U} 1$ ist vereinbar mit strukturellen Daten, die durch Aufreinigungen durch die MS2-Protein Markierungen der prä-mRNA erhalten wurden (Zhou et al., 2002). Diese Proben spleißosomaler Komplexe, die nicht in unterschiedliche Funktionszustände aufgetrennt wurden, wurden rotationsmetallbedampft um einzelne Komplexe zu visualisieren. Die einzelnen Komplexe zeigen globuläre Partikel von 400-600 Å Durchmesser, in denen häufig drei oder vier Dichtefortsätze zu erkennen sind. Dabei treten dreieckige und trapezförmige Ansichten auf, die Ansichten des Komplexes B $\Delta \mathrm{U} 1$ ähnlich sind. Allerdings wurden keine elektronenmikroskopischen Aufnahmen von negativ kontrastierten Proben gezeigt und keine statistische Auswertung vorgenommen.

Die Klassensummen und die Struktur des Komplexes $B \Delta \mathrm{U} 1$ können mit den Klassensummen und der Struktur des Komplexes C verglichen werden, der aus dem Komplex B nach der katalytischen Aktivierung hervor geht (Jurica et al., 2002; Jurica et al., 2004). Mit der MS2-Protein Aufreinigung wurden Proben des spleißosomalen Komplexes C erhalten. Diese Komplexe weisen eine Sedimentationskoeffizienten von 40S auf. Von diesen Proben wurden negativ kontrastierte elektronenmikroskopische Aufnahmen erhalten und eine 
statistische Bildanalyse angefertigt (Jurica et al., 2002). Die Ausmaße der Komplexe in den nach statistischer Analyse erhaltenen Klassensummen sind mit $270 \times 240 \AA$ angegeben (Abbildung 5.1 C und D).

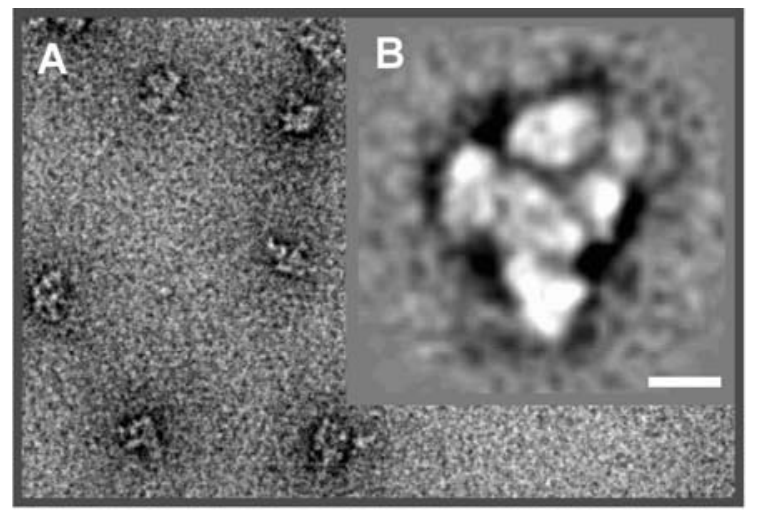

E
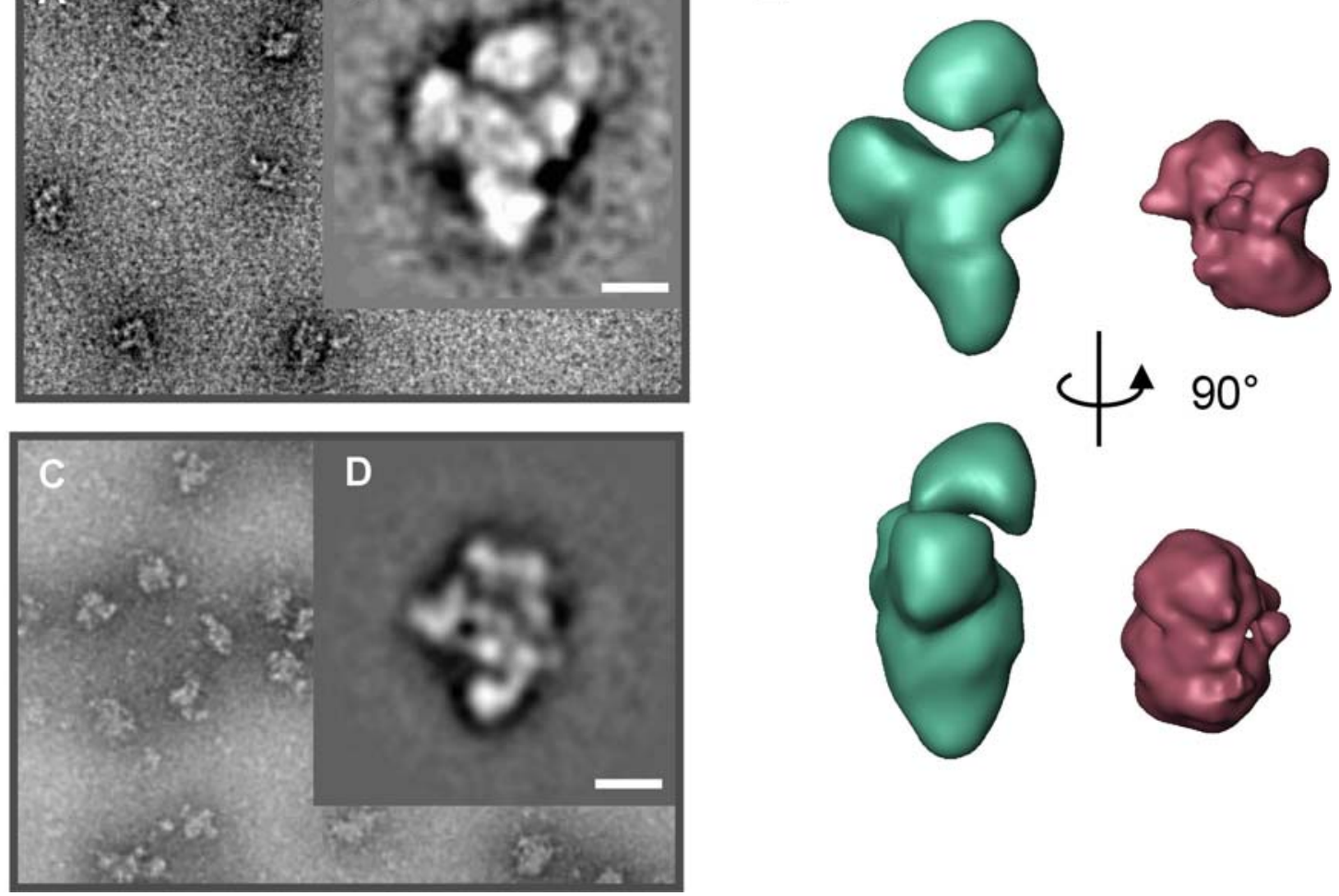

Abbildung 5.1 Vergleich der Struktur des Komplexes B $\Delta$ U1 mit der Struktur des Komplex C (Jurica et al., 2004)

A) Elektronenmikroskopische Aufnahme des Komplexes B $\Delta \mathrm{U} 1$, negativ kontrastiert mit Uranylformiat. B) häufige Klassensumme des Komplexes B $\Delta \mathrm{U} 1$ (Größenmaßstab 100 Å). C) Elektronenmikroskopische Aufnahme des Komplexes C, negativ kontrastiert mit Uranylacetat. D) häufige Klassensumme des Komplexes C (Größenmaßstab $100 \AA \AA$ ) E) Vergleich der Oberflächendarstellung der dreidimensionalen Rekonstruktionen des Komplexes B $\Delta \mathrm{U} 1$ (grün) und des Komplexes C (rot) in zwei Orientierungen. Die dreidimensionale Rekonstruktion des Komplexes C könnte in den unteren Teil der Struktur des Komplexes B $\Delta \mathrm{U} 1$ eingepasst werden.

Mit Hilfe der RCT-Methode wurde eine dreidimensionale Struktur berechnet (Abbildung 5.1 E)(Jurica et al., 2004). Die Struktur zeigt einen länglichen Partikel mit einem kleineren Dichtefortsatz an der Längsachse. Die Struktur hat damit Maße, die vergleichbar mit denen des tri-snRNPs sind. Diese relativ kleinen Maße sind nur schwer mit den massenspektrometrischen Daten zur Zusammensetzung des Komplexes in Einklang zu 
bringen, die eine kumulative Gesamtmasse aller Proteine von 6 MDa ergeben. Die Struktur ist deshalb als Kernkomplex beschrieben worden. In Übereinstimmung mit dieser Hypothese könnte die dreieckige Domäne des Komplexes B $\Delta \mathrm{U} 1$ den gesamten Komplex C aufnehmen. Es wurde allerdings kein Versuch unternommen, die stabil gebundenen Komponenten des Komplexes C zu identifizieren. Die Auflösung der Struktur ist mit $30 \AA$ ebenfalls nicht hoch genug, um einzelne snRNPs anhand ihrer Struktur sicher zu identifizieren. In der Publikation der Struktur wurde kein Vergleich mit den vorher veröffentlichten Klassensummen gezeigt und ein Teil der Klassensummen lässt sich nur schwer mit der Struktur erklären. Es hat deshalb den Anschein, dass auch im Fall des Komplexes C strukturelle Heterogenität vorhanden ist. Eine Analyse der strukturellen Heterogenität wurde von den Autoren aber nicht durchgeführt.

\subsection{Rekonstruktion von flexiblen makromolekularen Komplexen}

Strukturelle Heterogenität stellt für die elektronenmikroskopische dreidimensionale Rekonstruktion von makromolekularen Komplexen eine besondere Herausforderung dar. Der Komplex $\mathrm{B} \Delta \mathrm{U} 1$ gibt ein Beispiel für konformationelle Heterogenität durch die relative Bewegung zweier Domänen. In der statistischen zweidimensionalen Analyse können prinzipiell de novo unterschiedliche Konformere eines asymmetrischen Komplexes aufgelöst werden. Handelt es sich bei der strukturellen Heterogenität jedoch um eine kontinuierliche Bewegung zweier struktureller Domänen gegeneinander, so vervielfältigt sich die Zahl möglicher Ansichten des Komplexes in einer Orientierung. Da diese Ansichten nicht einfach in Klassen einzuteilen sind, wird nach der statistischen Analyse wahrscheinlich die über alle Konformere gemittelte Ansicht sichtbar. So kann erklärt werden, dass die unterschiedlichen Konformere des Komplexes B $\Delta \mathrm{U} 1$ in der ersten statistischen Analyse nur unzureichend aufgetrennt wurden und gemittelte Ansichten des Komplexes erhalten wurden. Erst die nachträgliche Analyse der Einzelpartikelbilder einer Orientierung des Komplexes zeigt dann vollständig die einzelnen Ansichten des Komplexes. Im Fall des Komplexes B $\Delta U 1$ kommen noch weitere Quellen struktureller Heterogenität, wie die substöchiometrische Bindung von Proteinen, zur konformationellen Heterogenität hinzu. Die Analyse der konformationellen Heterogenität ist dann vollständig erst mit einem dreidimensionalen Modell, also im Rückgriff, möglich. Ohne ein dreidimensionales Modell können die Einzelpartikelbilder nicht genau einer bestimmten Orientierung des Komplexes zugeordnet werden. Wenn aber durch die Analyse der strukturellen Heterogenität Ansichten verschiedener Konformere getrennt werden konnten, so können diese dann zur Berechnung weiterer dreidimensionaler Strukturen 
verwendet werden. Iterativ ist es so vielleicht künftig möglich, eine immer genauere Auftrennung der Konformere zu leisten.

Die strukturelle Heterogenität stellt jedoch hohe Anforderungen an den ersten Rekonstruktionsprozess der dreidimensionalen Struktur. Die Methoden des ,angular reconstitution' basieren auf der Identifikation gemeinsamer Linienprojektionen in den Klassensummen des Komplexes. Linienprojektionen reduzieren die Bildinformation allerdings sehr stark und so zeigen auch unterschiedliche Objekte gemeinsame Linienprojektionen. Die Identifikation der Linienprojektion wird durch das niedrige SignalRausch-Verhältnis zusätzlich erschwert (Penczek et al., 1996). Kommt strukturelle Heterogenität hinzu, so ist eine Identifikation der für die dreidimensionale Rekonstruktion benötigten gemeinsamen Linienprojektion meist nicht mehr sicher möglich. Als weiteres Problem bei der Berechnung der zutreffenden Struktur ergibt sich, dass die falsche Zuweisung von Projektionswinkeln in weiteren Berechnungszyklen der iterativen Verbesserung der Struktur beibehalten werden kann (Penczek et al., 1996; Yang et al., 2003). Es ist daher umso notwendiger, mehrere Startmodelle der Strukturbestimmung zu berechnen und nur bei übereinstimmenden Modellen die Berechnung fortzusetzen. Die hier vorgestellte iterative Berechnung von Startmodellen soll diesen Prozess unterstützen. Die iterative Berechnung gewährleistet, dass unabhängig von einem vermeintlichen Vorwissen über die Struktur, eine erste grobe Struktur bestimmt werden kann. Ferner ist diese Methode unabhängiger von Dichteunterschieden in den Projektionen als Methoden, die gemeinsame Linienprojektionen benutzen. Die Bildinformation wird auch nicht auf eine Linienprojektion eingeschränkt. Ein Nachteil dieser Methode ist, dass keine genaue Bestimmung der Projektionswinkel möglich ist. Außerdem lässt die stochastische Natur der Berechnung auch falsche Startmodelle zu, die dann visuell von den zutreffenden Startstrukturen unterschieden werden müssen. Ferner verlangt die Methode möglichst unterschiedlichen Partikelansichten, was wegen der präferentiellen Orientierung vieler Partikel auf dem Probenträger, eine weitere Quelle von Fehlern sein kann.

Dieser Methode gegenüber steht die etablierte Rekonstruktion dreidimensionaler Strukturen durch die ,random conical tilt' Technik. Hier sind nach der zweidimensionalen Analyse der von nicht gekipptem Probenträger erhaltenen Bilder alle Parameter der dreidimensionalen Rekonstruktion bestimmt. Die Probleme liegen hier in der Verzerrung der Struktur durch die fehlenden Winkel (Penczek et al., 1994). Die Übereinstimmung der Strukturen, die mit verschiedenen Rekonstruktionstechniken erhalten wurden, gibt allerdings erst die erforderliche Sicherheit bei der Beurteilung, ob eine Struktur zutreffend einen 
Komplex beschreibt. So können auch die Artefakte, die durch die Rekonstruktionstechnik in die dreidimensionale Struktur eingegangen sind, erkannt werden und ein Modell für die iterative Verbesserung der Struktur und die Auftrennung von Bereichen mit struktureller Heterogenität gewählt werden.

\subsection{Ausblick}

Diese Arbeit gibt einen ersten Einblick in die strukturelle Organisation des spleißosomalen Komplexes B $\Delta \mathrm{U} 1$. Es ist zu erwarten, dass sich mit der Isolierung von homogeneren Proben des Komplexes B die Auflösung der Struktur weiter verbessert. In Zukunft wird es so vielleicht möglich sein, auch snRNP Bestandteile direkt in der Struktur des Spleißosoms zu lokalisieren. Die Identifikation von strukturellen Domänen sollte in Zukunft auch durch Markierungen des Komplexes mit Antikörpern oder Oligonukleotiden möglich sein. Die asymmetrische Struktur des Komplexes und die Aufteilung in einzelne Domänen wird dabei die Lokalisierung der Markierungen erleichtern. Zusammen mit strukturellen Daten über die Organisation des Komplexes A und des Komplexes C wird diese Struktur dazu beitragen, die Interaktionen der snRNPs und zusätzlicher Faktoren im Spleißosom zu identifizieren. So soll es in Zukunft möglich sein, die Konformationswechsel des Spleißosoms bei der Assemblierung und der katalytischen Aktivierung auf einer molekularen Ebene zu beschreiben. 


\section{Literaturverzeichnis}

Abovich, N. and Rosbash, M. (1997) Cross-intron bridging interactions in the yeast commitment complex are conserved in mammals. Cell, 89, 403-412.

Achsel, T., Ahrens, K., Brahms, H., Teigelkamp, S. and Lührmann, R. (1998) The human U5220kD protein (hPrp8) forms a stable RNA-free complex with several U5-specific proteins, including an RNA unwindase, a homologue of ribosomal elongation factor EF-2, and a novel WD-40 protein. Mol. Cell. Biol., 18, 6756-6766.

Achsel, T., Brahms, H., Kastner, B., Bachi, A., Wilm, M. and Lührmann, R. (1999) A doughnut-shaped heteromer of human Sm-like proteins binds to the 3'-end of U6 snRNA, thereby facilitating U4/U6 duplex formation in vitro. EMBO J., 18, 5789-5802.

Achsel, T., Stark, H. and Lührmann, R. (2001) The Sm domain is an ancient RNA-binding motif with oligo(U) specificity. Proc. Natl. Acad. Sci. USA, 98, 3685-3689.

Adrian, M., Dubochet, J., Fuller, S.D. and Harris, J.R. (1998) Cryo-negative staining. Micron, 29, 145-160.

Adrian, M., Dubochet, J., Lepault, J. and McDowall, A.W. (1984) Cryo-electron microscopy of viruses. Nature, 308, 32-36.

Ajuh, P., Kuster, B., Panov, K., Zomerdijk, J.C., Mann, M. and Lamond, A.I. (2000) Functional analysis of the human CDC5L complex and identification of its components by mass spectrometry. EMBO J., 19, 6569-6581.

Alberts, B. (1998) The cell as a collection of protein machines: preparing the next generation of molecular biologists. Cell, 92, 291-294.

Ares, M., Jr. and Weiser, B. (1995) Rearrangement of snRNA structure during assembly and function of the spliceosome. Prog. Nucleic. Acid. Res. Mol. Biol., 50, 131-159.

Azubel, M., Wolf, S.G., Sperling, J. and Sperling, R. (2004) Three-dimensional structure of the native spliceosome by cryo-electron microscopy. Mol. Cell, 15, 833-839.

Bach, M. and Lührmann, R. (1991) Protein-RNA interactions in $20 \mathrm{~S}$ U5 snRNPs. Biochim. Biophys. Acta, 1088, 139-143.

Bach, M., Winkelmann, G. and Lührmann, R. (1989) 20S small nuclear ribonucleoprotein U5 shows a surprisingly complex protein composition. Proc. Natl. Acad. Sci. USA, 86, 60386042.

Banroques, J. and Abelson, J.N. (1989) PRP4: a protein of the yeast U4/U6 small nuclear ribonucleoprotein particle. Mol. Cell. Biol., 9, 3710-3719. 
Bartels, C., Klatt, C., Lührmann, R. and Fabrizio, P. (2002) The ribosomal translocase homologue Snu114p is involved in unwinding U4/U6 RNA during activation of the spliceosome. EMBO Rep., 3, 875-880.

Baserga, S.J. and Steitz, J.A. (1993) The diverse world of small ribonucleoproteins. In Gesteland, R.F. and Atkins, J.F. (eds.), The RNA World. Cold Spring Harbor Laboratory Press, Cold Spring Harbor, pp. 359-381.

Beck, M., Forster, F., Ecke, M., Plitzko, J.M., Melchior, F., Gerisch, G., Baumeister, W. and Medalia, O. (2004) Nuclear pore complex structure and dynamics revealed by cryoelectron tomography. Science, 306, 1387-1390.

Behrens, S.E., Tyc, K., Kastner, B., Reichelt, J. and Lührmann, R. (1993) Small nuclear ribonucleoprotein (RNP) U2 contains numerous additional proteins and has a bipartite RNP structure under splicing conditions. Mol. Cell. Biol., 13, 307-319.

Birney, E., Kumar, S. and Krainer, A.R. (1993) Analysis of the RNA-recognition motif and RS and RGG domains: conservation in metazoan pre-mRNA splicing factors. Nucleic Acids Res., 21, 5803-5816.

Black, D.L. and Pinto, A.L. (1989) U5 small nuclear ribonucleoprotein: RNA structure analysis and ATP-dependent interaction with U4/U6. Mol. Cell. Biol., 9, 3350-3359.

Blanton, S., Srinivasan, A. and Rymond, B.C. (1992) PRP38 encodes a yeast protein required for pre-mRNA splicing and maintenance of stable U6 small nuclear RNA levels. Mol. Cell. Biol., 12, 3939-3947.

Blobel, V. and Lohrmann, E. (1998) Statistische und numerische Methoden der Datenanalyse. Teubner, Stuttgart; Leipzig.

Borland, C. and van Heel, M. (1990) Classification of image data in conjugated representation spaces. J. opt. Soc. Am. A, 7, 601-610.

Branlant, C., Krol, A., Ebel, J.P., Lazar, E., Haendler, B. and Jacob, M. (1982) U2 RNA shares a structural domain with U1, U4, and U5 RNAs. EMBO J., 1, 1259-1265.

Brosi, R., Groning, K., Behrens, S.E., Lührmann, R. and Kramer, A. (1993a) Interaction of mammalian splicing factor SF3a with U2 snRNP and relation of its $60-\mathrm{kD}$ subunit to yeast PRP9. Science, 262, 102-105.

Brosi, R., Hauri, H.P. and Kramer, A. (1993b) Separation of splicing factor SF3 into two components and purification of SF3a activity. J Biol Chem, 268, 17640-17646.

Brown, J.D. and Beggs, J.D. (1992) Roles of PRP8 protein in the assembly of splicing complexes. EMBO J., 11, 3721-3729. 
Burge, C., Tuschl, T. and Sharp, P.A. (1999) Splicing of Percursors to mRNA by the Spliceosome. In Cech, T.R. and Atkins, J.F. (eds.), The RNA World. Cold Spring Harbor Laboratory Press, Cold Spring Harbor, pp. 525-560.

Burge, C.B., Padgett, R.A. and Sharp, P.A. (1998) Evolutionary fates and origins of U12-type introns. Mol. Cell, 2, 773-785.

Burgess, S.M. and Guthrie, C. (1993) A mechanism to enhance mRNA splicing fidelity: the RNA-dependent ATPase Prp16 governs usage of a discard pathway for aberrant lariat intermediates. Cell, 73, 1377-1391.

Chacon, P., Tama, F. and Wriggers, W. (2003) Mega-Dalton biomolecular motion captured from electron microscopy reconstructions. J. Mol. Biol., 326, 485-492.

Chan, S.P., Kao, D.I., Tsai, W.Y. and Cheng, S.C. (2003) The Prp19p-associated complex in spliceosome activation. Science, 302, 279-282.

Chen, C.H., Yu, W.C., Tsao, T.Y., Wang, L.Y., Chen, H.R., Lin, J.Y., Tsai, W.Y. and Cheng, S.C. (2002) Functional and physical interactions between components of the Prp19passociated complex. Nucleic Acids Res., 30, 1029-1037.

Chen, J.Y., Stands, L., Staley, J.P., Jackups, R.R., Jr., Latus, L.J. and Chang, T.H. (2001) Specific alterations of U1-C protein or U1 small nuclear RNA can eliminate the requirement of Prp28p, an essential DEAD box splicing factor. Mol. Cell, 7, 227-232.

Cheng, S.C., Tarn, W.Y., Tsao, T.Y. and Abelson, J. (1993) PRP19: a novel spliceosomal component. Mol. Cell. Biol., 13, 1876-1882.

Clark, M.W., Goelz, S. and Abelson, J. (1988) Electron microscopic identification of the yeast spliceosome. EMBO J., 7, 3829-3836.

Collins, B.M., Harrop, S.J., Kornfeld, G.D., Dawes, I.W., Curmi, P.M. and Mabbutt, B.C. (2001) Crystal structure of a heptameric Sm-like protein complex from archaea: implications for the structure and evolution of snRNPs. J. Mol. Biol., 309, 915-923.

Collins, C.A. and Guthrie, C. (2000) The question remains: is the spliceosome a ribozyme? Nat. Struct. Biol., 7, 850-854.

Crowther, R.A. and Prasad, B.V. (2004) Macromolecular assemblages - putting the pieces together. Curr. Opin. Struct. Biol., 14, 117-120.

Darst, S.A., Opalka, N., Chacon, P., Polyakov, A., Richter, C., Zhang, G. and Wriggers, W. (2002) Conformational flexibility of bacterial RNA polymerase. Proc. Natl. Acad. Sci. USA, 99, 4296-4301. 
Das, B.K., Xia, L., Palandjian, L., Gozani, O., Chyung, Y. and Reed, R. (1999) Characterization of a protein complex containing spliceosomal proteins SAPs 49, 130, 145, and 155. Mol. Cell. Biol., 19, 6796-6802.

Das, R., Zhou, Z. and Reed, R. (2000) Functional association of U2 snRNP with the ATPindependent spliceosomal complex E. Mol. Cell, 5, 779-787.

DeRosier, D. and Klug, A. (1968) Reconstruction ofthree-dimensional structures from electron micrographs. Nature, 217, 130-134.

Dix, I., Russell, C.S., O’Keefe, R.T., Newman, A.J. and Beggs, J.D. (1998) Protein-RNA interactions in the U5 snRNP of Saccharomyces cerevisiae. RNA, 4, 1675-1686.

Doherty, E.A. and Doudna, J.A. (2001) Ribozyme structures and mechanisms. Annu. Rev. Biophys. Biomol. Struct., 30, 457-475.

Dönmez, G., Hartmuth, K. and Lührmann, R. (2004) Modified nucleotides at the 5 ' end of human U2 snRNA are required for spliceosomal E-complex formation. RNA, 10, 19251933.

Du, H. and Rosbash, M. (2002) The U1 snRNP protein U1C recognizes the 5' splice site in the absence of base pairing. Nature, 419, 86-90.

Dube, P., Tavares, P., Lurz, R. and van Heel, M. (1993) The portal protein of bacteriophage SPP1: a DNA pump with 13-fold symmetry. EMBO J., 12, 1303-1309.

Fabrizio, P., Esser, S., Kastner, B. and Lührmann, R. (1994) Isolation of S. cerevisiae snRNPs: comparison of U1 and U4/U6.U5 to their human counterparts. Science, 264, 261265.

Fabrizio, P., Laggerbauer, B., Lauber, J., Lane, W.S. and Lührmann, R. (1997) An evolutionarily conserved U5 snRNP-specific protein is a GTP-binding factor closely related to the ribosomal translocase EF-2. EMBO J., 16, 4092-4106.

Fernandez, C. and Wider, G. (2003) TROSY in NMR studies of the structure and function of large biological macromolecules. Curr. Opin. Struct. Biol., 13, 570-580.

Fetzer, S., Lauber, J., Will, C.L. and Lührmann, R. (1997) The [U4/U6.U5] tri-snRNPspecific $27 \mathrm{~K}$ protein is a novel SR protein that can be phosphorylated by the snRNPassociated protein kinase. RNA, 3, 344-355.

Fischer, U., Sumpter, V., Sekine, M., Satoh, T. and Lührmann, R. (1993) Nucleo-cytoplasmic transport of U snRNPs: definition of a nuclear location signal in the Sm core domain that binds a transport receptor independently of the m3G cap. EMBO J., 12, 573-583.

Frank, J. (1996) Three-Dimensional Electron Microscopy of Macromolecular Assemblies. Academic Press, New York. 
Frank, J. and Agrawal, R.K. (2000) A ratchet-like inter-subunit reorganization of the ribosome during translocation. Nature, 406, 318-322.

Frank, J., Penczek, P.A., Agrawal, R.K., Grassucci, R.A. and Heagle, A.B. (1999) Threedimensional cryo-electron microscopy of ribosomes. Methods Enzymol., 317, 276-291.

Frilander, M.J. and Steitz, J.A. (2001) Dynamic exchanges of RNA interactions leading to catalytic core formation in the U12-dependent spliceosome. Mol. Cell, 7, 217-226.

Fu, X.D. and Maniatis, T. (1992) Isolation of a complementary DNA that encodes the mammalian splicing factor SC35. Science, 256, 535-538.

Furman, E. and Glitz, D.G. (1995) Purification of the spliceosome A-complex and its visualization by electron microscopy. J Biol Chem, 270, 15515-15522.

Golas, M.M., Sander, B., Will, C.L., Lührmann, R. and Stark, H. (2003) Molecular architecture of the multiprotein splicing factor SF3b. Science, 300, 980-984.

Golas, M.M., Sander, B., Will, C.L., Lührmann, R. and Stark, H. (2005) Major conformational change in the complex SF3b upon integration into the spliceosomal U11/U12 di-snRNP as revealed by electron cryomicroscopy. Mol. Cell, 17, 869-883.

Gottschalk, A., Neubauer, G., Banroques, J., Mann, M., Lührmann, R. and Fabrizio, P. (1999) Identification by mass spectrometry and functional analysis of novel proteins of the yeast [U4/U6.U5] tri-snRNP. EMBO J., 18, 4535-4548.

Gozani, O., Feld, R. and Reed, R. (1996) Evidence that sequence-independent binding of highly conserved U2 snRNP proteins upstream of the branch site is required for assembly of spliceosomal complex A. Genes Dev., 10, 233-243.

Gozani, O., Patton, J.G. and Reed, R. (1994) A novel set of spliceosome-associated proteins and the essential splicing factor PSF bind stably to pre-mRNA prior to catalytic step II of the splicing reaction. EMBO J., 13, 3356-3367.

Graveley, B.R. (2000) Sorting out the complexity of SR protein functions. RNA, 6, 11971211.

Guthrie, C. and Patterson, B. (1988) Spliceosomal snRNAs. Annu. Rev. Genet., 22, 387-419.

Hall, S.L. and Padgett, R.A. (1994) Conserved sequences in a class of rare eukaryotic nuclear introns with non-consensus splice sites. J. Mol. Biol., 239, 357-365.

Harauz, G. and van Heel, M. (1984) Direct threedimensionalreconstruction for macromolecular complexesfrom electron micrographs. Ultramicroscopy, 12, 309-319.

Harauz, G. and van Heel, M. (1986) Exact filters for general geometry three dimensional reconstruction. Optik, 73, 146-156. 
Hartmuth, K., Urlaub, H., Vornlocher, H.P., Will, C.L., Gentzel, M., Wilm, M. and Lührmann, R. (2002) Protein composition of human prespliceosomes isolated by a tobramycin affinity-selection method. Proc. Natl. Acad. Sci. USA, 99, 16719-16724.

Hausner, T.P., Giglio, L.M. and Weiner, A.M. (1990) Evidence for base-pairing between mammalian U2 and U6 small nuclear ribonucleoprotein particles. Genes Dev., 4, 21462156.

Heinrichs, V., Bach, M., Winkelmann, G. and Lührmann, R. (1990) U1-specific protein C needed for efficient complex formation of U1 snRNP with a 5' splice site. Science, 247, 69-72.

Hochleitner, E.O., Kastner, B., Frohlich, T., Schmidt, A., Lührmann, R., Arnold, G. and Lottspeich, F. (2005) Protein stoichiometry of a multiprotein complex, the human spliceosomal U1 small nuclear ribonucleoprotein: absolute quantification using isotopecoded tags and mass spectrometry. J Biol Chem, 280, 2536-2542.

Hoet, R.M., Kastner, B., Lührmann, R. and van Venrooij, W.J. (1993) Purification and characterization of human autoantibodies directed to specific regions on U1RNA; recognition of native U1RNP complexes. Nucleic Acids Res., 21, 5130-5136.

Huang, M., Rech, J.E., Northington, S.J., Flicker, P.F., Mayeda, A., Krainer, A.R. and LeStourgeon, W.M. (1994) The C-protein tetramer binds 230 to 240 nucleotides of premRNA and nucleates the assembly of $40 \mathrm{~S}$ heterogeneous nuclear ribonucleoprotein particles. Mol. Cell. Biol., 14, 518-533.

Huppler, A., Nikstad, L.J., Allmann, A.M., Brow, D.A. and Butcher, S.E. (2002) Metal binding and base ionization in the U6 RNA intramolecular stem-loop structure. Nat. Struct. Biol., 9, 431-435.

Izaurralde, E., Lewis, J., McGuigan, C., Jankowska, M., Darzynkiewicz, E. and Mattaj, I.W. (1994) A nuclear cap binding protein complex involved in pre-mRNA splicing. Cell, 78, 657-668.

Johnson, T.L. and Abelson, J. (2001) Characterization of U4 and U6 interactions with the 5' splice site using a S. cerevisiae in vitro trans-splicing system. Genes Dev., 15, 1957-1970.

Joyeux, L. and Penczek, P.A. (2002) Efficiency of 2D alignment methods. Ultramicroscopy, 92, 33-46.

Jurica, M.S., Licklider, L.J., Gygi, S.R., Grigorieff, N. and Moore, M.J. (2002) Purification and characterization of native spliceosomes suitable for three-dimensional structural analysis. $R N A, \mathbf{8}, 426-439$.

Jurica, M.S., Sousa, D., Moore, M.J. and Grigorieff, N. (2004) Three-dimensional structure of C complex spliceosomes by electron microscopy. Nat. Struct. Mol. Biol., 11, 265-269. 
Kambach, C., Walke, S. and Nagai, K. (1999a) Structure and assembly of the spliceosomal small nuclear ribonucleoprotein particles. Curr. Opin. Struct. Biol., 9, 222-230.

Kambach, C., Walke, S., Young, R., Avis, J.M., de la Fortelle, E., Raker, V.A., Lührmann, R., Li, J. and Nagai, K. (1999b) Crystal structures of two Sm protein complexes and their implications for the assembly of the spliceosomal snRNPs. Cell, 96, 375-387.

Kastner, B. (1998) Purification and electron microscopy of spliceosomal snRNPs. In Schenkel, J. (ed.), RNP particles, splicing and Autoimmune Diseases. Springer-Verlag, Berlin; Heidelberg; New York, pp. 95-140.

Kastner, B., Bach, M. and Lührmann, R. (1990) Electron microscopy of small nuclear ribonucleoprotein (snRNP) particles U2 and U5: evidence for a common structuredetermining principle in the major U snRNP family. Proc. Natl. Acad. Sci. USA, 87, 17101714.

Kastner, B., Bach, M. and Lührmann, R. (1991) Electron microscopy of U4/U6 snRNP reveals a Y-shaped U4 and U6 RNA containing domain protruding from the U4 core RNP. J. Cell Biol., 112, 1065-1072.

Kastner, B., Kornstadt, U., Bach, M. and Lührmann, R. (1992) Structure of the small nuclear RNP particle U1: identification of the two structural protuberances with RNP-antigens A and 70K. J. Cell Biol., 116, 839-849.

Kastner, B. and Lührmann, R. (1989) Electron microscopy of U1 small nuclear ribonucleoprotein particles: shape of the particle and position of the 5' RNA terminus. EMBO J., 8, 277-286.

Kastner, B. and Lührmann, R. (1999) Purification of U small nuclear ribonucleoprotein particles. Methods Mol. Biol., 118, 289-298.

Kellenberger, E., Haner, M. and Wurtz, M. (1982) The wrapping phenomenon in air-dried and negatively stained preparations. Ultramicroscopy, 9, 139-150.

Kim, C.H. and Abelson, J. (1996) Site-specific crosslinks of yeast U6 snRNA to the premRNA near the 5' splice site. RNA, 2, 995-1010.

Kirkpatrick, S., Gelatt, C.D. and Vecchi, M.P. (1983) Optimization by Simulated Annealing. Science, 220, 671-680.

Kohtz, J.D., Jamison, S.F., Will, C.L., Zuo, P., Lührmann, R., Garcia-Blanco, M.A. and Manley, J.L. (1994) Protein-protein interactions and 5'-splice-site recognition in mammalian mRNA precursors. Nature, 368, 119-124.

Krämer, A., Gruter, P., Groning, K. and Kastner, B. (1999) Combined biochemical and electron microscopic analyses reveal the architecture of the mammalian U2 snRNP. J. Cell Biol., 145, 1355-1368. 
Krecic, A.M. and Swanson, M.S. (1999) hnRNP complexes: composition, structure, and function. Curr. Opin. Cell Biol., 11, 363-371.

Kuhn, A.N., Li, Z. and Brow, D.A. (1999) Splicing factor Prp8 governs U4/U6 RNA unwinding during activation of the spliceosome. Mol. Cell, 3, 65-75.

Kuhn, A.N., Reichl, E.M. and Brow, D.A. (2002) Distinct domains of splicing factor Prp8 mediate different aspects of spliceosome activation. Proc. Natl. Acad. Sci. USA, 99, 91459149.

Laggerbauer, B., Achsel, T. and Lührmann, R. (1998) The human U5-200kD DEXH-box protein unwinds U4/U6 RNA duplices in vitro. Proc. Natl. Acad. Sci. USA, 95, 41884192.

Laggerbauer, B., Liu, S., Makarov, E., Vornlocher, H.P., Makarova, O., Ingelfinger, D., Achsel, T. and Lührmann, R. (2005) The human U5 snRNP 52K protein (CD2BP2) interacts with U5-102K (hPrp6), a U4/U6.U5 tri-snRNP bridging protein, but dissociates upon tri-snRNP formation. RNA, 11, 598-608.

Lake, J.A. (1976) Ribosome structure determined by electron microscopy of Escherichia coli small subunits, large subunits and monomeric ribosomes. J. Mol. Biol., 105, 131-139.

Lauber, J., Fabrizio, P., Teigelkamp, S., Lane, W.S., Hartmann, E. and Lührmann, R. (1996) The HeLa 200 kDa U5 snRNP-specific protein and its homologue in Saccharomyces cerevisiae are members of the DEXH-box protein family of putative RNA helicases. EMBO J., 15, 4001-4015.

Le Hir, H., Moore, M.J. and Maquat, L.E. (2000) Pre-mRNA splicing alters mRNP composition: evidence for stable association of proteins at exon-exon junctions. Genes Dev., 14, 1098-1108.

Lesser, C.F. and Guthrie, C. (1993) Mutations in U6 snRNA that alter splice site specificity: implications for the active site. Science, 262, 1982-1988.

Liu, Z.R., Laggerbauer, B., Lührmann, R. and Smith, C.W. (1997) Crosslinking of the U5 snRNP-specific 116-kDa protein to RNA hairpins that block step 2 of splicing. RNA, 3, 1207-1219.

Madhani, H.D. and Guthrie, C. (1992) A novel base-pairing interaction between U2 and U6 snRNAs suggests a mechanism for the catalytic activation of the spliceosome. Cell, 71, 803-817.

Madhani, H.D. and Guthrie, C. (1994) Randomization-selection analysis of snRNAs in vivo: evidence for a tertiary interaction in the spliceosome. Genes Dev., 8, 1071-1086.

Makarov, E.M., Makarova, O.V., Urlaub, H., Gentzel, M., Will, C.L., Wilm, M. and Lührmann, R. (2002) Small nuclear ribonucleoprotein remodeling during catalytic activation of the spliceosome. Science, 298, 2205-2208. 
Makarova, O.V., Makarov, E.M., Liu, S., Vornlocher, H.P. and Lührmann, R. (2002) Protein $61 \mathrm{~K}$, encoded by a gene (PRPF31) linked to autosomal dominant retinitis pigmentosa, is required for U4/U6*U5 tri-snRNP formation and pre-mRNA splicing. EMBO J., 21, 11481157.

Makarova, O.V., Makarov, E.M. and Lührmann, R. (2001) The 65 and 110 kDa SR-related proteins of the U4/U6.U5 tri-snRNP are essential for the assembly of mature spliceosomes. EMBO J., 20, 2553-2563.

Makarova, O.V., Makarov, E.M., Urlaub, H., Will, C.L., Gentzel, M., Wilm, M. and Lührmann, R. (2004) A subset of human 35S U5 proteins, including Prp19, function prior to catalytic step 1 of splicing. EMBO J., 23, 2381-2391.

Maroney, P.A., Romfo, C.M. and Nilsen, T.W. (2000) Functional recognition of 5' splice site by U4/U6.U5 tri-snRNP defines a novel ATP-dependent step in early spliceosome assembly. Mol. Cell, 6, 317-328.

Mattaj, I.W. (1986) Cap trimethylation of U snRNA is cytoplasmic and dependent on U snRNP protein binding. Cell, 46, 905-911.

Meister, G., Hannus, S., Plottner, O., Baars, T., Hartmann, E., Fakan, S., Laggerbauer, B. and Fischer, U. (2001) SMNrp is an essential pre-mRNA splicing factor required for the formation of the mature spliceosome. EMBO J., 20, 2304-2314.

Michaud, S. and Reed, R. (1991) An ATP-independent complex commits pre-mRNA to the mammalian spliceosome assembly pathway. Genes Dev., 5, 2534-2546.

Moore, M.J., Query, C.C. and Sharp, P.A. (1993) Splicing of precursors to mRNA by the spliceosome. In Gesteland, R.F. and Atkins, J.F. (eds.), The RNA World. Cold Spring Harbor Laboratory Press, Cold Spring Harbor, pp. 303-357.

Nelissen, R.L., Will, C.L., van Venrooij, W.J. and Lührmann, R. (1994) The association of the U1-specific 70K and C proteins with U1 snRNPs is mediated in part by common $\mathrm{U}$ snRNP proteins. EMBO J., 13, 4113-4125.

Newman, A.J. (1997) The role of U5 snRNP in pre-mRNA splicing. EMBO J., 16, 57975800 .

Nilsen, T.W (1994) RNA-RNA interactions in the spliceosome: unraveling the ties that bind. Cell, 78, 1-4.

Nilsen, T.W. (1998) RNA-RNA interactions in nuclear pre-mRNA splicing. In Simons, R. and Grunberg-Manago, M. (eds.), RNA Structure and Function. Cold Spring Harbor Press, Cold Spring Harbor, pp. 279-307.

Nottrott, S., Hartmuth, K., Fabrizio, P., Urlaub, H., Vidovic, I., Ficner, R. and Lührmann, R. (1999) Functional interaction of a novel 15.5kD [U4/U6.U5] tri-snRNP protein with the 5' stem-loop of U4 snRNA. EMBO J., 18, 6119-6133. 
Nottrott, S., Urlaub, H. and Lührmann, R. (2002) Hierarchical, clustered protein interactions with U4/U6 snRNA: a biochemical role for U4/U6 proteins. EMBO J., 21, 5527-5538.

Orlova, E.V. and Saibil, H.R. (2004) Structure determination of macromolecular assemblies by single-particle analysis of cryo-electron micrographs. Curr. Opin. Struct. Biol., 14, 584-590.

Padgett, R.A., Grabowski, P.J., Konarska, M.M., Seiler, S. and Sharp, P.A. (1986) Splicing of messenger RNA precursors. Annu. Rev. Biochem., 55, 1119-1150.

Parker, R. and Siliciano, P.G. (1993) Evidence for an essential non-Watson-Crick interaction between the first and last nucleotides of a nuclear pre-mRNA intron. Nature, 361, 660662.

Patel, A.A. and Steitz, J.A. (2003) Splicing double: insights from the second spliceosome. Nat. Rev. Mol. Cell. Biol., 4, 960-970.

Penczek, P.A., Grassucci, R.A. and Frank, J. (1994) The ribosome at improved resolution: new techniques for merging and orientation refinement in 3D cryo-electron microscopy of biological particles. Ultramicroscopy, 53, 251-270.

Penczek, P.A., Zhu, J. and Frank, J. (1996) A common-lines based method for determining orientations for N > 3 particle projections simultaneously. Ultramicroscopy, 63, 205-218.

Perriman, R., Barta, I., Voeltz, G.K., Abelson, J. and Ares, M., Jr. (2003) ATP requirement for Prp5p function is determined by Cus2p and the structure of U2 small nuclear RNA. Proc. Natl. Acad. Sci. U S A, 100, 13857-13862.

Plitzko, J.M., Frangakis, A.S., Nickell, S., Forster, F., Gross, A. and Baumeister, W. (2002) In vivo veritas: electron cryotomography of cells. Trends in Biotechnology, 20, S40-S44.

Query, C.C., Bentley, R.C. and Keene, J.D. (1989) A specific 31-nucleotide domain of U1 RNA directly interacts with the 70K small nuclear ribonucleoprotein component. Mol. Cell. Biol., 9, 4872-4881.

Query, C.C., Moore, M.J. and Sharp, P.A. (1994) Branch nucleophile selection in pre-mRNA splicing: evidence for the bulged duplex model. Genes Dev., 8, 587-597.

Query, C.C., Strobel, S.A. and Sharp, P.A. (1996) Three recognition events at the branch-site adenine. EMBO J., 15, 1392-1402.

Radermacher, M., Wagenknecht, T., Verschoor, A. and Frank, J. (1987) Three-dimensional reconstruction from a single-exposure, random conical tilt series applied to the 50S ribosomal subunit of Escherichia coli. J. Microsc, 146 (Pt 2), 113-136. 
Raker, V.A., Hartmuth, K., Kastner, B. and Lührmann, R. (1999) Spliceosomal U snRNP core assembly: Sm proteins assemble onto an Sm site RNA nonanucleotide in a specific and thermodynamically stable manner. Mol. Cell. Biol., 19, 6554-6565.

Rappsilber, J., Ajuh, P., Lamond, A.I. and Mann, M. (2001) SPF30 is an essential human splicing factor required for assembly of the U4/U5/U6 tri-small nuclear ribonucleoprotein into the spliceosome. J Biol Chem, 276, 31142-31150.

Reddy, R. and Busch, H. (1988) Small nuclear RNAs: RNA sequences, structure and modifications. In Birnstiel, M.L. (ed.), Structure and Function of Major and Minor Small Nuclear Ribonucleoprotein Particles. Springer-Verlag, Berlin; Heidelberg; New York, pp. $1-37$.

Reed, R. (2000) Mechanisms of fidelity in pre-mRNA splicing. Curr. Opin. Cell. Biol., 12, 340-345.

Reed, R., Griffith, J. and Maniatis, T. (1988) Purification and visualization of native spliceosomes. Cell, 53, 949-961.

Reed, R. and Palandjian, L. (1997) Spliceosome assembly. In Krainer, A.R. (ed.), Eukaryotic $m R N A$ processing. IRL Press, Oxford, pp. 1-37.

Reyes, J.L., Kois, P., Konforti, B.B. and Konarska, M.M. (1996) The canonical GU dinucleotide at the 5' splice site is recognized by p220 of the U5 snRNP within the spliceosome. RNA, 2, 213-225.

Roscigno, R.F. and Garcia-Blanco, M.A. (1995) SR proteins escort the U4/U6.U5 tri-snRNP to the spliceosome. RNA, 1, 692-706.

Ruskin, B., Zamore, P.D. and Green, M.R. (1988) A factor, U2AF, is required for U2 snRNP binding and splicing complex assembly. Cell, 52, 207-219.

Ryan, D.E., Kim, C.H., Murray, J.B., Adams, C.J., Stockley, P.G. and Abelson, J. (2004) New tertiary constraints between the RNA components of active yeast spliceosomes: a photo-crosslinking study. RNA, 10, 1251-1265.

Saibil, H.R. (2000) Conformational changes studied by cryo-electron microscopy. Nat. Struct. Biol., 7, 711-714.

Sander, B., Golas, M.M. and Stark, H. (2003) Corrim-based alignment for improved speed in single-particle image processing. J. Struct. Biol., 143, 219-228.

Sashital, D.G., Cornilescu, G., McManus, C.J., Brow, D.A. and Butcher, S.E. (2004) U2-U6 RNA folding reveals a group II intron-like domain and a four-helix junction. Nat. Struct. Mol. Biol., 11, 1237-1242. 
Sawa, H. and Shimura, Y. (1992) Association of U6 snRNA with the 5'-splice site region of pre-mRNA in the spliceosome. Genes Dev., 6, 244-254.

Scherly, D., Boelens, W., van Venrooij, W.J., Dathan, N.A., Hamm, J. and Mattaj, I.W. (1989) Identification of the RNA binding segment of human U1 A protein and definition of its binding site on U1 snRNA. EMBO J., 8, 4163-4170.

Schwelnus, W., Richert, K., Opitz, F., Gross, T., Habara, Y., Tani, T. and Kaufer, N.F. (2001) Fission yeast Prp4p kinase regulates pre-mRNA splicing by phosphorylating a non-SRsplicing factor. EMBO Rep., 2, 35-41.

Seipelt, R.L., Zheng, B., Asuru, A. and Rymond, B.C. (1999) U1 snRNA is cleaved by RNase III and processed through an Sm site-dependent pathway. Nucleic Acids Res., 27, 587-595.

Serysheva, II, Orlova, E.V., Chiu, W., Sherman, M.B., Hamilton, S.L. and van Heel, M. (1995) Electron cryomicroscopy and angular reconstitution used to visualize the skeletal muscle calcium release channel. Nat. Struct. Biol., 2, 18-24.

Singh, R. and Reddy, R. (1989) Gamma-monomethyl phosphate: a cap structure in spliceosomal U6 small nuclear RNA. Proc. Natl. Acad. Sci. USA, 86, 8280-8283.

Sontheimer, E.J. and Steitz, J.A. (1993) The U5 and U6 small nuclear RNAs as active site components of the spliceosome. Science, 262, 1989-1996.

Staley, J.P. and Guthrie, C. (1998) Mechanical devices of the spliceosome: motors, clocks, springs, and things. Cell, 92, 315-326.

Staley, J.P. and Guthrie, C. (1999) An RNA switch at the 5' splice site requires ATP and the DEAD box protein Prp28p. Mol. Cell, 3, 55-64.

Stark, H. (2002) Three-Dimensional Electron Cryomicroscopy of Ribosomes. Curr. Protein Pept. Sci., 3, 79-91.

Stark, H., Dube, P., Lührmann, R. and Kastner, B. (2001) Arrangement of RNA and proteins in the spliceosomal U1 small nuclear ribonucleoprotein particle. Nature, 409, 539-542.

Steinkilberg, M. and Schramm, H.J. (1980) Eine verbesserte Drehkorrelationsmethode für die Strukturbestimmung biologischer Makromoleküle durch Mittelung elektronenmikroskopischer Bilder. Hoppe-Seyler’s Z. Physiol. Chem., 361, 1363-1369.

Stevens, S.W., Barta, I., Ge, H.Y., Moore, R.E., Young, M.K., Lee, T.D. and Abelson, J. (2001) Biochemical and genetic analyses of the U5, U6, and U4/U6 x U5 small nuclear ribonucleoproteins from Saccharomyces cerevisiae. RNA, 7, 1543-1553.

Stevens, S.W., Ryan, D.E., Ge, H.Y., Moore, R.E., Young, M.K., Lee, T.D. and Abelson, J. (2002) Composition and functional characterization of the yeast spliceosomal pentasnRNP. Mol. Cell, 9, 31-44. 
Sun, J.S. and Manley, J.L. (1995) A novel U2-U6 snRNA structure is necessary for mammalian mRNA splicing. Genes Dev., 9, 843-854.

Tarn, W.Y., Hsu, C.H., Huang, K.T., Chen, H.R., Kao, H.Y., Lee, K.R. and Cheng, S.C. (1994) Functional association of essential splicing factor(s) with PRP19 in a protein complex. EMBO J., 13, 2421-2431.

Teigelkamp, S., Achsel, T., Mundt, C., Gothel, S.F., Cronshagen, U., Lane, W.S., Marahiel, M. and Lührmann, R. (1998) The 20kD protein of human [U4/U6.U5] tri-snRNPs is a novel cyclophilin that forms a complex with the U4/U6-specific $60 \mathrm{kD}$ and $90 \mathrm{kD}$ proteins. RNA, 4, 127-141.

Teigelkamp, S., Newman, A.J. and Beggs, J.D. (1995) Extensive interactions of PRP8 protein with the 5' and 3' splice sites during splicing suggest a role in stabilization of exon alignment by U5 snRNA. EMBO J., 14, 2602-2612.

Tischendorf, G.W., Zeichhardt, H. and Stoffler, G. (1974) Determination of the location of proteins L14, L17, L18, L19, L22, L23 on the surface of the 5oS ribosomal subunit of Escherichia coli by immune electron microscopy. Mol. Gen. Genet., 134, 187-208.

Urlaub, H., Raker, V.A., Kostka, S. and Lührmann, R. (2001) Sm protein-Sm site RNA interactions within the inner ring of the spliceosomal snRNP core structure. EMBO J., 20, 187-196.

Valadkhan, S. and Manley, J.L. (2000) A tertiary interaction detected in a human U2-U6 snRNA complex assembled in vitro resembles a genetically proven interaction in yeast. $R N A$, 6, 206-219.

Valadkhan, S. and Manley, J.L. (2001) Splicing-related catalysis by protein-free snRNAs. Nature, 413, 701-707.

van Heel, M. (1984) Multivariate statistical classification of noisy images (randomly oriented biological macromolecules). Ultramicroscopy, 13, 165-183.

van Heel, M. (1987) Angular reconstitution: a posteriori assignment of projection directions for 3D reconstruction. Ultramicroscopy, 21, 111-123.

van Heel, M. (1989) Classification of very large electron microscopical image data sets. Optik, 82, 114-126.

van Heel, M. (1992) Correlation functions revisited. Ultramicroscopy, 46, 304-316.

van Heel, M. and Frank, J. (1981) Use of multivariate statistics in analysing the images of biological macromolecules. Ultramicroscopy, 6, 187-194. 
van Heel, M., Gowen, B., Matadeen, R., Orlova, E.V., Finn, R., Pape, T., Cohen, D., Stark, H., Schmidt, R., Schatz, M. and Patwardhan, A. (2000) Single-particle electron cryomicroscopy: towards atomic resolution. Q. Rev. Biophys., 33, 307-369.

van Heel, M., Harauz, G., Orlova, E.V., Schmidt, R. and Schatz, M. (1996) A new generation of the IMAGIC image processing system. J. Struct. Biol., 116, 17-24.

van Heel, M. and Stoffler-Meilicke, M. (1985) Characteristic views of E. coli and B. Stearothermophilus 30S ribosomal subunits in the electron microscope. EMBO J., 4, 23892395.

van Heel, M., Winkler, H.P. and Orlova, E.V. (1992) Structure analysis of iceembedded single particles. Scanning Microsc. Suppl., 6, 23-42.

Vidal, V.P., Verdone, L., Mayes, A.E. and Beggs, J.D. (1999) Characterization of U6 snRNAprotein interactions. $R N A, 5,1470-1481$.

Walz, J., Erdmann, A., Kania, M., Typke, D., Koster, A.J. and Baumeister, W. (1998) 26S proteasome structure revealed by three-dimensional electron microscopy. J. Struct. Biol., 121, 19-29.

Wassarman, D.A. and Steitz, J.A. (1992) Interactions of small nuclear RNA's with precursor messenger RNA during in vitro splicing. Science, 257, 1918-1925.

Will, C.L. and Lührmann, R. (1997a) Protein functions in pre-mRNA splicing. Curr. Opin. Cell Biol., 9, 320-328.

Will, C.L. and Lührmann, R. (1997b) snRNP structure and function. In Krainer, A.R. (ed.), Eukaryotic mRNA Processing. IRL Press, Oxford, pp. 130-173.

Will, C.L., Urlaub, H., Achsel, T., Gentzel, M., Wilm, M. and Lührmann, R. (2002) Characterization of novel SF3b and 17S U2 snRNP proteins, including a human Prp5p homologue and an SF3b DEAD-box protein. EMBO J., 21, 4978-4988.

Wise, J.A. (1993) Guides to the heart of the spliceosome. Science, 262, 1978-1979.

Wyatt, J.R., Sontheimer, E.J. and Steitz, J.A. (1992) Site-specific cross-linking of mammalian U5 snRNP to the 5' splice site before the first step of pre-mRNA splicing. Genes Dev., 6, 2542-2553.

Yang, S., Yu, X., Galkin, V.E. and Egelman, E.H. (2003) Issues of resolution and polymorphism in single-particle reconstruction. J. Struct. Biol., 144, 162-171.

Yean, S.L. and Lin, R.J. (1991) U4 small nuclear RNA dissociates from a yeast spliceosome and does not participate in the subsequent splicing reaction. Mol. Cell. Biol., 11, 55715577. 
Yean, S.L., Wuenschell, G., Termini, J. and Lin, R.J. (2000) Metal-ion coordination by U6 small nuclear RNA contributes to catalysis in the spliceosome. Nature, 408, 881-884.

Yu, Y.T., Shu, M.D. and Steitz, J.A. (1998) Modifications of U2 snRNA are required for snRNP assembly and pre-mRNA splicing. EMBO J., 17, 5783-5795.

Yusupov, M.M., Yusupova, G.Z., Baucom, A., Lieberman, K., Earnest, T.N., Cate, J.H. and Noller, H.F. (2001) Crystal structure of the ribosome at 5.5 A resolution. Science, 292, 883-896.

Zhou, Z., Sim, J., Griffith, J. and Reed, R. (2002) Purification and electron microscopic visualization of functional human spliceosomes. Proc. Natl. Acad. Sci. USA, 99, 1220312207.

Zhuang, X., Kim, H., Pereira, M.J., Babcock, H.P., Walter, N.G. and Chu, S. (2002) Correlating structural dynamics and function in single ribozyme molecules. Science, 296, 1473-1476.

Zhuang, Y. and Weiner, A.M. (1989) A compensatory base change in human U2 snRNA can suppress a branch site mutation. Genes Dev., 3, 1545-1552. 


\section{Anhang}

\section{Abkürzungsverzeichnis:}

$\Lambda$

A

$\AA$

ATP

bzw.

BBP

C

ca.

CCF

CBC

CBP

CTF

D

d

Da

$\mathrm{DExH} / \mathrm{D}$

DTT

E. coli

engl.

F

$f_{d}$

$f_{n}$

FSC

$\mathrm{h}$

HAC

HEAT

HEPES

hnRNP

LSm

M

$m^{7} G$
Eigenwertmatrix

Adenosin

Ångström (0,1 nm)

Adenosintriphosphat

beziehungsweise

,branchpoint binding protein'

Korrelationskoeffizienten / Cytosin

circa

Kreuzkorrelationsfunktion

'cap binding complex'

,cap binding protein'

Kontrast-Transfer Funktion

Partikeldurchmesser / dreidimensionale Struktur

Bild

Dalton (g/mol)

Aspartat, Glutamat, eine beliebige Aminosäure, Histidin oder Apartat

Dithiothreitol

Escherichia coli

englisch

Strukturfaktor

Ortsfrequenz der Auflösung

Nyquistfrequenz

Fourier-Schalenkorrelation

human (als Präfix)

'hierachical ascendant classification'

Huntingtin protein, elongation faktor 3, Alpha regolatory subunit of PP2A, PI3-Kinase TOR

N-2-Hydroxyethylpiperazin-N-2-ethansulfonsäure

'heterogneous nuclear ribonucleoprotein'

,Like Sm'

Molarität / Metrik der Eigenwert-Eigenvektoranalyse

N7-Monomethylguanosin 


\begin{tabular}{|c|c|}
\hline $\mathrm{m}_{3} \mathrm{G}$ & 2,2,7-Trimethylguanosin \\
\hline MCF & 'mutual correlation funktion' \\
\hline MRA & 'multi reference alignment' \\
\hline MSA & multivariate statistische Analyse \\
\hline MW & ,moleculer weight' (g/mol) \\
\hline$N$ & Metrik der Eigenwert-Eigenvektoranalyse \\
\hline $\mathrm{Nt}$ & Nukleotide \\
\hline NTC & 'Nineteen complex' \\
\hline NP-40 & Nonidet P-40 \\
\hline prä-mRNA & Vorläufer-mRNA \\
\hline RCT & 'random conical tilt' \\
\hline RNA & Ribonukleinsäure \\
\hline RRM & 'RNA recognition motif' \\
\hline RS & Serin, Arginin \\
\hline S & Svedberg-Einheiten \\
\hline S. cerevisiae & Saccharomyces cerevisiae \\
\hline SDS & 'sodium dodecyl sulfate' \\
\hline SF & 'splicing factor' \\
\hline snRNA & 'small nuclear RNA' \\
\hline Snu & 'snurp associated protein' \\
\hline SPF & 'splicing factor' \\
\hline SR & Arginin, Serin \\
\hline $\mathrm{P}$ & Pixelgröße, Projektionswinkel \\
\hline Prp & 'precursor of RNA processing' \\
\hline $\mathrm{T}$ & Thymidin \\
\hline $\mathrm{U}$ & Uracil, Eigenvektormatrix \\
\hline U2AF65 & 'U2 auxiliary factor' \\
\hline U snRNP & 'uridin rich small nuclear ribonucleo particles' \\
\hline $\mathrm{v} / \mathrm{v}$ & Volumenprozent \\
\hline $\mathrm{w} / \mathrm{v}$ & Gewichtsprozent \\
\hline
\end{tabular}




\section{Danksagung}

An dieser Stelle möchte ich mich zuerst bei Dr. Holger Stark dafür bedanken, dass er mir die Arbeit an diesem Projekt ermöglicht und mich in die Arbeit mit dem Elektronenmikroskop eingeführt hat. Seine Anregungen und Ratschläge waren mir stets eine große Hilfe. Die freundliche und exzellente Betreuung hat mir die Arbeit immer sehr erleichtert.

Für das hervorragende Arbeitsumfeld möchte ich mich bei Prof. Reinhard Lührmann bedanken. Die Diskussionen mit ihm, besonders beim Verfassen der Publikation, waren für mich eine große Hilfe.

Mein besonderer Dank gilt Prof. Ralf Ficner für die Betreuung der Arbeit.

Bei Prof. Reinhard Jahn möchte ich mich für die Übernahme des Korreferats bedanken.

Für Hilfsbereitschaft während meiner Arbeit danke ich allen Mitgliedern der Arbeitsgruppe Elektronenkryomikroskopie. Dr. Prakash Dube danke ich besonders für die Hilfe bei der Probenträger-Herstellung und seine Erläuterungen über die Prinzipien der Elektronenmikroskopie. Bei Niels Fischer möchte ich mich für die vielen Diskussionen über die Elektronenmikroskopie bedanken, bei denen ich immer etwas gelernt habe. Monika Golas danke ich für ihre Unterstützung während meiner Promotion und die Etablierung der ProbenPräparationstechnik. Ohne Björn Sanders hervorragende Software wären viele Berechnungen nicht möglich gewesen; Ihm gebührt mein ganz besonderer Dank. Thomas Hauling danke ich für die Diskussionen über ribosomale Komplexe. Bei Mario Lüttich möchte ich mich für die Betreuung der Rechner bedanken.

Dr. Dietmar Riedel und Dr. Dirk Wenzel von der Arbeitsgruppe Elektronenmikroskopie möchte ich für ihre Unterstützung und die Bereitstellung ihres Mikroskops danken.

Für die Aufbereitung der Proben danke ich der Arbeitsgruppe Zelluläre Biochemie. Ein ganz besonderer Dank gebührt Dr. Evgeny Makarov für die vielen Stunden, die er mit der Isolierung von spleißosomalen Komplexen für die elektronenmikroskopische Analyse verbracht hat. Ohne die hervorragende Qualität der Proben wäre dieses Projekt nicht möglich gewesen. Bei Dr. Olga Makarova möchte ich mich für die Isolierung der spleißosomalen Komplexe bedanken. Mein Dank gilt Dr. Reinhard Rauhut für die Erläuterungen zu Proteininteraktionen. Die Gespräche mit Dr. Berthold Kastner sind mir stets eine große Hilfe 
gewesen und haben das Verfassen der Publikation sehr erleichtert. Zudem sind seine Arbeiten über die elektronenmikroskopische Struktur von snRNPs für diese Dissertation unverzichtbar gewesen.

Für ihre Ratschläge beim Verfassen dieser Arbeit danke ich: Björn, Heike, Ilonka, Jochen, Markus, Monika, Niels, Nina, Prakash, Simon und Thomas. 



\section{Lebenslauf}

\section{Persönliche Daten}

Name:

Daniel Böhringer

geboren am:

30. Mai 1977 in Siegen

Anschrift:

Valentinsbreite 1

37077 Göttingen

Staatsangehörigkeit:

deutsch

\section{Schulbildung}

1987-1996

17. Juni 1996

Evangelisches Gymnasium Siegen-Weidenau

Abitur

\section{Hochschulbildung}

$1996-1998$

Studium der Biochemie an der Ruhr-Universität Bochum

$1998-2001$

November 1999 - März 2000

Mai 2000 - Juni 2000

Mai 2001 - November 2001

15. November 2001

2002 - heute

Studium der Biochemie an der Universität Bayreuth

Auslandssemester an der University of York

(Großbritannien).

Projektarbeit bei Prof. Dr. G. Krauss, Thema: “AFM

Studien an Protein-DNA-Komplexen”

Diplomarbeit bei Prof. Dr. F. X. Schmid, Thema:

“Mutationsanalysen der Faltung des Kälteschockproteins

CspB aus Bacillus subtilis”

Diplom in Biochemie

Promotion bei Dr. H. Stark in der Abteilung

Elektronenkryomikroskopie am Max-Planck-Institut für biophysikalische Chemie in Göttingen, Thema:

“Elektronenmikroskopische 3D Strukturbestimmung des Spleißosoms“

\section{Beiträge zu Konferenzen:}

Ninth Annual Meeting of the RNA Society

Madison, Wisconsin, USA.

Plenarvortrag: "Three-dimensional structure of a precatalytic human spliceosomal complex B” 


\section{Publikationen:}

2002 Lysetska, M., Knoll, A., Boehringer, D., Hey, T., Krauss, G. and Krausch, G. (2002) UV light-damaged DNA and its interaction with human replication protein A: an atomic force microscopy study. Nucleic Acids Res., 30, 2686-2691.

2004 Boehringer, D., Makarov, E.M., Sander, B., Makarova, O.V., Kastner, B., Lührmann, R. and Stark, H. (2004) Three-dimensional structure of a pre-catalytic human spliceosomal complex B. Nat. Struct. Mol. Biol., 11, 463468.

Garcia-Mira, M.M., Boehringer, D. and Schmid, F.X. (2004) The folding transition state of the cold shock protein is strongly polarized. J. Mol. Biol., 339, 555-569. Boehringer, D., Thermann, R., Ostareck-Lederer, A., Lewis, J. and Stark, H. (2005) Structure of the hepatitis C virus IRES bound to the human ribosome: A snapshot of the native translation initiation complex. submitted. 